\title{
Onion and leek consumption, garlic supplement use and the incidence of cancer
}

Citation for published version (APA):

Dorant, E. (1994). Onion and leek consumption, garlic supplement use and the incidence of cancer. [Doctoral Thesis, Maastricht University]. Datawyse / Universitaire Pers Maastricht. https://doi.org/10.26481/dis.19941028ed

Document status and date:

Published: 01/01/1994

DOI:

10.26481/dis.19941028ed

Document Version:

Publisher's PDF, also known as Version of record

\section{Please check the document version of this publication:}

- A submitted manuscript is the version of the article upon submission and before peer-review. There can be important differences between the submitted version and the official published version of record.

People interested in the research are advised to contact the author for the final version of the publication, or visit the DOI to the publisher's website.

- The final author version and the galley proof are versions of the publication after peer review.

- The final published version features the final layout of the paper including the volume, issue and page numbers.

Link to publication

\footnotetext{
General rights rights.

- You may freely distribute the URL identifying the publication in the public portal. please follow below link for the End User Agreement:

www.umlib.nl/taverne-license

Take down policy

If you believe that this document breaches copyright please contact us at:

repository@maastrichtuniversity.nl

providing details and we will investigate your claim.
}

Copyright and moral rights for the publications made accessible in the public portal are retained by the authors and/or other copyright owners and it is a condition of accessing publications that users recognise and abide by the legal requirements associated with these

- Users may download and print one copy of any publication from the public portal for the purpose of private study or research.

- You may not further distribute the material or use it for any profit-making activity or commercial gain

If the publication is distributed under the terms of Article $25 \mathrm{fa}$ of the Dutch Copyright Act, indicated by the "Taverne" license above, 
Onion and Leek consumption Garlic supplement use and the Incidence of Cancer 


\section{CIP-DATA KONINKLIJKE BIBLIOTHEEK, DEN HAAG}

Doramt, Elisabeth

Onion and leek consumption, garlic supplement use and the incidence of cancer / Elisabeth Dorant. - Maastricht:

Universitaire Pers Maastricht. - III.

Thesis Maastricht. - With ref. - With summary in Dutch.

ISBN 90-5278-156-7

Subject headings: Allium vegetables / garlic suppleminnts / cancer.

Het onderzoek beschreven in dit proefschrift werd verricht vanuit de vakgroep Epidemiologie van de Rijksuniversiteit Limburg en de afdeling Epidemiologie van TNO-Voeding te Zeist, met financiële steun van de Nederlandse Kankerbestrijding.

In de drukkosten yan dit proefschrift werd bijgedragen door de Nederlandse Kankerbestrijding, Kneipp Nederland BV, Bloem, Natuurprodukten BV, Arizona knoflook - Nutrivital BV, Parmalux Voedingssupplementen Amsterdam. Orthica BV, AGB Fresh Foods, Kyolic/Wakunaga, Pharmafood BV, Nutramin BV, NL Pharma BV 


\title{
Onion and leek consumption, Garlic supplement use and the Incidence of Cancer
}

\author{
Proefschrift
}

ter verkrijging van de graad van doctor

aan de Rijksuniversiteit Limburg te Maastricht, op gezag van de Rector Magnificus, Prof. Dr. H. Philipsen, volgens het besluit van het College van Dekanen, in het openbaar te verdedigen op vrijdag 28 oktober 1994 om 14.00 uur

door 
Promotores:

Prof.dr. F. Sturmans

Prof.dr.ir. R.J.J. Hermus

Co-promotores:

Dr.ir. P.A. van den Brandt

Dr.ir. R.A. Bausch-Goldbohm

Beoordelingscommissie: Prof.dr. W.H.M. Saris, voorzitter

Prof.dr. G.H. Blijham, Universiteit Utrecht

Prof.dr. J.A. Knottnerus

Prof.dr. W.A. van Staveren, Landbouwuniversiteit Wageningen

Prof.dr. Sj.Sc. Wagenaar 
2 Garlic and its significance for the prevention of cancer in humans: a critical view

3 The use of vitamins, minerals and other dietary supplements in The Netherlands

4 Agreement between interview data and a self-administered questionnaire on dietary supplement use

5 A prospective cohort study on Allium vegetable consumption, garlic supplement use and the risk of lung carcinoma in The Netherlands

6 Allium vegetable consumption, garlic supplement intake and female breast carcinoma incidence

7 A prospective cohort study on the relation between onion and leek consumption, garlic supplement use and the risk of colon and rectum carcinoma in The Netherlands

8 Consumption of onions and a reduced risk of stomach carcinoma

$9 \quad$ Epilogue

Summary

Samenvatting

Dankwoord 


\section{Chapter 1}

\section{Introduction}

\section{Background}

Onions, leeks, and garlic are vegetables belonging to the Allium genus (a genus with more than 500 different species). The majority of the Allium plants, which can be found in all parts of the world, have merely decorative value, although most of them are edible. At present, only a few are produced as food ${ }^{1,2}$. Originally, Allium vegetables were cultivated in China, the Middle East and Egypt. These vegetables were subsequently introduced in Greece and from there in other countries in Europe by the Romans. Until the introduction of onions, leeks and garlic from Europe in the US and Canada, the Indian population occasionally consumed wild species ${ }^{1}$. Names of important Allium plants cultivated for food production are listed in the table below.

Table. Cultivated species of Allium.

\begin{tabular}{ll}
\hline Species & Common name \\
\hline Allium cepa L. var. cepa & common onion \\
Allium cepa L. var. ascalonicum & scallion, shallot \\
Allium fistulosum L. & Japanese bunching onion \\
Allium schoenoprasum L. & chives \\
Allium chinense (bakeri) & rakkyo \\
Allium sativum L. & garlic \\
Allium ampeloprasum L. var. porrum & leek \\
Allium tuberosum & Chinese chives
\end{tabular}

The Netherlands is one of the most important onion-producing countries in the world ${ }^{2}$. In the last two decades the yield of onions and shallots has nearly doubled in terms of absolute levels: from 284 million $\mathrm{kg}$ in 1970 to almost 500 million $\mathrm{kg}$ in $1991^{3,4}$, with approximately $80 \%$ being exported ${ }^{5}$. The present production of onions and shallots represents approxi- 
mately $14 \%$ of the total vegetable production in The Netherlands ${ }^{4}$. Production of leeks was nearly 100 million $\mathrm{kg}$ in 1991 , about twice as high as in $1980^{3,4}$.

Consumption of Allium vegetables, particularly of onions, is also very high in The Netherlands. According to the 1992. Dutch national Food Consumption Survey onions were ranked number one in the vegetable top ten, with more than $20 \%$ of the Dutch population consuming onions every day ${ }^{6}$. Earlier, in the 1987-1988 Dutch national Food Consumption Survey more than $30 \%$ of the total population reported the consumption of onionsi on at least one of the two days of the survey ${ }^{7}$. In another large household survey carried out in 1987 in The Netherlands, West-Germany, Great-Britain and France, neariy all respondents reported that they had been using onions during the 3 -month period before completion of the questionnaire (ranging from $92 \%$ of the population in West-Germany to $96 \%$ in France). In all four countries, onion consumption was highest among elderly persons, among those living in small househoids and in larger cities. The consumption decreased with increasing income and social class. Nearly two-thirds of the onions in The Netherlands were consumed cooked or baked and one third was consumed raw, while in France and great-Britain onions are most often consumed stewed or cooked ${ }^{5}$. More detailed information, especially on temporal trends in consumption of Allium vegetables in the Dutch population, is currently not available.

One of the striking features of Allium plants is the large amount of organic bound sulfur. Numerous different so-called organosulfur compounds have been isolated from Alliums, both from intact as well as from crushed plants. These organosulfur compounds, responsible for the typical odour and flavour of Alliums, are suggested to be accountable for the medicinal effects $^{8,9}$. Allium vegetables have been used for medical purposes for centuries to treat or prevent many different diseases, such as headache, worm infections and 'body weakiness", but also haemorrhoids, ulcers, pneumonia, suppurative wounds, clog and snake bites, baldness, eczema and other skin disorders, leprosy, cholera, influenza and chronic bronchitis. Onions and garlic were also claimed to possess diuretic, antidiabetic: and antirheumatic properties, to be good for the eyes and act as heart stimulant ${ }^{2 \cdot 10-14}$. Some of the edible Alliums are still being used in some cultures as natural remedy ${ }^{11,13,15,16}$. For instance, garlic extract has recently been used in China as adjuvant therapy to prevent fungal infection in patients with leukaemia treated with bone marrow transplantation ${ }^{15}$.

Experimental research into the prophylactic and therapeutic properties of Allium vegetables and Allium compounds has been conducted since the 19 th ceritury $^{2}$. However, most of the scientific research was initiated after the detection of important: chernical components by Cavallito and Bailey in $1944^{17}$, and by Stoll and Seebeck in $1947^{18}$. In many in vitro studies that were published since then, fresh Allium vegetables and preparations have been demonstrated to possess antibacterial and fungicidal activity ${ }^{2}$. However, there might be considerable variation in activity depending on type, variery or production method. For instance, it has been shown that fresh garlic and garlic compounds exhibit greater antibacterial activity than several onion types ${ }^{19}$. Another in vitro experiment showed that garlic supplements varied greatly in antibacterial and fungicidal activity, depending on the preparation method ${ }^{20}$. Nonetheless, the fungicidal activity of the garlic compound allicin was found to be similar to nystatin against Candida albicans ${ }^{21}$. Direct virucidal activity of fresh garlic and garlic supplements has also been demonstrated, but, like with the antibacterial activity, the in vitro virucidal activities of commercial garlic preparations also depended on their preparation process: those with the highest allicin levels had the best virucidal activity ${ }^{22}$. Probably the most intensive research up to now has been done on cardiovascular disease risk factors associated with intake of onions, garlic and garlic compounds ${ }^{2}$. Garlic and onions might inhibit platelet aggregation, enhance blood fibrinolytic activity, lower serum cholesterol, or act vasodilatory ${ }^{23}$. Nevertheless, the claims have been confirmed for fresh garlic only at unrealistically high dosages. Studies on the reduction of cardiovascular risk 
factors with use of garlic supplements showed severe shortcomings and results with onions were inconsistent ${ }^{24,25}$.

\section{Scope of the thesis}

This thesis concentrates on one particular feature of Allium vegetables: their suggested protective effect on cancer development in humans ${ }^{26.27}$. In a growing number of case-controll studies, conducted in many parts of the world since the early seventies, high consumption of onions or other Allium vegetables was negatively associated with risk for cancer at various sites $^{26.28-37}$. Support for the suggested negative association can be obtained from many in vitro and in vivo experiments on the anticarcinogenic potential of selected organosulfur compounds typically present in Allium vegetables. Most of the experiments showed that organosulfur compounds from garlic might inhibit carcinogenesis by inhibition of metabolic activation of procarcinogens, induction of enzymes important for detoxification of carcinogens or by inhibition of promotion ${ }^{38-40}$. Occasionally, results from experiments with onion compounds have also been reported (e.g. ${ }^{41-43}$ ).

The suggested association between the consumption of Allium vegetables and Allium vegetable products, garlic supplements, and the incidence of cancer was consequently investigated in the Netherlands Cohort study on diet and cancer.

\section{The Netherlands Cohort Study on diet and cancer}

The Netherlands Cohort Study on diet and cancer is a large-scale prospective cohort study, that was started in 1986 among 120,852 men and women, aged 55-69 years. A general outline of the design of the cohort study has been published elsewhere ${ }^{46}$. The main objective of the study is to examine diet in relation with cancer of the lung, breast, stomach, colon and rectum, since diet is suspected to play an important role in the etiology of cancer at these sites, and the incidence of lung, breast, stomach, colon and rectum malignancies is high in The Netherlands. Age between 55 and 69 years at baseline was used as selection criterion because dietary habits are relatively stable in elderly persons and a sufficient number of cases will occur within a reasonable time ${ }^{46}$. In a separate study among participants of the cohort, it has been confirmed that dietary habits changed little over a five year period ${ }^{47}$.

Respondents originate from the general population in The Netherlandsi sampled from 204. municipalities with computerized population registries. To enlarge the expected exposure contrast in the cohort, subjects with special dietary habits (vegetarians) were also invited to participate in the study. All participants completed a self-administered mailed questionnaire on usual dietary intake, the use of dietary supplements and other important lifestyle. characteristics ${ }^{46}$. The food and beverage part of the questionnaire has been validated against. a 9-day diet record ${ }^{48}$. Toenail clippings were collected for use as exposure biomarker ${ }^{46}$.

Follow-up for cancer in the entire cohort consists of record linkage with all nine regional cancer registries as well as with PALGA, the Dutch network and National Database for Pathology ${ }^{46}$. The development of the record linkage protocol has been published ${ }^{49}$. The study area from which the respondents were recruited was selected according to the degree of coverage by either one of the nine regional cancer registries or PALGA, in order to minimize loss to follow-up ${ }^{46}$. Mean coverage of the cohort increased from $98.5 \%$ at the start of the study to $100 \%$ by January $1,1988^{50}$. A case-cohort approach is being used in which a randomly sampled subcohort of 3500 subjects ( 1688 men and 1812 women) was followed up for vital status to estimate the accumulated person time in the entire cohort ${ }^{46}$. The procedures for statistical analyses of a case-cohort study have been described ${ }^{51}$. 
decarboxylase induction in isolated mouse epidermal cells treated with tumor promotors. Cancer Biochem Biophys 1986;8:299-312.

42. Belman S. Onion and garlic oils inhibit tumor promotion. Carcinogenesis 1983;4:1063-1065.

43. Niukian K, Schwartz J, Shklar G. Effects of onion extract on the development of hamster buccal pouch carcinomas as expressed in tumor burden. Nutr Cancer 1987;9:171-176.

44. Pitot HC. Principles of carcinogenesis: Chemical. In: De Vita VT, Hellman S, Rosenberg SA, eds. Cancer. Principles and Practice of Oncology, 3rd Edition. Philadelphia, JB Lippincott Comp, 1989.

45. Malone WF. Chemoprevention research. In: Mechanisms of Carcinogenesis, Vol 2, Kluwer Academic Press, Dordrecht, p 31-42, 1989.

46. Van den Brandt PA, Goldbohm RA, Van 't Veer P, Volovics A, Hermus RJJ, Sturmans F. A largescale prospective cohort study on diet and cancer in The Netherlands. J Clin Epidemiol 1990;43:285-295.

47. Goldbohm RA, Van 't Veer P, Van den Brandt PA, van 't Hof MA, Brants HAM, Sturmans F, Hermus RJJ. Reproducibility of a food frequency questionnaire and stability of dietary habits. determined from five annualiy repeated measurement. In: Van den Brandt PA. Bausch-Goldbohm RA. A prospective cohort study on diet and cancer in The Netherlands: design, conduct, analysis and first results. Maastricht, Universitaire Pers, 1993.

48. Goldbohm RA, Van den Brandt PA, Brants HAM, Van 't Veer P, Al M, Sturmans F, Hermus RJJ. Validation of a dietary questionnaire used in a large-scale prospective cohort study on diet and cancer. Eur J Clin Nutr 1994;48:253-265.

49. Van den Brandt PA, Schouten LJ, Goldbohm RA, Dorant E, Hunen PMH. Devalopment of a record linkage protocol for use in the Dutch Cancer registry for epidemiological research. Int $J$ Epidemiol 1990;19:553-558.

50. Goldbohm RA, Van den Brandt PA, Dorant E. Estimation of the coverage of municipalities by cancer registries and PALGA using hospital discharge data. Tijdschr Soc Gezondh 1994;72:8084.

51. Volovics A, Van den Brandt PA. Stratified and simple regression methods for the analysis of case-cohort studies. in: Van den Brandt PA, Bausch-Goldbohm RA. A prospective cohort study on diet and cancer in The Netherlands: design, conduct, analysis and first results. Maastricht, Universitaire Pers, 1993.

52. Dorant $E$, Van den Brandt PA, Goldbohm RA. Effectmeting met behulp van kankerregistratie en PALGA in een cohortonderzoek naar de relatie tussen voeding en kanker. Tijdschr Soc Gezondh 1991;69:10. 


\title{
Chapter 2
}

\section{Garlic and its significance for the prevention of cancer in humans: a critical view}

Elisabeth Dorant; Piet A. van den Brandt; R. Alexandra Goldbohm;

Rudolph J.J. Hermus; Ferd Sturmans

\begin{abstract}
Recently published results of epidemiologic case-control studies in China and Italy on gastric carcinoma in relation to diet suggest that consuming garlic may reduce the risk of gastric cancer. Chemical constituents of garlic have been tested for their inhibiting effect on carcinogenesis, using in vitro and in vivo models. In most experiments inhibition of tumour growth was established using fresh garlic extract, garlic compounds or synthetically prepared analogs. In this review the strengths and weaknesses of the experiments are discussed and the outcomes are evaluated to assess the possible significance of garlic or garlic compounds for the prevention of cancer in humans. It is concluded that evidence from laboratory experiments and epidemiologic studies is presently not conclusive as to the preventive activity of garlic. However, the available evidence warrants further research into the possible role of garlic in the prevention of cancer in humans.
\end{abstract}




\section{Introduction}

Elimination of carcinogenic substances from the environment is the preferable method to prevent malignant tumour development. However, contact with carcinogenic substances is not always avoidable ${ }^{1,2}$. Therefore, chemoprevention, in which the occurrence of cancer is prevented by administration of inhibitory compounds, has received increased attention ${ }^{1.3}$.

The relation between the use of Allium vegetables, especially garlic (Allium sativum, a member of the genus Allium to which some 500 species belong), and its constituents, and the occurrence of cancer in humans is of particular interest in this respect. In a number of reviews on the effects of garlic on health, possible preventive effects on the development of cancer in humans have been mentioned. Fenwick and Hanley reviewed experimental studies designed to demonstrate any anticancer activity of garlic, together with the results of an epidemiological study in China in which death rates between two adjacent provinces were compared. In the latter study the highest gastric death rate had been found in the province with the lowest intake ${ }^{4}$. The possible anticancer activity of garlic was illustrated in an earlier review of two studies reporting the inhibition of transplanted tumours in mice ${ }^{5}$. In a publication on new dietary anticarcinogens and the prevention of gastrointestinal cancer, dially! sulfide, a component of garlic, was identified as a suppressing agent in dimethylhydrazine (DMH)-induced colon and nitrosomethylbenzylamine (NMBA)-induced oesophageal cancer development in rats ${ }^{6}$. Suggested inhibitory mechanisms were evaluated in a review of selected recent publications on the effects of garlic on tumour formation in experimental animals ${ }^{7}$. In an earlier review free radical scavenging activity, immune system modulation and direct cytotoxic effect on cancer cells were discussed ${ }^{8}$. More recently the possible effects of garlic on detoxification systems in vivo and in vitro were reviewed ${ }^{9}$. The changing patterns of cancer in the United States, United Kingdom and the Federal Republic of Germany led to speculations on the role of synthetic and natural carcinogens and anticarcinogens. Compounds of garlic were mentioned as inhibitors of tumour promotion ${ }^{10}$. Based on the results from experimental and epidemiologic studies, Lau et al concluded that garlic may be categorized as a dietary anticarcinogen ${ }^{11}$.

Several investigators proposed a categorization of substances with possible anticarcinogenic activity based on the steps in chemical induction of neoplasia ${ }^{1,3,12,13}$. In contrast with earlier reviews, we have ordered the in vitro and in vivo screening tests on the possible anticarcinogenic effects of garlic and garlic constituents according to this categorization. Strengths and weaknesses of the experiments are discussed and whether their results provide any basis for the suggestion that garlic can prevent the development of cancer in humans.

\section{Methods}

Publications on garlic or garlic compounds and the relation with cancer, carcinogenicity or anticarcinogenicity were found by searching MEDLINE, a computer service available on CDROM (1983-1991) and by checking references to find earlier reports. After a short overview of the chemical composition and active compounds of garlic, studies are reviewed on garlic preparations or specific chemical compounds possibly related to the proposed antitumour effect. According to the components of a sequential staging in preclinical research on chemopreventive agents ${ }^{3}$, in vitro experiments on the identification of promising compounds are reviewed first. Next, in vivo screening tests involving animal models to evaluate the efficacy of compounds against carcinogenic agents at specific target sites, are reviewed. Studies employing models in which malignant tumours are transplanted into experimental animals or models using spontaneous tumour formation are not reviewed, because these 
models are not considered relevant for research on cancer prevention ${ }^{3}$. Finally, the results of epidemiological studies in human populations are summarized and suggestions for further research are given.

\section{Chemical composition and active compounds of garlic}

The main components of fresh garlic are water, carbohydrates, protein, fibre and fat. Garlic contains essential amino acids, vitamins and minerals. Garlic oil obtained by steam distillation, dehydrated garlic powder, pickled garlic, garlic juice and garlic extracts are available as condiments or nutritional supplements ${ }^{14}$. 'Aged garlic extract', a special garlic preparation, is obtained by extracting sliced raw garlic in a low concentration of ethanol at room temperature over a long period ${ }^{15}$.

The reported medicinal effects are ascribed to oil- and water-soluble organosulfur compounds, also responsible for the flavor and odor of garlic ${ }^{4,16-18}$. Chemical structures of compounds reported in this review, including the abbreviations used in the text, are listed below.

Compounds in garlic and garlic products tested by in vitro and in vivo assays for possible anticarcinogenic activity.

$\mathrm{CH}_{2}=\mathrm{CH}-\mathrm{CH}_{2}-\mathrm{S}(\mathrm{O})-\mathrm{S}-\mathrm{CH}_{2}-\mathrm{CH}=\mathrm{CH}_{2}$

$\mathrm{CH}_{2}=\mathrm{CH}-\mathrm{CH}_{2}-\mathrm{S}(\mathrm{O})-\mathrm{CH}_{2}-\mathrm{CH}=\mathrm{CH}-\mathrm{S}-\mathrm{S}-\mathrm{CH}_{2}-\mathrm{CH}=\mathrm{CH}_{2}$

$\mathrm{CH}_{2}=\mathrm{CH} \cdot \mathrm{CH}_{2}-\mathrm{S} \cdot \mathrm{CH}_{2}-\mathrm{CH}=\mathrm{CH}_{2}$

$\mathrm{CH}_{2}=\mathrm{CH}-\mathrm{CH}_{2}-\mathrm{S}-\mathrm{S}-\mathrm{CH}_{2}-\mathrm{CH}=\mathrm{CH}_{2}$

$\mathrm{CH}_{2}=\mathrm{CH}-\mathrm{CH}_{2}-\mathrm{S}-\mathrm{S}-\mathrm{S}-\mathrm{CH}_{2}-\mathrm{CH}=\mathrm{CH}_{2}$

$\mathrm{CH}_{2}=\mathrm{CH}-\mathrm{CH}_{2}-\mathrm{S}-\mathrm{S}-\mathrm{CH}_{3}$

$\mathrm{CH}_{2}=\mathrm{CH}-\mathrm{CH}_{2}-\mathrm{S}-\mathrm{S} \cdot \mathrm{S}-\mathrm{CH}_{3}$

$\mathrm{CH}_{2}=\mathrm{CH}-\mathrm{CH}_{2}-\mathrm{SH}$

$\mathrm{CH}_{2}=\mathrm{CH}-\mathrm{CH}_{2}-\mathrm{S}-\mathrm{CH}_{2}-\mathrm{CH}\left(\mathrm{NH}_{2}\right)-\mathrm{COOH}$<smiles>CCCCc1oc(C)c(OC)c(=O)c1O</smiles>

allicin

ajoene

diallylsulfide DAS

diallyidisulfide DADS

diallyltrisulfide DAT

allyimethyldisulfide AMD

allỵimethyltrisulfide AMT

allyimercaptan AM

S-allylcysteine SAC

allixin

One of the organosulfur compounds, the odorless amino acid allin, is enzymatically converted into allicin when the garlic cloves are crushed. Allicin is accountable for the characteristic odor of fresh garlic and has antibacterial properties ${ }^{19}$. In a study by Wills, the selective inactivation of SH-enzymes could be attributed to the presence of the -S-SO-bond 
in allicin ${ }^{20}$. Since this inactiva-tion might be important in relation to inhibition of malignant tumour growth, Weisberger and Pensky initiated studies of compounds related to allicin. A progressive decrease in uptake of ${ }^{35} \mathrm{~S}$ in leukemic leukocytes, supposedly related to - SH inactivation, was observed in an experiment on the effect of a diethyl analog of allicin, ethylthiosulphinic ethyl ester ${ }^{21}$. The-S-SO-bond in other allicin-like substances and the ability to react with - $\mathrm{SH}$ groups was thought to be essential for tumour formation inhibition ${ }^{22}$.

Allicin, however, is unstable and converts readily into mono-, di-, tri- and polysulfides, sulfur oxide and other compounds such as ajoene ${ }^{14,16}$. An extensive overview of the chemistry of the organosulfur compounds in both intact and crushed garlic is published by Whitaker ${ }^{23}$. Allixin, a so-called phytoalexin or 'stress compound', is a phenolic compound synthesized by garlic ${ }^{24}$.

\section{Identification of possible chemopreventive compounds through in vitro techniques}

The first stage in preclinical research on chemopreventive agents, as in drugs screening, is the identification of promising compounds through in vitro screening systems ${ }^{3}$. A large variety of garlic compounds have been investigated in models using chemical carcinogens (initiators and promoters) or radiation. Extracts of garlic and fractions isolated from it, as well as specific chemical compounds, both naturally derived or synthetically made, were identified as possible chemopreventive agents (Appendix-table 1).

Ajoene, DAS, allixin and crude garlic extract exhibited a dose-dependent inhibition of aflatoxin $B_{1}\left(A F B_{1}\right)$-mutagenesis, inhibition of DNA binding and adduct formation, as well as inhibition of the formation of AFB $_{1}-$ metabolites ${ }^{24,25}$. Crude aqueous garlic extract showed antimutagenic activity against $\gamma$-radiation, peroxides, adriamycine and $\mathrm{N}$-methyl- $\mathrm{N}$-nitro- $\mathrm{N}$ nitrosoguanidine (MNNG). No effect was detected against several other mutagens. A dosedependent decrease of $\mathrm{H}_{2} \mathrm{O}_{2}$-induced lipid peroxidation suggested radical-scavenging activity. Of the purified compounds allicin, alliin and cysteine only allicin showed inhibition of $\gamma$ radiation-induced mutagenesis ${ }^{26}$.

DAS reduced the macromolecular binding of dimethylhydrazine (DMH) in hepatocytes, while levels of glutathione S-transferase (GST), glutathione reductase or glutathione peroxidase were not influenced ${ }^{27}$. Garlic oil inhibited both the prolonged decrease in activity of the glutathione-dependent antioxidant protective system and the induction of ornithine decarboxylase (ODC) activity (an enzyme important in the regulation of DNA synthesis and involved in the early phase of the second stage of tumour promotion) caused by tetradecanoyl-phorbol-acetate (TPA) and other promoters. The effect was time and dosedependent. Onion oil and dipropenylsulfide were less effective ${ }^{28}$. Both ethanolic garlic extract and allixin inhibited ${ }^{32}$ P-incorporation into cell phospholipids in the early phase of TPAinduced tumour promotion in a dose-dependent manner ${ }^{29,30}$. Tests on the stimulating effect. on macrophage activity against heterogeneous tumour cells revealed that a high moleculari fraction isolated from aged garlic extract was more effective than aged garlic extract itself and other, low molecular, compounds like allicin, DADS and AMT. Mitotic activity of spleen cells was enhanced by preculturing the cells with the high-molecular fraction ${ }^{15}$.

In one study the effect of garlic oil was not published, because the cell morphology was drastically altered at the concentration used ${ }^{31}$. In another study it was suggested that both garlic oil and onion oil act as promoting agents. Enhancement of NIH-3T3 cell proliferation was seen following treatment with either oil at nontoxic levels, but in combination with the tumour promoter phorbol-myristate-acetate (PMA) the growth stimulating activity was inhibited $^{32}$. 
Some studies focus on showing antimitotic activity in cultured cells. The effects displayed with ethanolic and aqueous extract of dried powdered garlic depended on the test cells used. Ethanolic extract exhibited a stronger effect than aqueous extract. But, although inhibition of DNA-synthesis could be established, the concentrations needed were higher than the concentrations required to affect cell viability ${ }^{33}$. Ajoene exerted a stronger effect on the viability of tumourigenic cells than of non-tumourigenic cells. The effect depended on the amount of ajoene per cell, the protein content of the cell and duration of treatment. Ajoene was twice as active as allicin and seemed to act immediately after its uptake ${ }^{34}$. In a test with raw garlic juice a dose-dependent inhibition of mitosis was observed, with sticking and clotting of chromosomes ${ }^{35}$.

\section{In vivo assays evaluating the efficacy of garlic and garlic compounds against carcinogenic agents at specific target sites}

Any anticarcinogenic agent identified by in vitro screening should be further evaluated by in vivo screening ${ }^{3}$. According to the opportunities for chemical intervention proposed by Wattenberg ${ }^{1,13}$, Malone ${ }^{3}$ and Bertram ${ }^{12}$, we have ordered those animal experiments in which the effect of the potentially chemopreventive compounds from garlic on carcinogenic mechanisms have been studied, into those dealing with initiation and those dealing with promotion (Appendix-table 2).

\section{Initiation}

Initiation might be inhibited by preventing the formation of carcinogens from precursors, blocking the metabolic activation of carcinogens, increasing the detoxification of carcinogens by increasing the level of the enzymes involved (e.g. glutathione S-transferase), interception of carcinogens prior to their reaction with DNA, stimulation of error-free DNA repair or suppression of cell proliferation ${ }^{1,3,13}$. However, although many tests on inhibition of initiation have been performed, the results are not conclusive yet and the mechanisms of action still remain unclear.

AMT (with doses ranging from 0.003-0.024 mmol p.0.) showed an inhibitory effect on the number and malignancy of benzo(a)pyrene $(\mathrm{BaP})$-induced forestomach tumours in mice, whereas no effect on tumour development in the lung could be detected. However, a dosedependent enhancement of GST activity was observed in the forestomach and in the iung. as well as in the liver andi small intestines ${ }^{36,37}$. DAT $(0.02 \mathrm{mmol}$ p.o.) and AMD 10.01-0.04 mmol p.o.) inhibited tumour development in both forestomach and lung and alsa induced an increase in GST activity. DAS $10.02 \mathrm{mmol}$ p.o.) had little effect on forestomach tumour development, but stimulated GST activity in this organ, whereas inhibition of lung tumour development was found without an increase of GST activity. Saturated analogs of the garlic compounds showed almost no activity ${ }^{37}$. DAS $(0.02 \mathrm{mmol}$ p.o.) was less effective in inhibiting the $\mathrm{N}$-nitrosodiethylamine (NDEA)-induced development of forestomach papillomas. and carcinomas when compared with DADS $10.02 \mathrm{mmol}$ p.a.j. Aiv (0.01 mmol p.o.) and AMD $(0.02 \mathrm{mmol}$ p.o.). All four garlic compounds showed little inhibition of pulmonary' neoplasm development. The inhibitory capacities depended on the number of a!lyl groups and fluctuated with varying times of administration ${ }^{38}$. The observed difference between several oil- and water-soluble garlic compounds in stimulating GST activity in colon and liver also depended on the presence of allyl groups ${ }^{18}$. DAS $(200 \mathrm{mg} / \mathrm{kg}$ p.o.) could not inactivate the direct acting carcinogens $\mathrm{N}$-methylnitrosourea (MNU) and MNNG in mice, whereas a strong. dose-dependent, inhibition of the procarcinogen $\mathrm{DMH}$, requiring metabolic activation, was observed in mice as well as in rats ${ }^{27,39}$. Because DAS $(200 \mathrm{mg} / \mathrm{kg}$ p.o.) did not induce GST or DT-diaphorase in the liver of mice, it was suggested that DAS induces alterations in 
hepatic mixed function oxidase activity leading to modification of carcinogen metabolism ${ }^{40}$. In another study DAS $(200 \mathrm{mg} / \mathrm{kg}$ i.g.) was found to be a time-dependent competitive inhibitor of NMBA- and N-dimethylnitrosamine (DMNA)-induced hepatic microsomal monooxygenase activity in rats, probably by selective inhibition of the cytochrome $\mathrm{P} 450$ isozymes active in the oxidative metabolism of various carcinogenic compounds ${ }^{41}$. Orally $(200 \mathrm{mg} / \mathrm{kg})$ or topically administered DAS prevented the induction of nuclear aberrations in hair follicle cells and in the bladder induced by cyclophosphamide, either by mitotic inhibition of target cells or a diversion of excretion of cyclophosphamide from urine to faeces ${ }^{42}$.

In rats, $y$-radiation-induced ODC activity and DNA synthesis in colon mucosa cells was partially suppressed by DAS $(50-400 \mathrm{mg} / \mathrm{kg} \mathrm{p.o.).} \mathrm{But,} \mathrm{since} \mathrm{the} \gamma$-radiation-induced nuclear aberration formation was not decreased by DAS $(200 \mathrm{mg} / \mathrm{kg}$ p.o. $)$ in the presence of an ODC inhibitor, the investigators suggested that DAS stimulates the DNA repair process ${ }^{43}$. DAS (50-400 mg/kg p.o. or i.p.) also suppressed ODC activity and nuclear aberration formation in the stomach after induction with $M N N G{ }^{44}$, reduced NMBA-induced nuclear aberration formation and the conversion of NMBA by hepatic microsomes. Oesophageal cancer development was completely inhibited, although no direct effect on oesophageal microsome activity was observed ${ }^{45}$. Oral treatment with fresh garlic $(400 \mathrm{mg} / \mathrm{kg})$ significantly reduced the percentage mice with 3 -methyl-cholanthrene $(\mathrm{MC})$-induced tumours of the uterine cervix ${ }^{48}$.

Topically applied garlic oil in the initiating phase of BaP-induced skin carcinogenesis decreased the number of mice with skin tumours as well as the mean number of tumours per mouse ${ }^{47}$. In one report the anticarcinogenic properties of fresh ground garlic were compared with the activity of the carcinogens BaP and 5-nitro-2,4,6-triaminopyrimidine (NTP). It is therefore not surprising that the mean tumour number in the garlic group was significantly lower than in the other groups ${ }^{48}$.

\section{Promotion}

Two-stage skin carcinogenesis models have been used to separately test inhibition of tumour promotion by garlic extract or compounds. Low doses of topically applied garlic oil inhibited tumour formation induced by DMBA and PMA, but the effect was generally less than with onion oil ${ }^{49}$. Fresh garlic extract reduced the percentage of mice with skin papillomas and the mean number of papillomas per tumour-bearing mouse. Inhibition of DMBA-induced malignant carcinoma development was also observed by other investigators ${ }^{50,51}$. Garlic extract completely inhibited skin tumour formation induced by the first stage promoter TPA, while less inhibition was observed with the second stage promoter mezerein ${ }^{29}$. Treatment with $1 \mathrm{mg}$ allixin simultaneously with TPA resulted in a significant inhibition of tumour development ${ }^{30}$.

\section{Toxicity}

An important element in the evaluation of the possible role of chemopreventive compounds is the assessment of preclinical toxicity ${ }^{3}$. In most of the in vivo experiments the activity of the garlic constituent DAS has been studied, although one fresh garlic clove contains only a very small amount of this specific chemical compound: less than $1 \mathrm{mg}^{40}$. Conversion and extrapolation of the effective doses used in these tests would lead to unrealistic quantities of fresh garlic humans should use to exhibit similar effects on carcinogenesis: 25-400 garlic. cloves per $\mathrm{kg}$ body weight. In humans the consumption of small amounts of raw garlic may already lead to toxic effects. Garlic, raw or cooked, infused into the stomachs of healthy volunteers on separate days induced a significant mean increase in DNA content of gastric aspirates with a dose of $0.75 \mathrm{~g}$ or more, indicating damage of the gastric mucosa ${ }^{52}$. However, no important negative side effects were reported in a human experiment 
investigating the effect on natural killer cell activity of eating raw garlic $(0.5 \mathrm{~g} / \mathrm{kg}$ bw daily) or taking garlic capsules (dose $1800 \mathrm{mg}$ daily) for 3 weeks ${ }^{53}$.

The toxicity of garlic oil and of fresh garlic extract has also been studied in rats and mice. Albino rats fed garlic oil intragastrically $(100 \mathrm{mg} / \mathrm{kg}$ body weight) after a period of fasting. died within a few hours from pulmonary oedema. Rats fed with fresh raw garlic extract 1200 g/l drinking water) exhibited non-specific liver injury. Combining normal diet with intragastrically feeding of garlic oil $\left(100 \mathrm{mg} / \mathrm{kg}\right.$ bw) did not elicit toxic effects ${ }^{54}$. On the other hand, in one of the aforementioned studies no toxic effects were observed after oral administration of fresh ground garlic $(400 \mathrm{mg} / \mathrm{kg} \mathrm{bw})^{46}$. In the study by Belman all mice died after a single application of $10 \mathrm{mg}$ garlic oil on the $\mathrm{skin}^{49}$.

\section{Epidemiologic research}

Very few epidemiologic studies have been carried out on the possible preventive activity of garlic on tumour development. In 1988, You et al. reported the results of a population-based case-control study in China on the relation between diet and gastric carcinoma. A structured questionnaire was used in 1984 by trained interviewers to assess the usual frequency of intake and portion size of foods and beverages in 1980 (approximately four years before the diagnosis) as well as prior to the Cultural Revolution in 1965. Cases and controls were grouped into tertiles or quartiles of intake, based on their annual consumption of specific or total Allium vegetables. An inverse trend with increased total Allium intake was found which persisted after adjustment for intake of other fresh vegetables. The odds ratio of the highest quartile of consumption of Alliums $(>24.0 \mathrm{~kg} / \mathrm{yr}$ or $>65 \mathrm{~g} / \mathrm{day})$ compared to the lowest quartile ( $\leq 11.5 \mathrm{~kg} / \mathrm{yr}$ or $\leq 32 \mathrm{~g} /$ day) was 0.4 (95\% Cl 0.3-0.6). Analysis of the effect of specific Allium vegetables (garlic, garlic stalks, scallions, Chinese chives and onions) showed a protective effect of each Allium vegetable. Comparing the highest tertile of garlic intake ( $\geq 1.5 \mathrm{~kg} /$ year or $\geq 2$ cloves per day) with the nonusers resulted in an odds ratio of 0.7 (95\% $\mathrm{Cl}$ 0.4-1.0) when adjusted for sex, age, family income and intake of other Alliums. The highest intake of chinese chives $(>3.7 \mathrm{~kg} / \mathrm{yr})$ compared to the lowest intake $(<1.5 \mathrm{~kg} / \mathrm{vr}$ ) was associated with the lowest odds ratio compared with other Allium vegetables $1 \mathrm{OR}=0.6$ adjusted for sex, age, family income and intake of other Alliums, $95 \% \mathrm{Cl}$ 0.4-0.8). These associations were unlikely to be related to changes in the diet because no differences in consumption pattern for Aliums could be found between intake in 1980 and in 1965 . However, $50 \%$ of the carcinomas were not histopathologically confirmed: $32 \%$ were based on surgical or endoscopic information and $17 \%$ on radiological or clinical examination ${ }^{55.56}$. In a case-control study conducted in Italy, the role of dietary factors associated with the regional variation in gastric carcinoma has been investigated. Patients with histopathologically confirmed epithelial gastric carcinoma, and contrcls, randomly selected from the general population with the same age and sex distribution, were interviewed. A structured questionnaire was used to assess the usual frequency of intake and portion size of food and beverages consumed during a one-year period two years prior to the interview. Intake was categorized into tertiles defined by weekly frequency of consumption among controls. A significant trend of decreasing risk of gastric carcinoma was observed with increasing frequency of intake of condiments containing garlic and onions, when adjusted for age, sex, study area, social class, residence, migration from the south, family history of gastric cancer and Quetelet Index. Aware of the results of the Chinese case-control study, the Italian investigators included during the study a question on the frequency of intake of raw or cooked garlic. A significantly decreased risk was observed with increasing frequency of consumption of cnoked garlic by the $27 \%$ of the participants who were asked this question 
$(n=275$ ), with persons in the highest tertile of intake having $40 \%$ of the risk compared to those in the lowest tertile. The consumption of raw garlic was too low for evaluation ${ }^{57}$.

\section{Discussion}

Among the medicinal effects of garlic, a widely used food item worldwide, is its suggested inhibitory activity on malignant tumour growth. To evaluate the magnitude of the antitumour effect and to assess its relevance for the prevention of cancer in humans, we have reviewed publications on the relation between garlic or garlic constituents and anticarcinogenic activity or inhibition of the development of malignant tumours.

Although not all publications on in vitro screening tests did report a positive effect of garlic compounds on anticarcinogenic mechanisms, most of the outcomes support the hypothesis that garlic or specific garlic compounds have at least antimutagenic properties. According to the sequentia! staging in chemoprevention and pharmaceutical research, these compounds (DAS, ajoene, allixin, allicin, garlic oil, fresh and aged garlic extract and high molecular fractions prepared from aged garlic extract) are eligible for further investigation. Many in vivo experiments, using initiation-promotion models and chemical induction, were performed to assess the anticarcinogenic activity of promising compounds, and of compounds not yet tested by in vitro experiments. However, definite conclusions cannot be drawn.

The allyl $\left(\mathrm{CH}_{2}=\mathrm{CHCH}_{2}-\right)$ containing compounds DAS, DADS, DAT, AM, AMD, AMT, SAC and fresh garlic extract inhibited the formation of malignant tumours induced by various initiators, although the mechanisms of action are not evident. In several studies organspecific ${ }^{37}$, and dose- and time-dependent ${ }^{18,36}$ enhancement of GST activity could be detected. However, some investigators concluded that the observed tumour inhibition cannot simply be a consequence of this enhancement ${ }^{18,27,37,40}$. Furthermore, selective inhibition of hepatic procarcinogen (NMBA, DMNA) activation was measured ${ }^{41}$, suppression of MNNGinduced or $\gamma$-radiation-induced ODC activation in stomach and colon ${ }^{43,44}$, and suppression of $y$-radiation-induced DNA synthesis in the colon ${ }^{43}$. DAS, which did not inactivate direct acting carcinogens in mouse colonic mucosa ${ }^{39}$, but produced a marked inhibition in the stomach of rats using a similar dose and route of administration ${ }^{44}$, might exhibit different results dependent on the species or animal strain studied.

Inhibition of tumour promotion has the greatest potential for human intervention, because the promotion phase takes a long time, promotors act less specifically compared with initiators and repeated exposures are needed to induce permanent alterations ${ }^{1,3}$. However, only a few studies have been performed to establish the effect of garlic in the promotion phase. All studies employed the mouse skin carcinogenesis model initiated with DMBA and promoted with PMA, TPA or mezerein. Garlic oil, garlic extracts and allixin recluced the percentage of mice with skin tumours as well as the mean number of tumours per tumourbearing mouse. Antipromoting activity of other garlic compounds has not yet: been investigated.

Safety and toxicity of the possible anticarcinogenic compounds also deserve more attention. Conversion of the doses of pure chemicais tested in animals to their equivalent in terms of fresh garlic cloves and extrapolation of the effective doses to humans will lead to unrealistic amounts of garlic having to be consumed in order to profit from the described antitumour effects, as is mentioned earlier.

Epidemiologic studies are required in which the prevention of cancer in humans by garlic: and related Alliums is further investigated. Although epidemiologic studies in China and Italy suggest a decreasing risk for stomach cancer with increasing consumption of garlic or related Allium vegetables, both the design of the studies, the ascertainment of the cases and the 
measurement of the garlic intake, limit the possibility of drawing definite conclusions. In the Chinese case-control study only $50 \%$ of the gastric carcinoma cases were histopathologically confirmed. It is not clear whether the other cases did have gastric cancer or other gastric defects such as ulcers ${ }^{55,56}$. If garlic consumption differs between the 2 groups inclusion of all cases in the analysis might give invalid results. In the Italian case-control study the frequency of garlic consumption was assessed in $27 \%$ of the participants. A decreasing risk with increasing level of consumption of cooked garlic was reported. The results, however, cannot easily be interpreted and compared with the reported effects in China, because the actual levels of weekly consumption of garlic were not given ${ }^{57}$.

An important difficulty in investigating the relation between the use of garlic and cancer development in humans is the determination of the actual intake of possible preventive compounds from garlic or garlic supplements. The activity of garlic and garlic preparations is ascribed to compounds containing allyl groups bonded to sulfur ${ }^{18,38}$. Recent research on quantification of organosulfur compounds in fresh garlic and commercially available garlic products revealed considerable variation in the results. The highest total amount of sulfur compounds was detected in steam-distilled garlic oils. However, in only one of the 39 different preparations tested was the total amount of organosulfur compounds per gram product shown to be higher than in store-purchased garlic cloves ${ }^{58}$.

In epidemiologic studies information on the timing of exposure is crucial. If garlic has an inhibitory effect on initiation, the garlic consumption should precede or accompany the contact with the initiating agent. However, if garlic inhibits promotion the relevant time period of garlic consumption is closer to the moment of diagnosis. In the Italian case-control study the habitual frequency of garlic consumption two years before the interview was assessed. Thus, it was implicitly assumed that garlic intake two years prior to diagnosis reflected the intake during either the initiation or promotion phase of gastric carcinoma development ${ }^{57}$. If preclinical gastric cancer does not cause symptoms prior to this two year interval, leading to avoidance of irritating foods such as garlic, this assumption might be true. If not, the results might have been biased.

A prospective study in which the dietary intake is assessed before cancer develops, is a preferable method to study a possible preventive effect of garlic on cancer development in humans. In 1986 a large-scale prospective cohort study on diet, life style factors, use of dietary supplements and the occurrence of cancer was started in The Netherlands. The cohort comprises 120,852 men and women, aged $55-69$ years. At baseline, a questionnaire on dietary habits and potential confounders was completed ${ }^{60}$. The analysis on the relation between garlic and cancer development will be focused on the relation between the use of garlic supplements and cancer. The effects of related foods of the Allium genus, onions and leeks, will be studied as well, because a negative association between other Allium vegetables and cancer has also been reported ${ }^{55-57,59}$.

In summary, evidence from laboratory experiments and epidemiologic studies is not yet conclusive as to the preventive capacity of garlic or garlic constituents. However, the available evidence warrants further research into the possible role of garlic in the prevention of cancer in humans.

\section{References}

1. Wattenberg LW. Chemoprevention of cancer. Cancer Res 1985;45:1-8.

2. Weinstein IB. The scientific basis for carcinogen detection and primary cancer prevention. Cancer 1981:47:1133-1141.

3. Malone WF. Chemoprevention research. In: Mechanisms of Carcinogenesis, Vol 2, Kluwer Academic Press, Dordrecht, p 31-42, 1989.

4. Fenwick GR, Haniey AB. The genus Allium - Part 3. CRC Crit Rev Food Sci Nutr 1985;23:1-73. 
5. Bolton S, Null G, Troetel WM. The medical uses of garlic. Facts and fiction. Am. Pharmacy $1982 ; 22: 40-43$.

6. Wargovich MJ. New dietary anticarcinogens and prevention of gastrointestinal cancer. Dis. Colon Rectum 1988;31:72-75.

7. Sumiyoshi H, Wargovich MJ. Garlic (allium sativum): a review of its relationship to cancer. Asia Pac J Pharmacol 1989;4:133-140.

8. Abdullah TH, Kandil O, Elkadi A, Carter J. Garlic revisited: therapeutic for the major diseases of our times ? J Natl Med Assoc 1988;80:439-445.

9. Dausch JG, Nixon DW. Garlic: a review of its relationship to malignant disease. Prev Med 1990; 19:346-361.

10. Davis DL. Natural anticarcinogens, carcinogens, and changing patterns in cancer: some speculation. Environ Res 1989;50:322-340.

11. Lau BHS, Tadi PP, Tosk JM. Allium sativum (garlic) and cancer prevention. Nutr Res 1990;10: 937-948.

12. Bertram JS, Kolonel LN, Meyskens FL. Rationale and strategies for chemoprevention of cancer in humans. Cancer Res 1987:47:3012-3031.

13. Wattenberg LW. Inhibition of carcinogenesis by minor anutrient constituents of the diet. Proc Nutr Soc 1990;49:173-183.

14. Raghavan B, Abraham KO, Shankaranarayana ML. Chemistry of garlic and garlic products. J Sci Ind Res 1983;42:401-409.

15. Hirao Y, Sumioka I, Nakagami S, Yamamoto M, Hatono S, Yoshida S, Fuwa T, Nakagawa S. Activation of immunoresponder cells by the protein fraction from aged garlic extract. Phytotherapy Res 1987:1:161-164.

16. Block E. The chemistry of garlic and onions. Sci Am 1985;252:114-119.

17. Dubick MA. Historical perspectives on the use of herbal preparations to promote health. J Nutr 1986;116:1348-1354.

18. Sumiyoshi H. Wargovich MJ. Chemoprevention of 1,2-dimethylhydrazine-induced colon cancer in mice by naturally occurring organosulfur compounds. Cancer Res 1990;50:5084-5087.

19. Cavallito CJ, Bailey JH. Allicin, the antibacterial principle of allium sativum. I. Isolation, physical properties and antibacterial action. J Am Chem Soc 1944;66:1950-1951.

20. Wills ED. Enzyme inhibition by allicin, the active principle of garlic. Biochem J 1956;63:514-520.

21. Weisberger AS, Pensky J. Tumour inhibiting effects derived from an active principle of garlic (allium sativum). Science 1957;126:1112-1114.

22. Weisberger AS, Pensky J. Tumour inhibition by a sulfhydryl-blocking agent related to an active principle of garlic (allium sativum). Cancer Res 1958;18:1301-1308.

23. Whitaker JR. Development of flavor, odor, and pungency in onion and garlic. Adv Food Res 1976;22:73-133.

24. Yamasaki T, Teel RW, Lau BHS. Effect of allixin, a phytoalexin produced by garlic, on mutagenesis, DNA-binding and metabolism of Aflatoxin $B_{1}$. Cancer Lett 1991;59:89-94.

25. Tadi PP, Teel RW, Lau BHS, Organosulfur compounds of garlic modulate mutagenesis, metabolism, and DNA binding of Aflatoxin B. Nutr Cancer 1991:15:87-95.

26. Knasmuller S, De Martin A, Domjan G, Szakmary A. Studies in the antimutagenic activities of garlic extract. Environ Mol Mutagen 1989:13:357-365.

27. Hayes MA, Rushmore TH, Goldberg MT. Inhibition of hepatocarcinogenic responses to 1,2-dimethylhydrazine by diallyl sulficle, a component of garlic oil. Carcinogenesis 1987;8:1155-1157.

28. Perchellet JP, Perchellet EM, Abney NL, Zirnstein JA, Belman S. Effects; of garlic and onion oils on glutathione peroxidase activity, the ratio of reduced/oxidized glutathione and ornithine decarboxylase induction in isolated mouse epidermal cells treated with tumour promotors. Cancer Biochem Biophys 1986;8:299-312.

29. Nishino H, Iwashima A, Itakura Y, Matsuura H, Fuwa T. Antitumor-promoting activity of garlic extracts. Oncology 1989;46:277-280.

30. Nishino H, Nishino A, Takayasu J, Iwashima A, Itakura Y, Kodera Y, Matsuura H, Fuwa T. Antitumor-promoting activity of allixin, a stress compound produced by garlic. Cancer J 1990;3:20-21.

31. Zelikoff JT. Effect of onion and garlic oils on 3 T3 cell transformation. In Vitro $1985 ; 21: 41 \mathrm{~A}$.

32. Zelikoff JT, Atkins N, Belman S. Stimulation of cell growth and proliferation in NIH-3T3 cells using onion and garlic oil. In Vitro 1984;20:276.

33. Unnikrishnan MC, Kuttan R. Cytotoxicity of extracts of spices to cultured cells. Nutr Res $1988 ; 11: 251-257$.

34. Scharfenberg K, Wagner R, Wagner KG. The cytotoxic effect of ajoene, a natural product from garlic, investigated with different cell lines. Cancer Lett 1990;53;103-108. 
35. Konvicka O. Zum mitotischen Hemmungseffekt von Allium sativum Extrakt. Cytologia 1984;49: 761-769.

36. Sparnins VL, Mott AW, Barany G, Wattenberg LW. Effects of allyl methyl trisulfide on glutathione S-transferase activity and BP-induced neoplasia in the mouse. Nutr Cancer 1986;8:211-215.

37. Sparnins V, Barany G, Wattenberg LW. Effects of organosulfur compounds from garlic and onions on benzolalpyrene-induced neoplasia and glutathione S-transferase activity in the mouse. Carcinogenesis 1988;9:131-134.

38. Wattenberg LW, Sparnins VL, Barany G. Inhibition of $\mathrm{N}$-nitrosodiethylamine carcinogenesis in mice by naturally occurring organosulfur compounds and monoterpenes. Cancer Res 1989;49:26892692.

39. Wargovich MJ, Goldberg MT. Diallyl sulfide: a naturally occurring thioether that inhibits carcinogen induced damage to colon epithelial cells in vivo. Mutat Res 1985:143:127-129.

40. Wargovich MJ. Diallyl sulfide, a flavor component of garlic (allium sativum), inhibits dimethylhydrazine-induced colon cancer. Carcinogenesis 1987;8:487-489.

41. Brady JF, Li DC, Ishizaki H, Yang CS. Effect of diallyl sulfide on rat liver microsomal nitrosamine metabolism and other monooxygenase activities. Cancer Fes 1988;48:5937-5940.

42. Goldberg MT, Josephy PD. Studies on the mechanism of action of diallyl sulfide, an inhibitor of the genotoxic effects of cyclophosphamide. Can J Physiol Pharmacol 1987;65:467-471.

43. Baer AR, Wargovich MJ. Role of ornithine decarboxylase in diallyl sulfide inhibition of colonic radiation injury in the mouse. Cancer Res 1989;49:5073-5076.

44. Hu PJ, Wargovich MJ. Effect of diallyl sulfide on MNNG-induced nuclear aberrations and ornithine decarboxylase activity in the glandular stomach mucosa of the Wistar rat Cancer Lett 1989;47:153-158.

45. Wargovich MJ, Woods C, Eng VWS, Stephens C, Gray K. Chemoprevention of NNitrosomethylbenzylamine-induced esophageal cancer in rats by the naturally occurring thioether, diallyl sulfide. Cancer Res 1988;48:6872-6875.

46. Hussain SP, Jannu LN, Rao AR. Chemopreventive action of garlic on methylcholanthrene-induced carcinogenesis in the uterine cervix of mice. Cancer Lett 1990;49:175-180.

47. Sadhana AS, Rao AR, Kuchera K, Bijani V. Inhibitory action of garlic oil on the initiation of benzola]pyrene-induced skin carcinogenesis in mice. Cancer Lett 1988;40:193-197.

48. Shyu KW, Meng CL. The inhibitory effect of oral administration of garlic on experimental carcinogenesis in hamster buccal pouches by DMBA painting. Proc Natl Sci Counc Repub China 1987; $11: 137-147$.

49. Belman S. Onion and garlic oils inhibit tumor promotion. Carcinogenesis 1983;4:1063-1065.

50. Rao AR, Sadhana AS, Goel HC. Inhibition of skin tumors in DMBA-induced complete carcinogenesis system in mice by garlic (allium sativum). Indian J Exp Biol 1990;28:405-408.

51. Unnikrishnan MC, Kuttan R. Tumour reducing and anticarcinogenic activity of selected spices. Cancer Lett 1990;51:85-89.

52. Desai HG, Kalro RH, Choksi AP. Effect of ginger and garlic on DNA content of gastric aspirate. Indian J Med Res 1990;92:139-141.

53. Kandil OM, Abdullah TH, Elkadi A. Garlic and the immune system in humans: its effect on natural killer cells Fad Proc 1987:46:441.

54. Joseph PK, Rao KR. Sundaresh CS. Toxic effects of garlic extract and garlic oil in rats, Indian J Exp Biol 1989;27:977-979.

55. You WC, Blot WJ, Chang YS, Ershow AG, Yang ZT, An Q, Henderson B, Xu GW, Fraumeni JF, Wang TG. Diet and high risk of stomach cancer in Shandong, China. Cancer Res 1988;48:35183523.

56. You WC, Blot WJ, Chang YS, Ershow AG, Yang ZT, An Q. Henderson B, Fraumeni JF, Wang TG. Allium vegetables and reduced risk of stomach cancer. J Natl Cancer Inst 1989;81:162-164.

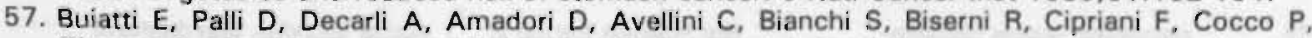
Giacosa A, Marubini E. Puntoni R, Vindigni C, Fraumeni J. Bilot W. A case-control study of gastric cancer and diet in Italy. Int J Cancer 1989;44:611-616.

58. Lawson LD, Wang ZJ, Hughes BG. Identification and HPLC Quantification of the sulfides and dialk(en $)$ yl thiosulfinates in commercial garlic products. Planta Med 1991;57:363-370.

59. Steinmetz KA. Potter JD. Vegetables, fruit, and cancer, i. Epidemiology. Cancer Causes and Control 1991;2:325-357.

60. Van den Brandt PA, Goldbohm RA, Van 't Veer P, Volovics A, Hermus PJJ, Sturmans F. A largescale prospective cohort study on diet and cancer in The Netherlands. J Clin Epidemiol 1990;43:285 295. 
Appendix-table 1. Important results from in vitro assays on anticarcinogenic mechanisms of garlic and garlic compounds.

\begin{tabular}{lll}
\hline Peference Test system of specific endpoints Results & Test compound
\end{tabular}

$25 \quad$ Ames test

DNA binding and adduct formation $A F B$, metabolite formation

24

Ames test

DNA binding and adduct formation

AFB, metabolite formation

\section{Ames test}

differential DNA repair test

$\mathrm{CHO}$ cell TG-resistant clones

modified TBA lipid peroxidation test

Ames test

initiator $\mathrm{I}^{14} \mathrm{C}$-methyllOMH in cultured rat hepatocytes

epidermal cells incubated with TPA, mezerein, $\mathrm{H}_{2} \mathrm{O}_{2}$, benzoylperoxide, anthralin GSH peroxidase activity intracellular GSH/GSSG ratio ODC activity

TPA induced ${ }^{3 \mathrm{P}}$-incorporation into Hela cell phospholipids

TPA.induced ${ }^{3} \mathrm{P}_{\text {, incorporation into Hela }}$ cell phospholipids

TPA-induced ${ }^{2} \mathrm{H}$-choline incorporation into mouse fibroblast phospholipids

\section{macrophage glucose utilization} macrophage cytostatic activity against P815 tumour cells DNA synthesis spleen cells $\left[{ }^{3} \mathrm{H}\right]-$ thymidine incorporation alliin

allicin

cysteine

DAS

garlic extract

ajoene

DAS

allixin

fresh aqueous.

garlic extract

garlic oil

onion oil

dipropenylsulfide

ethanolic garlic extract

allixin

high molecular fraction of aged garlic

aged garlic

low molecular fraction

less effective
+ ${ }^{32}$ p incorperation

- $\mathrm{H}$-choline incorporation

- $\mathrm{AFB}_{1}$ mutagenesis, dose-dependent

+ DNA binding and adduct formation

$+\mathrm{AFB}_{1}$ metabolite formation

$\downarrow$ formation $\mathrm{AFB}_{1}$-glutathione conjugates

$\downarrow$ AFB mutagenesis, dose-dependent

$\downarrow$ DNA binding and adduct formation

$+\mathrm{AFB}_{1}$-metabolite formation

$\downarrow$ formation $\mathrm{AFB}_{1}$-glutathione conjugates

+ mutagenesis induced by $\gamma$-radiation and radio-mimetic mutagens, dose-dependent

- mutagenic activity on $\mathrm{CHO}$ cells

$\downarrow$ DNA damage

$\downarrow$ lipid peroxidation, dose-dependent

no effect

$\downarrow \gamma$-radiation-induced mutagenesis

$\uparrow$ mutagenesis even without $y$-radiation

\ macromolecular binding DMH no effect on GST-activity, glutathione reductase or peroxidase

† GSH peroxidase, dose-dependent and time-dependent

$\downarrow$ induction OOC activity, time-dependent

$\downarrow$ decrease GSH/GSSG ratio, dosedependent

\section{less effective}

1 ${ }^{32} p_{\text {,incorporation, dose-dependent }}$

$\uparrow$ glucose utilization, dose-dependent

$\uparrow$ cytostatic activity on tumour cells

$\uparrow$ DNA synthesis, dose-dependent

less effective

less effective 
Appendix-table 1, continued

Reference Test system or specific endpoints

33

surviving fraction of Dalton lymphoma ascites cells, human Iymphocytes, cultured Vero cells; and $\mathrm{CHO}$ cells

DNA synthesis $\left[{ }^{3} \mathrm{H}\right]$ thymidine incorporation!

34

surviving fraction of human foreskin fibroblasts, nontumourigenic BHK21 cells and tumourigenic BJA.B cells

35 mitosis inhibition test

31 NIH-3T3 cell transformation $\mathrm{BaP}+\mathrm{PMA}$
Test compound

Besults

dried powdered garfic extracted with water or ethanol

ajoene

raw garlic juice

onion oil

garlic oil
+ mitosis, dose-dependent:

$\downarrow$ number transformed cells

stronger effect ethanolic extract, more effect on cultured cells, dependent on dose and cell line

\DNA. synthesis, dose-dependent

strongest effect on Iumourigenic cells dependent on dose, cell proteins, time of administration arid duration of ireatment

not published 
Appendix-table 2. In vivo assays evaluating the efficacy of garlic and garlic compounds against carcinogenic agents at specific target sites.

\begin{tabular}{ll}
\hline Ref. Test animal Carcinogen & $\begin{array}{l}\text { Test compound, route and dose of Results } \\
\text { administration }\end{array}$ \\
\hline
\end{tabular}

\section{INITIATION}

36

A/J mice

BaP

37

A/J mice

Bap

DAS p.o. 10.02 mmol)

AMT p.o. (0.008-0.024 mmol)

AMD p.0. (0.01-0.04 mmol)

saturated analogs p.o.

NDEA

DADS p.0. $(0.02 \mathrm{mmol})$

AM p.0. $(0.01$ mmol)

AMD p.o. $(0.02 \mathrm{mmol})$

DAS p.o. $[0.02$ mmoli

39

C57BL/6.J mice

MNU, MNNG

DAS p.o. $(200 \mathrm{mg} / \mathrm{kg})$

DMH

DAS p.o. $550-200 \mathrm{mg} / \mathrm{kg})$

40
DMH
DAS p.o. $(200 \mathrm{mg} / \mathrm{kg})$ $\uparrow$ GST activity forestomach, liver, small bowel, lung, dose-dependent

t number and degree of malignancy of forestamach tumours/mouse

no effect on lung papilloma development

$\downarrow$ mean number of forestomach tumours/mouse

no effect on mean number lung adenoma per mouse

$\uparrow$ GST activity forestomach, liver, small bowel, lung

no effect on forestomach tumours formation

$\checkmark$ mean number lung adenomas/mouse

$\uparrow$ GST activity forestomach, liver, small bowel

$\downarrow$ mean number forestomach tumours/mouse

no effect on lung adenoma formation + GST activity forestomach, liver, small bowel, lung

$\downarrow$ mean number forestomach tumours/mouse

$\downarrow$ mean number lung adenomalmouse

$\uparrow$ GST activity forestomach, liver, small bowel, lung

no effect

$\downarrow \%$ mice with ferestomach papillomas $\downarrow$ \% mice with forestomach carcinomas less effective on lung adenomas

no effect on nuclear aberrations in colọn

I nuclear aberrations in colon, dosedependent

- number and degree of malignancy of colon tumours

no induction GST or DT-diaphorase in liver

Appendix-table 2 continues on next page 
Appendix-table 2, continued

Ref. Test animal Carcinogen Test compound, route and dose of Results administration

$43 \quad$ C57BL/6J mice $\quad \gamma$-radiation DAS p.0. (50-400 mg/kg)

I nuclear aberration in colon, dose dependent, time-dependent

DAS p.0. $1400 \mathrm{mg} / \mathrm{kg})$

$\gamma$-radiation + ODC inhibitor (DMFO)

18 C57BL./6J mice DMH

C57B. 6 J mice DMH

CF-1 mice

DMH

42

C57BL/6J mice

cyclophos. phamide

46 Swiss albino mice MC

27
Fisher 344 rats

DMH
DAS p.0. $(200 \mathrm{mg} / \mathrm{kg})$ $\mathrm{mg} / \mathrm{kg})$

CyS p.o. $(400 \mathrm{mg} / \mathrm{kg})$

DAS p.0. $(200 \mathrm{mg} / \mathrm{kg})$ (400 mg/kg)
DAS p.0. (200 mg/kg)

$\downarrow \mathrm{ODC}$ activity in colon

$\downarrow\left[^{3} \mathrm{H}\right]$ thymidine incorporation in colon DNA

no effect on nuclear aberration formation

DADS, ajoene p.o. $(200 \mathrm{mg} / \mathrm{kg})$

DPS , DPDS p.o. $(200 \mathrm{mg} / \mathrm{kg})$

SAC p.0. $(50-400 \mathrm{mg} / \mathrm{kg})$

SAMC $^{*}$ p.0. $(200 \mathrm{mg} / \mathrm{kg})$

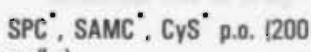

SAC p.o. $(200,400 \mathrm{mg} / \mathrm{kg})$

fresh aqueous garlic extract p.o. $\quad \%$ mice with uterine cervix tumours

DAS p.0. $(25-100 \mathrm{mg} / \mathrm{kg})$ no effect

- nuclear aberrations in bladder

- nuclear aberrations in hair follicle

$\downarrow$ nuclear aberrations in colon

$\uparrow$ GST activity in colon

$\uparrow$ GST activity in liver, time-dependent

no effect on nuclear aberrations in colon

$\uparrow$ GST activity in colon

^ GST activity in liver, time-dependent

no effect on nuclear aberrations in colon

$\uparrow$ GST activity in liver, time-dependent

$\downarrow$ nuclear aberrations in colon, dosedependent

$\uparrow$ GST activity in colon

$\uparrow$ GST activity in liver, time-dependent

no effect on nuclear aberrations in colon + colonic GST activity

no effect

$\downarrow \%$ mice with colon tumours, dosedependent

i mean number colon tumours/mouse, dose-dependent

$\downarrow \gamma$-GT and number GST.P foci in liver, dose-dependent 
Apperifineth 2 enifinued

\begin{tabular}{|c|c|c|c|c|}
\hline fisf. & feat arimit & farcinogent & $\begin{array}{l}\text { Tent cumpound, raute and thas of } \\
\text { aftinisistration }\end{array}$ & fierilts: \\
\hline 4t & $\begin{array}{l}\text { Soraguetiawtey } \\
\text { rafs }\end{array}$ & 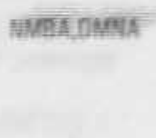 & DAS ig. $(2000 \mathrm{mg} k \mathrm{~kg}$ & 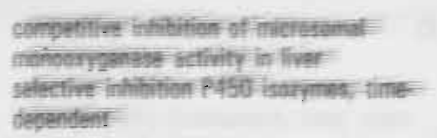 \\
\hline 45 & $\begin{array}{l}\text { Sersigue thisley } \\
\text { rafts }\end{array}$ & AMBA & Dîs in - 200 - migh| & 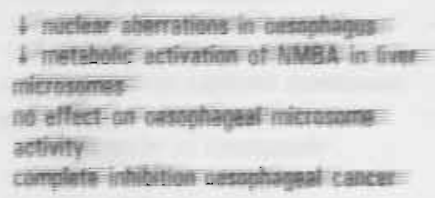 \\
\hline Af & Whitar rats & Metif & Das ip: 50.400 mikg) & $\begin{array}{l}\text { i DDE edtivity in stomach, duse } \\
\text { depandant }\end{array}$ \\
\hline & 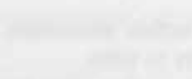 & & DAS $p n \cdot$ or ip $(200$ mgligl: & $\begin{array}{l}\text { if nuclear aburrations ar stamach: } \\
\text { i- } 000 \text { activity in stamach }\end{array}$ \\
\hline 47 & Swiss albino mice & BaP & garfic oil skin application & $\begin{array}{l}\text { \$ mice with skin tumours } \\
\downarrow \text { mean number skin tumours/mouse }\end{array}$ \\
\hline
\end{tabular}

\section{PROMOTION}

HallCR mice

DMBA + PMA onion oil skin application

$\$$ mice with skin tumours, dosedependent

- number skin tumours/mouse, dosedependent

garlic oil skin application

all mice died with $10 \mathrm{mg}$ dose

$\downarrow \%$ mice with skin tumours with lowwer dose

50 Swiss albine mice DMBA

fresh aqueous garlic extract skin application

i $*$ mice with skin papilloma $\downarrow$ mean number papilloma/mouse $\downarrow$ degree of malignancy of tumours

51 Swiss albino mice DMBA

dried garlic extracted with sthanol skin application

$\downarrow \%$ mice with skin papilloma

$\downarrow$ mean number papillomalmouse

$29 \quad$ ICR mice

DMBA + TPA ethanolic garlic extract $5 \mathrm{mg}$ skin application

complete inhibition skin tumour formation

DNBA + TPA ethanolic garlic extract

+ mezerein $\quad 5 \mathrm{mg}$ skin application

$\downarrow \%$ mice with skin tumours

$\downarrow$ mean number tumours/mouse

30

ICR mice

DMBA + TPA

allixin $1 \mathrm{mg}$ skin application

- \% mice with skin tumours

i mean number skin tumours/mice

$\$$ size of tumours

-: SPC: S-propyl-cysteine, SAMC: S-allyImercaptocysteine, CyS: cysteine, DPS: dipropylsulfide, DPDS: dipropyidisulfide 


\section{Chapter 3}

\section{The use of vitamins, minerals and other dietary supplements in The Netherlands}

Elisabeth Dorant; Piet A. van den Brandt; Anneke M. Hamstra;

Marijke H. Feenstra; R. Alexandra Goldbohm; Rudolf J.J. Hermus;

Ferd Sturmans

\section{Abstract}

By means of a two-day dietary record information on the use of dietary supplements has been collected in 1987 and 1988 in a representative sample of the Dutch population aged 1-75 years. More than 17 percent of the population had been using at least one dietary supplement on at least one day of the survey. Age, sex, season, social class, alternative food habits, smoking and diet were related to the use of supplements. In young persons mainly fluoride and vitamin AD preparations were used, while a shift toward other supplements, like garlic and brewer's yeast preparations, was observed as age progresses. The use of single vitamin $\mathrm{C}$ supplements was not related to the level of mean daily vitamin $\mathrm{C}$ intake by food consumption. 


\section{Introduction}

The role of dietary supplements in maintaining health and preventing disease is becoming increasingly important. In studies on the relation of nutrition to disease, knowledge of dietary supplement intake is essential, since many types of supplements have to be regarded as important sources of micronutrients ${ }^{1-3}$.

Despite the considerable interest in The Netherlands and the growing promotion to use dietary supplements, little is known about the prevalence of dietary supplement use in the Dutch population. Recently, a dietary survey in a representative sample of the Dutch population was authorized by the Dutch Ministry of Welfare, Health and Cultural Affairs, and the Ministry of Agriculture and Fisheries. In this Dutch national Food Consumption Survey, data have been collected on food consumption, personal and demographic characteristics and the use of dietary supplements. This paper deals specifically with the analysis of dietary supplement use.

\section{Subjects and Methods}

The Dutch national Food Consumption Survey took place during forty weeks evenly spread over a one year period in 1987 and 1988. No data were collected during national and summer holidays. The study population was a representative sample of 5898 persons living in 2204 households. All geographic regions were included. Children under one year, people living in households in which the person responsible for buying and preparing the food was older than seventy-five, institutionalized people and individuals not mastering the Dutch language were excluded. Information on diet was collected by means of a dietary record of two consecutive days. Each individual completed a personal dietary record, while a separate record on the use of foods per household was completed by the person responsible for buying and preparing the food. The recording days were uniformly distributed over the weekdays and the seasons. Questions were asked regarding use of a dietary regimen, alternative food habits (e.g. vegetarian), smoking behavior, pregnancy, profession, and education. In the personal diary a question on the use of dietary supplements on each of the two days was included. In response to the open-ended question: 'Did you use today: minerals, tonics, vitamins or health preparations ?', up to eight different brand or generic names of dietary supplements could be listed. Questions on dose of the supplement, or number of pills or tablets used each day were not included ${ }^{4}$.

Individuals using at least one dietary supplement on one of the two recording days were defined as supplement users. Each dietary supplement was coded according to its main constituent(s). Separate categories were defined for the single vitamins A, B, C, D and E, and the minerals calcium, fluoride and iron. The other single mineral supplements (zinc, potassium) were grouped forming the 'other minerals' category. Other supplement categories were: vitamin $A D$ preparations, vitamin B complex and other multivitamins, combinations of multivitamins with multiminerals, and other vitamins/minerals. Combinations of calcium with vitamin $C$, calcium with vitamin D and iron with vitamin $C$ supplements are categorized as 'combination of 1 vitamin and 1 mineral'. The health preparations, mostly derived from natural products such as garlic, kelp and spirulina, were categorized based on their main ingredients. Products not belonging in one of the aforementioned groups were categorized as 'other supplements'.

We tested whether the use of dietary supplements was associated with various personal and demographic characteristics. These characteristics are: sex, age, season, geographic region, social class, alternative food habits, dieting and smoking behavior. The classification of social class into five consecutive levels ranging from $A$ (the highest social class) to $D$ (the 
lowest) was defined by a combination of profession and educational level. Alternative food habits were categorized as none, vegetarians, either veganistic or macrobiotic and other alternative food habits. To test whether geographic region of residence was associated with the use of dietary supplements a northern, eastern, southern and western region were defined. Both the associations between dietary supplement use and smoking behavior, categorized as nonsmoker, light smoker ( $\leq 10$ cigarettes, cigars or pipes per day), or heavy smoker ( $>10$ cigarettes, cigars or pipes per day) and between dietary supplement use and dieting (none, prescribed by a physician or own initiative) were examined in the population aged 22 to 75 years. Since no information on dosage or nutrient content of the supplements was collected, we could not measure the total nutrient intake by food and dietary supplements. Instead, we examined whether the use of supplements was associated with nutrient intake from foods by calculating the mean daily vitamin $C$ intake from foods and stratifying the population by level of intake of vitamin $\mathrm{C}$ recommended by the Dutch Food and Nutrition Council in $1989^{5}$. Three categories of vitamin C intake from foods were defined. The first category ranged from $0 \mathrm{mg}$ to the minimum allowance of $50 \mathrm{mg}$, defined by a mean daily vitamin $C$ intake of $0.6-0.7$ times the recommended vitamin $C$ intake. The second category ranged from the minimum allowance to the RDA (50-70mg), while in the third category at least $100 \%$ of the RDA ( $\geq 70 \mathrm{mg}$ ) had to be consumed. In each category the percentage of single vitamin $C$ supplement users was determined. Statistical analyses were performed with SPSSX using $x^{2}$ tests ${ }^{6}$. In the case of social class we used a $x^{2}$ test for trend to evaluate a linear trend with supplement use. Results mentioned and discussed as 'significant' are statistically significant at the $p<0.05$ level.

\section{Results}

In table 1 the distribution of the sample and the proportion of dietary supplement users by various personal and demographic characteristics is presented. In the total population aged $1-75$ years $17.2 \%$ of the individuals reported the use of dietary supplements. The percentage of supplement users among women was significantly higher than among men: $19.0 \%$ versus $15.1 \%$. There was no association between dietary supplement use and region of residence. The percentage of dietary supplement users decreased with declining social class from $23.8 \%$ in the highest category to $9.4 \%$ in the lowest category. The test for trend was highly significant $(p<0.001)$. Among individuals without alternative food habits the proportion reporting use of dietary supplements was lower than among individuals in any of the other categories. Because only a few subjects younger than 22 years were smoking or following a dietary regimen, the associations between the use of dietary supplements and these characteristics were studied in the adult population. The percentages users among nonsmokers and individuals smoking less than 10 cigarettes/cigars/pipes per day were aimost equal: $14.6 \%$ and $14.3 \%$ respectively. Only $9.9 \%$ of the subjects smoking ten or more times a day took dietary supplements. Following a dietary regimen, either on prescription or own initiative was associated with a higher percentage users $(20.8 \%$ and $26.0 \%$ respectively). than not following a diet $(11.9 \%)$.

The number and percentage of users of twenty-six different types of dietary supplements consumed by each sex in the total population are presented in table 2 in decreasing order. Fluoride was the most commonly consumed dietary supplement $(4.8 \%)$, followed by vitamin $A D(4.6 \%)$, vitamin $C(3.6 \%)$, multivitamins $(1.8 \%)$, garlic supplements $(1.5 \%)$, vitamin $B$ complex $(1.4 \%)$ and brewer's yeast $(1.2 \%)$. The percentages users of supplements in the remaining supplement categories were $1.0 \%$ or less. With a few exceptions (fluoride, vitamin $A D$ and vitamin $D$ supplements) a higher percentage of women than men reported the consumption of each individual supplement. The mean number of different types of 
Table 1. Dietary supplement use in the Dutch population. Number and percentage of subjects by various personal and demographic characteristics. The 1987-1988 Dutch national Food Consumption Survey.

\begin{tabular}{lrcc}
\hline Characteristics & Total $(n)$ & Supplement users (\%) & \\
\hline Overall & 5898 & 17.2 & \\
Gender & & & \\
men & 2788 & 15.1 & $x^{2}=15.2$ \\
women & 3110 & 19.0 & $p=0.00$ \\
Geographical distribution & & & \\
west & 2488 & 18.5 & \\
north & 705 & 16.0 & $x^{2}=5.5$ \\
east & 1234 & 16.5 & $p>0.1$ \\
south & 1471 & 16.0 &
\end{tabular}

Social class
A (high)
622
23.8
B1
1292
20.4
B2
1165
15.5
C
2512
15.5
Trend test $\chi^{2}=42.9$
D (low)
307
9.4

Alternative food habits

none
vegetarian
veganism/macrobiotic
other

5767

16.9

67

4

29.9

60

50.0

$x^{2}=14.7$

26.7

Smoking behaviour ${ }^{*}$

nonsmoker

2329

14.6

$<10 /$ day

544

$\geq 10 /$ day

1111

14.3

9.9

$$
x^{2}=14.9
$$

$\mathrm{p}<0.001$

Dietary regimen ${ }^{*}$

$\begin{array}{lr}\text { none } & 3478 \\ \text { prescribed } & 356 \\ \text { own initiative } & 150\end{array}$

11.9

20.8

26.0

$x^{2}=44.4$

$\mathrm{p}<0.001$

$\because$ Analysis restricted to the population aged $22-75$ years. 
Table 2. Number and percentage of men and women reporting use of dietary supplements in the 1987-1988 Dutch national Food Consumption Survey. Dietary supplements categorized according to main compounds and presented in descending order of frequency.

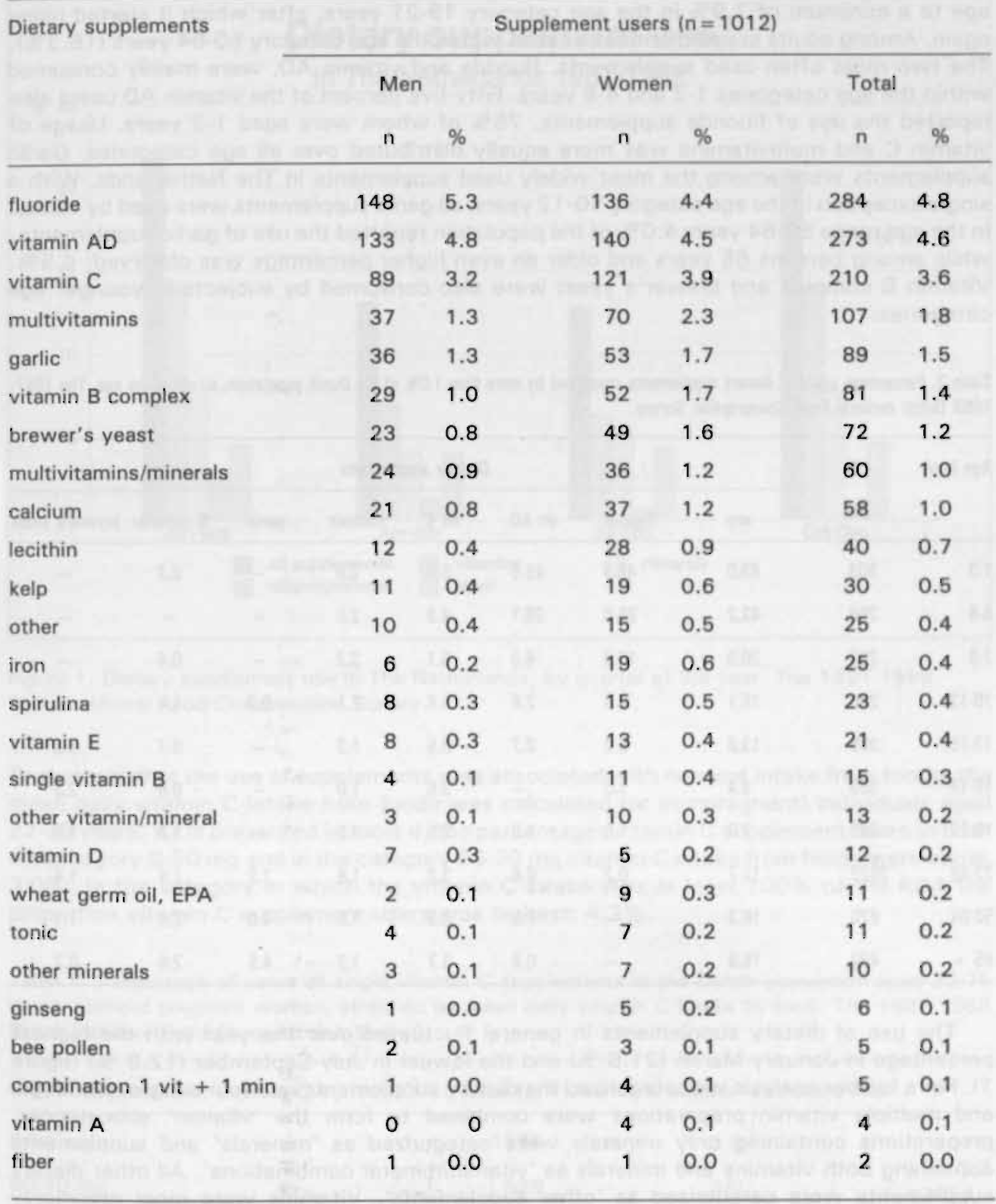


supplements used was identical in both sexes: 1.5 .

In table 3 the proportion of the users of supplements consumed by more than $1.0 \%$ of the total population is presented according to age. The age category 1-3 years showed the highest percentage of supplement users $(63.0 \%)$. Supplement usage declined with increasing age to a minimum of $7.9 \%$ in the age category $19-21$ years, after which it started rising again. Among adults supplement use peaked within the age category 50-64 years (16.3\%). The two most often used supplements, fluoride and vitamin $A D$, were mainly consumed within the age categories $1-3$ and $4-6$ years. Fifty-five percent of the vitamin AD users also reported the use of fluoride supplements, $75 \%$ of whom were aged $1-3$ years. Usage of vitamin $\mathrm{C}$ and multivitamins was more equally distributed over all age categories. Garlic supplements were among the most widely used supplements in The Netherlands. With a single exception in the age category 10-12 years, all garlic supplements were used by adults. in the age range $50-64$ years $4.0 \%$ of the population reported the use of garlic supplements, while among persons 65 years and older an even higher percentage was observed: $4.5 \%$. Vitamin B complex and brewer's yeast were also consumed by subjects in younger age categories.

Table 3. Percentage users of dietary supplements consumed by more than 1.0\% of the Dutch population, stratified by age. The 1987 . 1988 Dutch national Food Consumption Survey.

\begin{tabular}{lcrrrrrrrr}
\hline \multirow{2}{*}{ Age (yrs) } & \multirow{2}{*}{$N$} & \multicolumn{7}{c}{ Dietary supplements } \\
\cline { 3 - 10 } & & any & fluoride & vit AD & vit C & multivit & garlic & B complex brewer's yeast \\
\hline 1.3 & 303 & 63.0 & 46.5 & 45.5 & 5.3 & 2.6 & - & 0.3 & - \\
4.6 & 256 & 42.2 & 25.8 & 26.1 & 4.3 & 2.0 & - & - & - \\
7.9 & 253 & 20.9 & 10.3 & 6.3 & 5.1 & 3.2 & - & 0.4 & - \\
$10-12$ & 286 & 16.1 & 7.3 & 2.8 & 5.6 & 2.1 & 0.3 & 1.4 & - \\
$13-15$ & 305 & 13.8 & 5.2 & 0.7 & 3.6 & 1.3 & - & 0.7 & 1.3 \\
16.18 & 309 & 9.4 & 1.3 & - & 3.6 & 1.0 & - & 0.6 & 2.3 \\
$19-21$ & 202 & 7.9 & 1.0 & 1.0 & 2.5 & 1.5 & - & 1.0 & 1.5 \\
$22-49$ & 2622 & 11.7 & 0.2 & 0.8 & 3.2 & 1.8 & 1.2 & 1.4 & 1.4 \\
$50-64$ & 370 & 16.3 & - & 1.6 & 2.9 & 1.8 & 4.0 & 2.1 & 1.1 \\
$65+$ & 492 & 15.9 & - & 0.8 & 3.7 & 1.2 & 4.5 & 2.6 & 0.2 \\
\hline
\end{tabular}

The use of dietary supplements in general fluctuated over the year with the highest percentage in January-March (21.8\%) and the lowest in July-September (12.8\%) (figure 1). For a further analysis we categorized the dietary supplements into four subgroups. Single and multiple vitamin preparations were combined to form the 'vitamin' subcategory, preparations containing only minerals were categorized as 'minerals' and supplements containing both vitamins and minerals as 'vitamin/mineral combinations'. All other dietary supplements were categorized as 'other supplements'. Vitamins were most commoniy consumed in autumn and winter: $14.9 \%$ and $16.5 \%$ respectively, while in spring and summer only $8.2 \%$ and $6.7 \%$ of the population reported the use of vitamins. Mineral usage 
showed an analogous distribution over the year. In contrast, the use of the 'other supplements', like garlic and kelp, was almost equally distributed over the year.

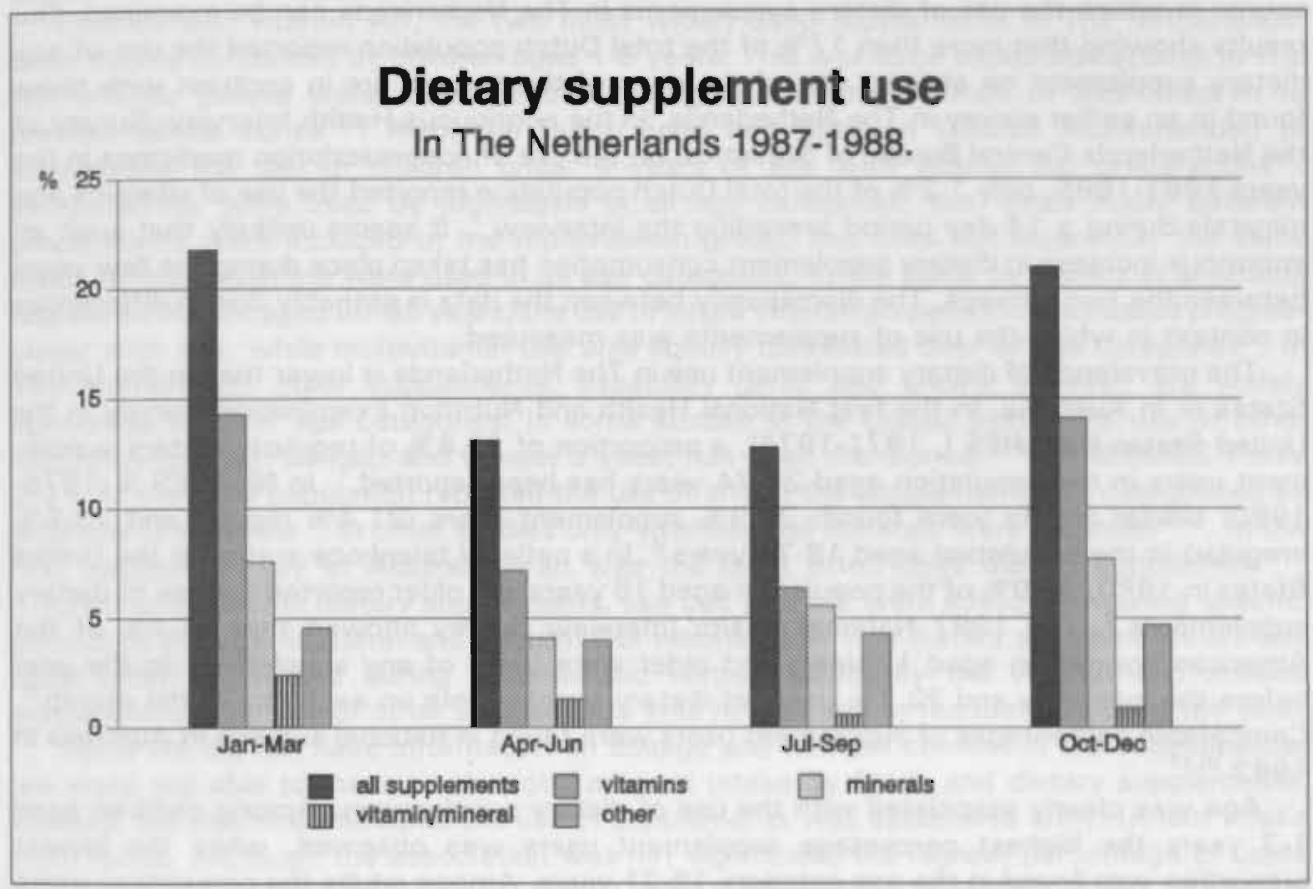

Figure 1. Dietary supplement use in The Netherlands, by quarter of the year. The 1987-1988 Dutch national Food Consumption Survey.

To test whether the use of supplements was associated with nutrient intake from foods, the mean daily vitamin $C$ intake from foods was calculated for (nonpregnant) individuals aged 22-75 years. As is presented in table 4 , the percentages vitamin $\mathrm{C}$ supplement users in both: the category 0-50 $\mathrm{mg}$ and in the category $50-70 \mathrm{mg}$ vitamin $\mathrm{C}$ intake from foods were equal: $3.0 \%$. In the category in which the vitamin $\mathrm{C}$ intake was at least $10 \mathrm{C} \%$ of the RDA the proportion vitamin $\mathrm{C}$ supplement users was highest: $4.2 \%$.

Table 4. Percentage of users of single vitamin C supplements in the Dutch population aged 22-75 years, without pregnant women, stratified by mean daily vitamin $\mathrm{C}$ intake by food. The 1987-1988. Dutch national Food Consumption Survey.

Mean daily intake of vitamin $\mathrm{C}$ by foods

Total (n) Vitamin C supplement users (\%)

\begin{tabular}{lrrr}
$0-50 \mathrm{mg}$ & 1354 & 3.0 & $x^{2}=3.3$ \\
$50-70 \mathrm{mg}$ & 629 & 3.0 & $\mathrm{p}>0.1$ \\
$\geq 70 \mathrm{mg}$ & 1560 & 4.2 & \\
\hline
\end{tabular}




\section{Discussion}

The Dutch national Food Consumption Survey 1987-1988 is the best currently available source in which the use of dietary supplements in The Netherlands can be examined. Our resuits showing that more than $17 \%$ of the total Dutch population reported the use of any dietary supplement on at least one of the days of the survey, are in contrast with those found in an earlier survey in The Netherlands. In the continuous Health Interview Survey of the Netherlands Central Bureau of Statistics, on the use of nonprescription medicines in the years $1981-1985$, only $1.2 \%$ of the total Dutch population reported the use of vitamins and minerals during a 14-day period preceding the interview ${ }^{7}$. It seems unlikely that such an enormous increase in dietary supplement consumption has taken place during the few years between the two surveys. The discrepancy between the data is probably due to differences in context in which the use of supplements was measured.

The prevalence of dietary supplement use in The Netherlands is lower than in the United States or in Australia. In the first National Health and Nutrition Examination Survey in the United States (NHANES I, 1971-1974), a proportion of $22.8 \%$ of regularly dietary supplement users in the population aged $25-74$ years has been reported ${ }^{1}$. In NHANES II (1976$1980)$ similar results were found: $34.9 \%$ supplement users $121.4 \%$ regular and $13.5 \%$ irregular) in the population aged $18-74$ years $^{8}$. In a national telephone survey in the United States in $1980,39.9 \%$ of the population aged 16 years and older reported the use of dietary supplements ${ }^{9}$. The 1987 National Health Interview Survey showed that $51.1 \%$ of the American population aged 17 years and older were users of any supplement in the year before the interview and $23.1 \%$ users of dietary supplements on each day of the month ${ }^{2}$. Comparable percentages of supplement users were found in national surveys in Australia in $1983^{10,11}$.

Age was clearly associated with the use of dietary supplements. Among children aged 1-3 years the highest percentage supplement users was observed, while the lowest proportion was found in the age category 19-21 years. Among adults the percentage users increased with increasing age. In the United States usage also increased with age ${ }^{1,2,8}$.

Only in the study by Schutz et al. among respondents aged 18 years and older in seven Western states in the US, the consumption rate among younger respondents was significantly higher ${ }^{14}$. In Australia no association was found between age and overall dietary supplement use ${ }^{10}$. A significantly higher percentage of women than men reported the consumption of dietary supplements in The Netherlands. Similar results were reported in national studies in the United States and Australia ${ }^{1,2,8-11}$. In contrast with reports from the US ${ }^{1-3,9}$, geographical region of residence was not associated with the use of dietary supplements in The Netherlands. A significant trend was observed between declining level of social class (defined by education and profession) and decreasing percentage supplement users in the Dutch population. In the United States both a high educational level, a high family income and working in traditional 'white-collar' professions were associated with a high prevalence 1,8,9. in Australia overal! supplement use was unrelated to education and occupational status. ${ }^{10}$. Following alternative food habits was positively related with the use of dietary supplements. Nearly 30 percent of the vegetarians took dietary supplements. In a recent study in The Netherlands among elderly vegetarians comparable results were reported ${ }^{12}$. However, in the last study vitamin B complex and calcium were the two most frequentiy used supplements, while in our study garlic and vitamin C were the most popular supplements among the vegetarian supplement users in the same age category. The prevalence of supplement use among heavy smokers was considerably less than among nonsmokers or light smokers. In NHANES I a similar pattern was reported ${ }^{1}$. In NHANES II former smokers were the heaviest supplement users, followed by nonsmokers ${ }^{8}$. Following a special diet was positively related 
with the use of supplements in the adult Dutch population. Comparable results were reported in an Australian study investigating the prevalence of dietary supplement use in an elderly. population ${ }^{13}$.

Fluoride and vitamin $A D$, the two most widely used supplements in The Netherlands, were mainly consumed by children aged 1-6 years. This was to be expected because in The Netherlands people were recommended to supply systemic fluoride to their children to prevent dental caries ${ }^{15}$. Also, the Dutch Food and Nutrition Council recommended to supplement the diet of children under 4 years of age with vitamin AD preparations ${ }^{5}$. Multivitamins were used by individuals in all age categories, but, since many different preparations were included in the multivitamin group, this does not mean that the same types of multivitamins were used in all age categories. In the study by. Willett et al among registered nurses aged 30-60 years, the use of single vitamin preparations increased progressively with age, while multivitamin use was equally distributed over all age categories ${ }^{3}$. In The Netherlands other supplements, especially garlic and brewer's yeast, are widely consumed in older age categories. In some studies in the United States the use of other supplements such as kelp and brewer's yeast has been mentioned ${ }^{1.14}$. In NHANES I only $2.3 \%$ of the total population reported the use of any of the supplements not categorized as vitamins or minerals ${ }^{1}$. In other studies only vitamins and minerals were recorded ${ }^{6,11}$. In the first national survey in Australia bran was the most often used dietary supplement ${ }^{10}$. Traditionally specific dietary supplements, like cod liver oil, were advocated during specific periods of the year (autumn and winter). Our results show that dietary supplements are still most often consumed during autumn and winter, especially the vitamin and mineral preparations. The use of other supplements was not subject to fluctuation during the year.

Since we did not have information on dosage and nutrient content of the supplements, we were not able to measure the total nutrient intake by foods and dietary' supplements. Instead, we examined whether the use of supplements was associated with nutrient intake from foods. Although the association was not significant, the highest percentage of users of vitamin C supplements was observed in the category with the highest intake of vitamin $\mathrm{C}$ from foods. Thus, individuals already consuming enough vitamin $\mathrm{C}$ to meet the RDA were more likely to supplement their cliet. This is in accordance with findings in NHANES II, in which a striking association was found between daily nutrient intake and supplementation. Persons with a high nutrient intake were most likely to supplement their diet ${ }^{8}$.

Because of the widespread use of dietary supplements and the fact that dietary supplements have to be regarded as important sources of nutrients, attention must be paid to the use of supplements in studies concerning dietary factors associated with health ${ }^{1-3}$. Also, the use of supplements itself has to be examined in order to assess their proclaimed health consequences ${ }^{3}$. Currently, the long-term health effects of dietary supplements are being investigated in a large-scale prospective cohort study in The Netherlands. In this study the relation between diet, lifestyle factors and the risk of cancer will be studied among 120,852 persons aged 55-69 years. A detailed description of the design of the cohort study. has been published ${ }^{16}$. One quarter of the study population reported regular use of dietary, supplements in a five-year time period preceding the baseline measurements in 1986 . One of the objectives of the cohort study is to evaluate the relationship between the use of dietary supplements and the incidence of cancer of the stomach, colon, rectum, lung and breast.

\section{References}

1. Block G, Cox C. Madans J, Schreiber GB, Licitra L, Melia N. Vitamin supplement use, by demographic characteristics. Am J Epidemiol 1988;127:297-309. 
2. Subar AF, Block G. Use of vitamin and mineral supplemenst: demographics and amounts of nutrients consumed. The 1987 Health Interview Survey. Am J Epidemiol 1990;132:1091-1101.

3. Willett W, Sampson L, Bain C, Rosner B, Hennekens CH, Witschie J, Speizer FE. Vitamin supplement use among registered nurses. Am J Clin Nutr 1981;34:1121-1125.

4. Beschrijvend rapport inzake de opzet en uitvoering van de Voedselconsumptiepeiling (VCP) 1987/1988. Dongen:Atwood, 1988.

5. Voedingsraad. Nederlandse voedingsnormen 1989. 's Gravenhage: Voorlichtingsbureau voor de Voeding, 1989.

6. SPSS Inc. SPSS-X User's guide, 3rd ed. Chicago, 1988.

7. Van den Brekel EJG. Zelfmedicatie, 1981-1985. Mndber gezondheid 1987;4:11-21.

8. Koplan JP, Annest JL, Layde PM, Rubin GL. Nutrient intake and supplementation in the United. States (NHANES II). Am J Public Health 1986;76:287-289.

9. Stewart ML, McDonald JT, Levy AS, Schucker RE, Henderson DP. Vitamin/mineral supplement. use: a telephone survey of adults in the United States. J Am Diet Assoc 1985;85:1585-1590.

10. Worsley A, Crawford D. Australian dietary supplementation practices. Health and dietary supplements. Med J Aust 1984;140:579-583.

11. Worsley A, Crawford D. Australian dietary supplementation practices: an overview of two recent. surveys. Food Technol Aust 1984;36:547-551.

12. Brants HAM, Lowik MRH, Westenbrink S, Hulshof KFAM, Kistemaker C. Adequacy of a vegetarian diet at old age. J Am Coll Nutr 1990;9:292-302.

13. Horwath CC, Worsley A. Dietary supplement use in a randomly selected group of elderly Australians. J Am Geratr Soc 1989;37:689-696.

14. Schutz HG, Read M, Bendel R, Bhalla VS, Harrill I, Monagle JE, Sheehan ET, Standal BR. Food supplement usage in seven Western states. Am J Clin Nutr 1982:36:897-901.

15. Ten Cate JM. Nieuwe inzichten over fluoride. Ned Tijdschr Tandheelkd 1989;96:7-9.

16. Van den Brandt PA, Goldbohm RA, Van 't Veer P, Volovics A, Hermus RJJ, Sturmans F. A largescale prospective cohort study on diet and cancer in The Netherlands. J Clin Epidemiol $1990 ; 43: 285-295$. 


\title{
Chapter 4
}

\section{Agreement between interview data and a self-administered questionnaire on dietary supplement use}

Elisabeth Dorant; Piet A. van den Brandt; R. Alexandra Goldbohm;

Rudolph J.J. Hermus; Ferd Sturmans

\begin{abstract}
Objective: to study the relative validity of an open-ended question on the consumption of dietary supplements in the preceding five-year period, incorporated in a self-administered questionnaire used in the NLCS, the Netherlands Cohort Study on diet and cancer $(120,852$ men and women aged 55-69).

Design: questionnaire data were compared with reference information from three personal interviews carried out within a period of 10 months.

Setting and Subjects: a randomly selected subgroup (59 men and 50 women) of the cohort living in 12 municipalities in the eastern and western region of The Netherlands.

Results and conclusions: the overall sensitivity of the questionnaire concerning the use of any dietary supplement was $65.9 \%$, the specificity was $98.5 \%$; kappa as measure of agreement was estimated at 0.69. A high percentage recall was observed among women, users of at least three types of dietary supplements, long-term supplement users and those in the oldest age group. Recall of intake of specific supplements ranged from $77.8 \%$ for garlic preparations to $11.8 \%$ for 'other' supplements. Estimates of consumption of specific supplements (garlic and vitamin preparations) may provide enough precision to correctly classify individuals as user or nonuser of those supplements.
\end{abstract}




\section{Introduction}

Dietary supplements, especially vitamin and mineral preparations, may be regarded as important sources of micronutrients. Therefore, studies of nutrient intakes should include the intake of dietary supplements ${ }^{1-4}$. Moreover, because of their widespread use and their proclaimed long-term health effects, it will be important to investigate the health consequences of dietary supplements specifically ${ }^{1,4}$.

In epidemiologic research on the role of diet in relation to disease, self-administered questionnaires are frequently being used to estimate an individual's long term nutrient intake. To estimate the intake of micronutrients on a large scale a questionnaire is often the only feasible method ${ }^{5}$. For accurate ranking of individuals into vitamin and mineral intake categories the inclusion of dietary supplements in the assessment of dietary iritake is required, since much of the variation in total vitarnin intakes may be due to variation in supplemental vitamin intakes ${ }^{6,7}$. Ideally, the ability of a questionnaire to measure what it intends to measure, i.e. the validity, should be established before the study is started, preferably in the population in which the relation between the exposure and the outcome will be studied ${ }^{8-10}$. In some studies on the relation between diet and disease using questionnaire information of dietary intake of macro- and micronutrients, the intake of micronutrients has been validated also taking the consumption of micronutrients by dietary supplements into account ${ }^{5,6,11}$. The validity of data concerning dietary supplement use itself, however, has received only limited attention ${ }^{6}$.

In 1986, the Netherlands Cohort Study (NLCS), a large-scale cohort study on the relation between diet, dietary supplement use, lifestyle factors and cancer, has been started among 120,852 persons aged $55-69$ years ${ }^{12}$. The validity of the self-administered, semiquantitative food frequency questionnaire has been studied in a subgroup of the cohort by comparing the questionnaire with three 3 -day diet records four to five months apart ${ }^{13}$. As part of this validation study the participants have also been interviewed by trained dieticians regarding the use of dietary supplements. The aim of the current report is to describe the relative validity of the questionnaire on the use of dietary supplements by comparing it with data collected by interview.

\section{Methods}

\section{Subjects}

Subjects were participants in a validation study of a semiquantitative food frequency questionnaire against the 9 -day record. These persons $(n=212)$ were sampled from the cohort after the baseline measurement. The study population consisted of 109 participants $\$ 59$ men, 50 women). Reasons for nonparticipation could be attributed to: unavailability (e.g. death, absence, $n=29$ ) or refusal $(n=68)$ and unability to keep a good record $(n=6)$. A detailed description of the response and reasons for dropout or exclusion has been described ${ }^{13}$.

\section{Reference method}

The reference method in the validation study consists of information collected by interview. Although dietary intake itself has been validated against the mean of three 3 -clay cliet records, additional information on use of dietary supplements has been collected by interviewing participants at home by trained (student) dieticians in September 1987', Jarıuary 1988 and July 1988. Participants were probed to report their current use of dietary supplements by asking: ' Do you use vitamins, minerals, garlic pills, lecithin or other health preparations ?'. For each reported supplement, the following information was recorded: type of supplement (generic name), brand name, manufacturer or distributor, location of purchase, 
frequency of consumption, number of doses per consumption and the starting date. When available, information from product labels has been copied.

\section{Questionnaire}

On average three months after the third interview the participants were requested to complete a duplicate of the self-administered questionnaire used to measure baseline exposure in the entire cohort in 1986. The question on the use of dietary supplements included in this questionnaire is as follows: 'During the past five years did you use vitamin tablets, drops or other preparations (for example tonics, vitamins, garlic pills, brewer's yeast, calcium) ?'. In the open-ended part of this question the participant could add the type of supplement, brand name and dose per day. For each of the maximal four supplements that could be listed, information on the starting and stopping year of intake had to be provided. Vitamin $A D$ supplement was given as example.

\section{Coding and key-entering of reference and questionnaire data}

Because both the reference and questionnaire data on the use of specific dietary supplements were derived from an open-ended question, we had to develop a definition of a dietary supplement in order to exclude information on other preparations, such as drugs or cosmetics. A preparation was defined as dietary supplement based on the following criteria: tablets, capsules, oral solutions, syrups, powders, or wafers containing substances that can be consumed as part of a normal diet. Besides vitamins, minerals or preparations derived from complete foods such as garlic, supplements like spirulina, which contains B complex vitamins, or wheat germ oil, an important contributor of vitamin $\mathbf{E}$, were included. Preparations that cannot be taken orally (e.g. injectable solutions, or shampoos and cosmetics containing vitamins) were excluded, as well as preparations that have been 'potentiated' (homeopathic drugs), medicinal herbs and drugs. All information on dietary supplements collected by interview has been coded as detailed as possible. For this reason we used a comprehensive list of dietary supplements available in The Netherlands, which we constructed based on detailed information provided by manufacturers and distributors. Questionnaire data have been double-keyed and checked by research assistants using the same list of dietary supplements. When details on the brand name or manufacturer were not available, the preparation was coded according to its generic (type) name. Since we only have reference data of dietary supplements consumed at the time of the interviews, information from the questionnaire has been excluded if the preparation had not been used in the period covered by the interviews.

\section{Data analysis}

Concerning the interview data, individuals reporting the use of any dietary supplement in at least one of the three interviews were considered as dietary supplement users. An individual was classified as a 'true positive' overall user of dietary supplements when at least one specific type of dietary supplement was recorded in the questionnaire and in at least one interview. 'True negatives' were individuals who did not consume supplements according to both the interview and the questionnaire.

Regarding overall use of dietary supplements, a two-by-two table was used to calculate the sensitivity (i.e. the probability that a user of dietary supplements as defined by interview wili be correctly classiffied based on questionnaire information), specificity (i.e. the probability that a person not using supplements as defined by interviewi will be classified as nonuser based on questionnaire information) and the predictive value of a positive or negative response to the open-ended question included in the questionnaire. To account for the contribution of chance agreement between the interview method and the questionnaire, we also calculated kappa values ${ }^{14}$. 
Since only one supplement user recorded the consumption of dietary supplements in the questionnaire while in the interviews this person did not mention the use of any dietary supplement (i.e. a 'nonuser'), we further concentrated on sensitivity of overall supplement use when analyzing the effect of factors that might have influenced the use of dietary supplements or the ability to recall their consumption. Besides personal characteristics lage and sex), we studied the influence of the number of different supplements used and the total number of doses per day on recall of dietary supplement use. To evaluate the influence of duration of supplement use on the sensitivity of the questionnaire, we categorized subjects into short-term (1 year) and long-term ( $\geq 2$ years) users according to the total duration of dietary supplement use as assessed in the interviews. For each subject the total duration of use was calculated by subtracting the earliest year in which the subject had started with the consumption of supplements from the year in which the current use had been reported. Participants were categorized' in the ' 1 year' category when the consumption of all supplements was started in the year preceding the interviews (1987-1988). When at least one supplement had been used for two years or more or when only 'years' was mentioned, the user was categorized in the ' $\geq 2$ years' category. When one of the data on starting or stopping year in the questionnaire was missing, the total duration was set to one year. Finally, for each specific supplement type the percentage recall obtained by questionnaire was measured by assessing the degree to which the consumption of these supplements was recalled by the participants.

\section{Results}

Table 1. Characterization of persons participating in a study on the validity of a self-administered questionnaire, interviewed at home on the use of dietary supplements.

\begin{tabular}{lccc}
\hline Characteristic & Total & \multicolumn{2}{c}{ Dietary supplement users } \\
\cline { 2 - 4 } & & Interview & Questionnaire \\
\hline
\end{tabular}

All

109

41

37.6

28

25.7

Gender

$\begin{array}{llllll}\text { Men } & 59 & 19 & 32.2 & 9 & 15.6 \\ \text { Women } & 50 & 22 & 44.0 & 19 & 38.0\end{array}$

Age (years)

55-59

60-64

$65-69$

\section{3}

42

23
18

14

9
41.9

33.3

37.5
13

30.2

16.7

7

33.3 
Table 1 presents a description of the study population. Of the 109 participants included. in the analysis, 41 were users of dietary supplements according to the interviews. The proportion of dietary supplement users was higher among women than among men $147.6 \%$ and $32.2 \%$ respectively). The highest proportion of users was found in the youngest age category (55-59 years): $41.9 \%$. Among women the proportion of supplement users within each age category was higher than among men. The proportion of dietary supplement users according to the questionnaire was lower than the proportion found by interviewing the subjects $(25.7 \%)$. The highest proportion of users was also observed among women $138.0 \%$ versus $15.6 \%$ in men), while in contrast with data from the interviews, a higher proportion was found among persons in the oldest age category $(33.3 \%)$ than in the youngest age category $(30.2 \%)$.

Table 2 shows a two-by-two table comparing the information on overall use of dietary supplements collected by the questionnaire with those from the interviews. Twenty-seven of the 41 individuals using dietary supplements according to the interviews mentioned at least one type of supplement in the questionnaire that aiso had been reported in one of the interviews. Thus, the sensitivity was $65.9 \%$. Only one of the 68 nonusers according to the interviews reported the consumption of a dietary supplement in the questionnaire, resulting in a specificity of $98.5 \%$. The predictive value of a positive response was higher than of a negative response $(96.4 \%$ versus $82.7 \%)$. The value of kappa was 0.69.

Table 2. Use of dietary supplements according to questionnaire information and information from three personal interviews.

\begin{tabular}{|c|c|c|c|c|}
\hline \multirow{2}{*}{$x^{2}$} & & \multicolumn{2}{|c|}{ Interview } & \multirow[b]{2}{*}{ Total } \\
\hline & & User & Non-user & \\
\hline \multirow[t]{3}{*}{ Questionnaire } & User & 27 & 1 & 28 \\
\hline & Non-user & 14 & 67 & 81 \\
\hline & Total & 41 & 68 & 109 \\
\hline
\end{tabular}

Because of the high specificity of the questionnaire concerning the overall use of dietary supplements, the influence of various factors is only reported for the sensitivity (table 3). The percentage recall of overall dietary supplement use in the questionnaire was higher among women than among men $(81.8 \%$ and $47.4 \%$ respectively). When the number of different types of supplements reported in the questionnaire rose from 1 to 3 or more, the sensitivity increased from $50.0 \%$ to $100 \%$. Among subjects using only one type of supplement the sensitivity was also higher for women than for men $(70 \%$ and $33.3 \%$ respectively). Table 3 also shows that the percentage recall of overall dietary supplement use was higher in the oldest age category than in the category $55-59$ years $(88.8 \%$ and $66.7 \%$ respectively) or among persons aged 60-64 years $(50 \%)$. Six of the 14 ' 1 year' users $(42.9 \%)$, and 21 of the 27 subjects in the ' $\geq 2$ years' category $(77.8 \%)$ recalled their consumption in the questionnaire. The total number of doses per day was not related to recall of dietary supplement use.

In table 4, the sensitivity of the questionnaire is presented for each type of supplement separately, in descending order of percentage recall. Although broad categories of supplements are presented, analysis of agreement per unique type of dietary supplement was conducted. Of the 86 supplements reported by interview, 46 were mentioned in the 
questionnaire $(53.5 \%)$. The percentage recall of the use of garlic preparations was highest $(77.8 \%)$. Recall of overall vitamin supplement use was $72.7 \%$, although both vitamin $E$ $(n=4)$ and vitamin $A D(n=3)$ were recalled by $100 \%$ of the users. Vitamin $B$ consumption (including the B complex preparations, vitamin B1, B6 and B12) was recalled by $72.7 \%$ and vitamin $\mathrm{C}$ and multivitamin/minerals both by $60 \%$ of the users. The most frequently consumed supplement according to the interviews, calcium $(n=15)$, was recorcled in the questionnaire by 8 subjects $(53.3 \%)$. The percentage agreement between questionnaire and reference interviews regarding other supplement types was considerably lower.

Table 3. Number and percentages with $95 \%$ confidence intervals of subjectsi using dietary supplements as reported by a self-administered questionnaire compared to information from three personal interviews, stratified by several characteristics.

\begin{tabular}{|c|c|c|c|c|}
\hline \multirow[t]{2}{*}{ Characteristics } & Interview & \multicolumn{3}{|c|}{ Recall in Questionnaire } \\
\hline & $n$ & $n$ & $\%$ & $(95 \% \mathrm{Cl})$ \\
\hline Overall & 41 & 27 & 65.9 & (49.4-791.9) \\
\hline \multicolumn{5}{|l|}{ Gender } \\
\hline men & 19 & 9 & 47.4 & $(24.4-71.1)$ \\
\hline women & 22 & 18 & 81.8 & $(57.9-100)$ \\
\hline
\end{tabular}

Number of different types of supplements

$\begin{array}{cccc}1 & 22 & 11 & 50.0 \\ 2 & 8 & 5 & 62.5 \\ \geq 3 & 11 & 11 & 100\end{array}$

Age (years)

$\begin{array}{rcccc}55-59 & 18 & 12 & 06.7 & (41.0-86.7) \\ 60-64 & 14 & 7 & 50.0 & (23.0-77.0) \\ 55-69 & 9 & 8 & 88.8 & (51.8-100)\end{array}$

Total number of years of supplement use

$\begin{array}{llccc}1 & 14 & 6 & 42.9 & (17.7-71.1) \\ \geq 2 & 27 & 21 & 77.8 & (57.7-91.3)\end{array}$

Total number of doses per day

$\begin{array}{llll}<3 & 22 & 15 & 68.2 \\ \geq 3 & 19 & 12 & 63.2\end{array}$


Table 4. Numbers and percentages with $95 \%$ confidence intervals of different types of dietary supplements as reported in a self-administered, mailed questionnaire compared to information from three interviews, ordered in decreasing percentage of agreement.

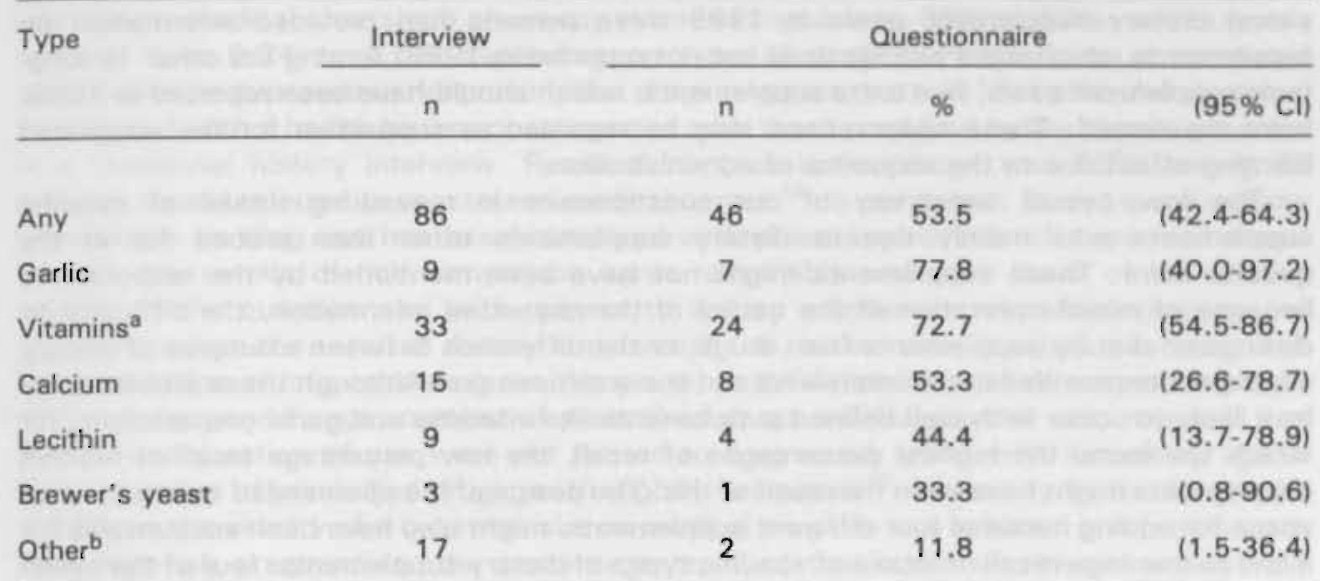

a: vitamin A, AD, B1, B2, B6, B12, B complex, C, E, multivitamins.

b: iron, zinc, kelp, beepollen, fiber, wheat germ oil, ginseng, combinations or other.

\section{Discussion}

In The Netherlands, dietary supplements are obtainable from pharmacies on prescription or as 'over the counter' products, and from drugstores, health food stores, supermarkets and mail order companies. Dietary supplements are generally used by inclividuals to supplement a potential deficiency in the diet and/or to benefit from their supposed health effects ${ }^{15 \cdot 20}$. Some preparations, such as vitamin B complex, iron, multivitamins, and calcium with vitamin $D$, are also being prescribed or recommended by health professionals to treat or prevent symptoms of deficiency ${ }^{2,21-25}$.

In our cohort study, baseline information on the intake of dietary supplements has been collected in 1986 with a self-administered questionnaire. The relative validity of the questionnaire on the use of specific types of dietary supplements has been examined afterwards by using interviews held in 1987 and 1988 as reference method for comparison. with data collected by readministering the questionnaire in 1988. Although the overall sensitivity of the questionnaire concerning the measurements of overall use of clietary supplements is moderate $(65.9 \%)$, a high percentage recall was observed among women. users of at least three dietary supplements, long-term supplement users and in the oldest age group. According to the classification of kappa proposed by Landis and Koch, our questionnaire is an instrument with 'substantial' validity in measuring overall use of dietary supplements (kappa $=0.69)^{14}$. The percentage recall of specific types of supplements varied. considerably: from $77.8 \%$ for garlic supplements to $11.8 \%$ for supplements in the 'other' category.

Besides general problems of using interview data as reference (interview data can be subject to response error as well and aiso might not reflect true intake ${ }^{5,9,26,27}$, the relative validity might have been affected by the sequence of administration of the interviews and the questionnaire. Since reference data were collected before completion of the questionnaire 
and within the predefined period of consumption, a better interpretation of the open-ended question in the questionnaire or, less likely, induction of a change in dietary supplement consumption might have occurred ${ }^{10,11,27}$. Comparison of questionnaire data collected in 1988 with those collected at baseline in 1986, revealed that among the 18 long-term (i.e. $\geq 2$ years) dietary supplement users in 1988 three persons had provided information on supplements which were already used but not reported in 1986. Among the other 15 longterm supplement users, five extra supplements, which should have been reported in 1986 , were mentioned. These observations may be regarded as supportive for the suggested learning-effect due to the sequence of administration.

The low overall sensitivity of our questionnaire in measuring intake of specific supplements was mainly due to dietary supplements other than probed for in the questionnaire. These supplements might not have been mentioned by the respondents because of misinterpretation of the nature of the requested information, the difficulty to distinguish dietary supplements from drugs, or the difference between examples of dietary supplements provided in the interviews and the questionnaire. Although these problems are less likely to occur with well defined supplements like vitamins and garlic preparations, for which we found the highest percentages of recall, the low percentage recall of lecithin supplements might have been the result of this. The design of the open-ended question, with space for adding maximal four different supplements, might also have been accountable for a low percentage recall of intake of specific types of dietary supplements: four of the seven 'unrecorded' calcium supplements were consumed by subjects taking at least four other supplements. The low percentage recall of calcium supplement use might also have been caused by their use as 'therapeutics', since most of them were consumed by the female participants, for whom calcium supplements might have been recommended by health professionals to prevent postmenopausal complications ${ }^{28}$. The lower recall of vitamin $\mathrm{C}$ $(60 \%)$ may be due to a seasonal variation in use reported for vitamins ${ }^{29}$ : some people take vitamin $C$ in the winter only, whereas the questionnaire was completed in September.

The consumption of dietary supplements cannot be assumed to be stable over time. Apart from the already mentioned seasonal variation in use, proclaimed beneficial effects of dietary supplements, especially for elderly persons, might lead to variations in consumption. Furthermore, the availability of supplements on the market as well as the number of available supplement types might have changed. The validity of the questionnaire might have been affected by these circumstances and our results reported here relate therefore, strictly speaking, only to the time period in which the validation study took place. However, in the study by Gray et al. in 1984 , a high degree of agreement $(84 \%)$ between questionnaire information on overall use of vitamin supplements; has been reported after comparing it. with interview data collected 15 months later ${ }^{6}$. Thus, for specific categories of dietary supplements the validity of the questionnaire might not be confined to a specific period. Comparison of our results with those reported in other studies on validity' of dietary intake measurements is complicated because, in contrast with other studies, we have validated an open-ended question, and we developed a definition of a dietary supplement that includes other preparations than vitamins and minerals as well, except drugs. Also, this is the first study that specifically investigated the relative validity of a questionnaire on dietary supplement use. However, since dietary supplements closely resemble drugs lin form and pattern of use) and reasons for taking them are reported to be similar ${ }^{15,16,30}$, the validity of the questionnaire estimating exposure to dietary supplements can also be compared to the validity of questionnaires measuring long-term drug use.

In medical research self-administered questionnaires are sometimes being used as the only source of information on exposure to medical treatments or interventions, such as exposure to drugs or radiation. However, the validity of exposure estimates, obtained from self- 
administered questionnaires, has still received limited attention. In a literature search by Harlow and Linet (1989) only two studies were identified concerning nonhormonal, nonpregnancy related drugs ${ }^{31}$. In one of these studies, by Paganini-Hill and Ross (1982), the proportion of agreement with respect to information on nonhormonal drug use between interviews, medical charts and pharmacy records ranged from $69 \%$ to $87 \%$, with kappa's ranging from 0.24 to 0.62 , depending on type of drug ${ }^{32}$. Pecoraro et al compared information on exposure to nonprescription drugs or tonics, such as 'diet pills' and vitamins, determined with a health history questionnaire with those produced by the history provided in a traditional history interview. Recall of nonprescription drugs was $65 \%$ among 23 patients newly referred to a veterans medical centre ${ }^{33}$. In our cohort study, questionnaire information on drug use has been compared with pharmacy records of dispensed drugs. Overall, the results of this comparison agree reasonably well with those of the relative validity of the questionnaire with respect to dietary supplement use. Analogous to our observations on the recall of dietary supplement use, an increase in recall was seen with longer duration of long-term drug use. However, stratification of recall of current long-term drug use by gender, age, number of prescribed drugs and duration of use, revealed that gender and duration of use were not related to drug recall, while with increasing age or higher number of prescribed drugs recall slightly decreased ${ }^{26}$. In a study by De Jong et al. (1991) on the validity of a questionnaire on medical drug use in a selected group of women with high-risk pregnancies, the percentage recall of the intake of vitamin and mineral containing drugs during pregnancy was very low $(31 \%)$ compared to our results ${ }^{34}$.

In epidemiologic studies on the relation between nutrition and disease, the intake of dietary supplements should be measured in order to estimate the exposure of the study population to important nutrients. Gray et al. suggested that estimating total vitamin A and $\mathrm{C}$ intakes might best be accomplished by asking the amount of vitamin supplement intake and frequency of use of a few selected foods ${ }^{6}$. However, this is only correct when a considerable proportion of the study population consumes specific vitamin supplements, information on the vitamin content of each supplement is available, valid estimates of true intake by supplements can be calculated, and information on timing of consumption is available. Furthermore, if supplement use varies between different demographic subgroups ${ }^{3.5}$, problems may arise in the estimation of nutrient intake proposed by Gray et $a^{6}{ }^{6}$. In general, estimating the total consumption of vitamins by supplements is complicated because vitamins are not only consumed as single vitamin preparations but also as multivitaminmineral preparations with varying amounts of vitamins ${ }^{35}$, and other vitamin containing supplements such as wheat germ oil and brewer's yeast ${ }^{29}$. To separately evaluate the effect of dietary supplements on disease, valid estimates should be available on the use of these supplements.

In our prospective cohort study, estimates on intake of specific supplements (e.g. garlic preparations and vitamins) may provicle enough precision to correctly classify individuals as user or nonuser of those supplements.

\section{References}

1. Willett W, Sampson L, Bain C, Rosner B, Hennekens CH, Witschie J, Speizer FE. Vitamin supplement use among registered nurses. Am J Clin Nutr 1981;34:1121-1125.

2. Gray GE, Paganini-Hill A, Ross RK. Dietary intake and nutrient supplement use in a Southern California retirement community. Am J Clin Nutr 1983;38:122-128.

3. Block G, Cox CC, Madans J, Schreiber GB, Licitra L, Melia N. Vitamin supplement use, by demographic characteristics. Am J Epidemiol 1988;127:297-309.

4. Subar AF, Block G. Use of vitamin and mineral supplements: demographics and amounts of nutrients consumed. Am J Epidemiol 1990;132:1091-1101. 
5. Block G, Woods M, Potosky A, Clifford C. Validation of a self-administered diet history questionnaire using multiple diet records. J Clin Epidemiol 1990;43:1327-1335.

6. Gray GE, Paganini-Hill A, Ross RK, Henderson B. Assessment of three brief methods of estimation of vitamin $A$ and $C$ intakes for a prospective study of cancer: comparison with dietary history. Am J Epidemiol 1984;119:581-590.

7. Kune S, Kune GA, Watson LF. Observations on the reliability and validity of the design and diet history method in the Melbourne colorectal cancer study. Nutr Cancer 1987;9:5-20.

8. Block G. A review of validations of dietary assessment methods. Am J Epidemiol 1982;115:492505.

9. Block G, Hartman AM. Issues in reproducibility and validity of dietary studies. Am J Clin Nutr 1989;50:1133-1138.

10. Nelson M. The validation of dietary questionnaires. In: Design concepts in nutritional epidemiology, eds BM Margetts \& M Nelson, pp 266-296. Oxford UK, Oxford University Press. 1991.

11. Willett W, Sampson L, Stampfer MJ, Rosner B, Bain C, Witschi J, Hennekens CH, Speizer F. Reproducibility and validity of a semiquantitative food frequency questionnaire. Am J Epidemiol $1985 ; 122: 51-65$.

12. Van den Brandt PA, Goldbohm RA, Van 't Veer P, Volovics A, Hermus RJJ, Sturmans F. A largescale prospective cohort study on diet and cancer in the Netherlands. J Clin Epidemiol $1990 ; 43: 285-295$.

13. Goldbohm RA, Van den Brandt PA, Brants HAM, Van 't Veer P, Al M. Validation of a dietary questionnaire used in a large-scale prospective cohort study on diet and cancer. Eur J Clin Nutr $1994 ; 48: 253-265$.

14. Landis JR, Koch GG. The measurement of observer agreement for categorical data. Biometricsi 1977:33:159-174.

15. English EC, Carl JW. Use of nutritional supplements by family practice patients. JAMA $1981 ; 246: 2819-2721$.

16. Read MH, Graney AS. Food supplement usage by the elderly. J Am Diet Assoc 1982;80:250253.

17. Kellett M, Kelleher E, Crutchfields J, Dubes M, Glasser C, Lazure G. Vitamin and mineral supplement usage by retired citizens. J Nutr Elderly 1984;3:7-19.

18. Worsley A, Crawford D. Australian dietary supplementation practices. Health and dietary supplements. Med J Austr 1984:140:579-583.

19. Turlings JDM, Feenstra MH. Aanbod en gebruik van voedingssupplementen. 's Gravenhage, The Netherlands, SWOKA institute for consumer research, 1987.

20. Payette H, Gray-Donald K. Do vitamin and mineral supplements improve the dietary intake of elderly Canadians ? Can J Publ Health 1991;82:58-60.

21. Groot EH, Hautvast JGA. Zin en onzin van het voorschrijven van multivitaminepreparaten aan bejaarden. Ned Tijdschr Geneeskd 1979;123:1339-1344.

22. Sorensen AA, Sorensen DI, Zimmer JG. Appropriateness of vitamin and mineral prescription orders for residents of health related facilities. J Am Geriatr Soc 1979;27:425-430.

23. Schneider CA, Nordlund DJ. Prevalence of vitamin and minerat supplement use in the elderly. J Fam Practice 1983; 17:243-247.

24. Council on scientific affairs. Vitamin preparations as dietary supplements and as therapeutic agents. JAMA 1987;257:1929-1936.

25. Sobal J, Muncie HL, Koch H. Prescription and recommendation of multivitamins by physicians in office based amulatory care in the United States. Nutr Res 1988;8:1129-1141.

26. Van den Brandt PA. Petri H, Dorant $E_{s}$ Goldbohm RA, Van de Crommert S. Comparison of questionnaire information and pharmacy data on drug use. Pharm Weekbl[Scil 1991;13:91-96.

27. Fogelholm M, Lahti-Koski M. The validity of a food use questionnaire in assessing the nutrient intake of physically active young men. Eur J Clin Nutr 1991:45:267-272.

28. Thompson MP, Tollison JW. Caring for the elderly. In: Textbook of family practice, 4th edn, ed. RE Rakel, p. 169-170. Philadelphia: W.B. Saunders Company, 1990.

29. Dorant E, Van den Brandt PA, Hamstra AM, Feenstra. MH, Bausch-Goldbohm RA, Gebruik van voedingssupplementen in Nederland. Ned Tijdschr Geneeskd 1991;135:68-73.

30. Levy AS, Schucker RE. Patterns of nutrient intake among dietary supplement users: attitudinal and behavioral correlates. J Am Diet Assoc 1987;87:754-760.

31. Harlow SD, Linet MS. Agreement between questionnaire data and medical records. The evidence for accuracy of recall. Am J Epidemiol 1989;129:233-248. 
32. Paganini-Hiil A, Ross RK. Reliability of recall of drug usage and otherm health-related information. Am J Epidemio! 1982;116:114-122.

33. Pecorarc RE, Inui TS, Chen MS, Plorde DK, Heller JL. Validity and reliability of a self-administered, health history questionnaire. Public Health Reports 1979;94:231-238.

34. De Jong PCM, Huijsmans AA, Nienhuis HE, Nijdam WS, Zielhuis GA, Eskes TKAB. Validation of a questionnaire on medical drug use during pregnancy. Am J Epidemiol 1991;134:998-1002.

35. Park YK, Kim I, Yetley EA. Characteristics of vitamin and mineral supplement products in the United States. Am J Clin Nutr 1991;54:750-759. 



\title{
Chapter 5
}

\section{A prospective cohort study on Allium vegetable consumption, garlic supplement use and the risk of lung carcinoma in The Netherlands}

\author{
Elisabeth Dorant; Piet A. van den Brandt; R. Alexandra Goldbohm
}

\begin{abstract}
The association between the consumption of onions and leeks (vegetables belonging to the Allium genus), garlic supplements and the risk of lung carcinoma was investigated in a largescale prospective cohort study on diet and cancer in The Netherlands. The Netherlands Cohort Study was started in 1986 among 120,852 men and women, aged 55-69 years, by collecting information on usual diet and important lifestyle characteristics. After 3.3 years of follow-up, 550 incident lung carcinoma cases were observed. Information on Allium vegetable consumption was available for 484 lung carcinoma cases, and 3123 members of a randomly sampled subcohort. After controlling for important dietary and nondietary risk factors, intake of onions or leeks turned out to be not associated with lung carcinoma risk: compared to the lowest intake categories, the rate ratios (RR) in the highest intake categories were $0.80(95 \%$ confidence interval $(\mathrm{Cl}) \quad 0.52-1.24)$ and $1.08(95 \% \mathrm{Cl} 0.80-1.45)$, respectively. No statistically significant trends in the rate ratios associated with increasing consumption of onions or leeks were detected for lung carcinoma or the four histologic: subtypes. A higher lung carcinoma risk was observed for those subjects who used. exclusively garlic supplements ( $R R=1.78,95 \% \mathrm{Cl} 1.08-2.92$ ), compared to those not taking dietary supplements. A lower lung carcinoma risk was seen for those using garlic supplements together with any other supplement (RR $=0.93,95 \% \mathrm{Cl} 0.46-1.86$ ) compared to those using any other supplement.

In conclusion, we found no evidence of a relation between the consumption of onions, or leeks and the risk of lung carcinoma or any of the histologic subtypes. Garlic supplement use seems not associated with a lower risk of lung carcinoma.
\end{abstract}




\section{Introduction}

The possible inverse association between Allium vegetable consumption and cancer risk is a subject of growing interest. In a recent review on the relation between vegetable and fruit consumption and cancer, Steinmetz and Potter identified 12 case-control studies in which an association between Allium vegetable consumption and specific sites of cancer had been investigated. In eight of these studies a negative association with cancer was reported; one study showed no association and three a positive association ?.

It has been shown in experimental studies that fresh garlic (Allium sativum L.), garlic oil and specific compounds of garlic possess in vitro antimutagenic properties and might even exhibit in vivo anti-initiating or anti-promoting activity against a variety of carcinogens. The results of these studies, however, are not conclusive ${ }^{2}$. Other plants belonging to the genus Allium (e.g. onion, leek, shallot, chives, Chinese chives) also contain large amounts of these so-called organosulfur compounds, which are responsible for the characteristic odor and flavor of Alliums ${ }^{3}$. Among the other chemical compounds found in Alliums are glutathione, a cysteine-containing tripeptide, which is involved in anticarcinogenic action ${ }^{4-6}$, and the potentially chemopreventive flavonols quercetin and kaempferol ${ }^{7.8}$.

None of the studies reviewed in 1991 by Steinmetz and Potter or reviewed in 1992 by Block et al. specifically investigated the association between Allium vegetable consumption and lung cancer, although most evidence for a lower cancer risk associated with a higher intake of fruit and vegetables has been reported for lung cancer ${ }^{1,9}$. All published studies on the association between Allium vegetable consumption and cancer used the case-control study design in which the exposure of interest is measured retrospectively.

In the Netherlands Cohort Study, a large-scale prospective cohort study on diet and cancer was started in The Netherlands in 1986, we assessed the usual consumption of onions and leeks, as well as the use of garlic supplements before cancer was diagnosed. Garlic supplements are reported to contain detectable amounts of potential chemopreventive garlic compounds ${ }^{10}$ and are the most widely used dietary supplements among elderly persons in The Netherlands ". In the present report we evaluate the association between onion and leek consumption, garlic supplement use and the incidence of lung carcinoma after 3.3 years of follow-up.

\section{Materials and methods}

\section{The cohort}

The prospective cohort study has been started in The Netherlands in 1986 among 58,279 men and 62,573 women aged 55-69 years, who completed a self-administered mailed questionnaire on habitual dietary intake, dietary supplement use, lifestyle characteristics, medical history and other potential risk factors for cancer. The study population originated from 204 municipalities with computerized population registries. A description of the design of the study and the characteristics of the cohort has been published ${ }^{12}$. Following the casecohort approach for analysis of the study, a subcohort of 3500 subjects (1688 men and 1812 women) was randomly sampled from the large cohort and followed up for vital status. The entire cohort has been followed-up for the incidence of cancer.

\section{Follow-up for cancer}

The method of record linkage that has been developed to ascertain information on cancer incidence in the entire cohort has been published previously ${ }^{13}$. In brief, personal ideritifying items have been linked with records of all nine cancer registries in The Netherlands and with PALGA, the Dutch network and National Database for Pathology. The computerized 
pathology reports provided by PALGA were coded according to ICD-O ${ }^{14}$ to make the information on topography and morphology analogous to the information provided by the cancer registries. The present analysis is restricted to cancer incidence in the first 3.3 years of follow-up (from baseline in September 1986 to December 1989). In this period completeness of follow-up is estimated to be $95 \%{ }^{15}$.

\section{Population available for analysis}

After excluding subjects from the entire case group who reported prevalent cancer other than skin cancer, and subjects with incident in situ lung carcinoma, lungl cancer other than carcinoma (sarcoma, lymphoma, unspecified morphology), or without at least a microscopically confirmed diagnosis, 550 incident primary lung carcinoma cases (ICD-O codes T 162.2 - T 162.9) were availabie for analysis. Information on morphological characteristics was used to categorize these cases into four distinct histologic subgroups: squamous cell carcinoma (ICD-O codes M8052-M8073), adenocarcinoma (M8140-M8560), small cell carcinoma (M8041-M8047), and large cell, other and unspecified carcinoma (M8001-M8021) ${ }^{14}$. From the subcohort, 3346 persons (1630 men and 1716 women) remained for analysis after excluding prevalent cancer cases other than skin cancer.

\section{Questionnaire}

A 150-item semi-quantitative food frequency questionnaire was used to collect information on the usual intake of food and beverages in the year preceding the start of the study ${ }^{16}$. Two of the questions on vegetable intake specifically focused on the consumption of Allium vegetables: ' How many onions did you usually eat per week?", and 'How often have you consumed leek in summer and how often in winter?' The latter question asked, for each season, to choose from one of six categories ranging from 'never or less than once per month' to '3-7 times per week', including leeks consumed in mixed vegetable dishes. Fresh garlic was not included as separate food item in the questionnaire. The question on the use of dietary supplements was formulated as follows: ' During the past five years did you use vitamin tablets, drops, or other preparations (for example tonics, vitamins, garlic pills, brewer's yeast, calcium) ?'. In the open-ended part of this question information on type of dietary supplement, brand name, dose per day, as well as the specific period in which the consumption took place could be listed. The food and beverage part of the questionnaire has been validated against three 3 -day diet records ${ }^{16}$. The dietary supplement question has, been validated as part of the larger validation study, using data from three interviews as reference method $^{17}$.

\section{Data analysis}

Questionnaire data of all cases and subcohort members have been key-entered twice and blinded with respect to case/subcohort status to avoid random and systematic coding errors. Subjects with incomplete or inconsistent dietary information. were excluded from. the analyses in which dietary variables were included ${ }^{15}$. Thus, the analyses concerning onion and leek consumption are based on 484 lung carcinoma cases and 3123 subcohort members. Subjects were classified into four categories of onion consumption based on numbers per day: 0 . $\leq 0.25,0.25-0.5$, and $\geq 0.5$ onions per day. Classification of subjects according to leek con-sumption was based on the mean frequency of consumption in summer and winter: $0, \leq 2$ and $>2$ times per month. Garlic supplement users were defined as those respondents who reported the use of at least one garlic supplement per day for at least one year in the five-year period preceding the baseline. Subjects with missing values on the dietary supplement question were excluded from the analysis, leaving 546 lung carcinoma cases and 3340 subcohort members available for analyses that did not include dietary variables. 
Age, gender, smoking habits, educational level, history of chronic obstructive pulmonary disease (COPD), lung cancer in first or second degree relatives, and vitamin $C$ and $\beta$-carotene intakes from food were considered as potential confounders. Dietary vitamin $C$ and $\beta$ carotene intakes were calculated using the computerized Dutch food composition table ${ }^{18}$. Case-cohort analyses were performed based on the assumption that survival times were exponentially distributed in this follow-up period ${ }^{15}$. In stratified analyses we computed Mantel-Haenszel rate ratios and $95 \%$ confidence intervals for each of the onion and leek consumption categories adjusted for age, gender and smoking status, and tests for trend in the rate ratios. In the multivariable analyses, we also adjusted for other covariables. The $95 \%$ confidence intervals were corrected for the additional variance introduced by using a subcohort instead of the complete cohort. Tests for trend in the rate ratios were based on likelihood ratio tests. Analyses were conducted for all cases combined, for men and women separately, for all cases without those diagnosed in the first year after baseline, and for each of the four histologic subtypes of carcinoma. The rate ratios and corrected $95 \%$ confidence intervals computed in stratified and multivariable analyses of the relation between garlic supplement use and lung carcinoma are reported in a separate table for all cases combined, and in strata of smoking status. Since a large proportion of the garlic supplement users took other dietary supplements as well, the relation with lung carcinoma was also evaluated for those using exclusively garlic supplements with those not taking supplements as reference and for those using garlic together with any other supplement with those using any other supplement as reference.

\section{Results}

A description of the 484 lung carcinoma cases and 3123 subcohort members with complete dietary data is presented in table 1. Overall, there are large differences in the distribution of gender, age, smoking habits, and history of chronic obstructive pulmonary disease between cases and subcohort members. The differences in relative frequencies of highest educational level were less marked and those of lung cancer in close relatives very small.

Table 2 shows the distribution of onion and leek consumption in all 484 lung carcinoma cases and the four histologic subgroups and in the 3123 subcohort members with complete dietary data. Compared with the subcohort, onion consumption was lower and varied by histologic subtype of the cases. Among squamous cell carcinoma, adenocarcinoma and small ce!! carcinoma cases the proportions in the highest onion consumption category were lower than among subcohort members, while among large cell and other carcinoma cases the proportion in this category wias higher. The largest difference in proportion nonusers between cases and subcohort was seen for small cell carcinoma cases $131.5 \%$ and $20.7 \%$, respectively). Comparison of the distribution of leek consumption in cases and subcohort revealed a higher proportion of nonusers and a lower proportion in the ' $\leq 2$ times/munth' category in the case group. Except in small cell carcinoma cases, the proportions nonusers in the histologic Subgroups were higher than in the subcohort.

The distribution of garlic supplement consumption among cases and subcohort is presented for the population of 546 cases and 3340 subcohort members with complete data on dietary supplement use. The proportion of persons only consuming garlic supplements (i.e. without any other supplement) was slightly higher in all cases than in the subcohort, whereas the proportion of subjects who used garlic together with any other supplement was lower in the cases. Other dietary supplements used by the 19 lung carcinoma cases who reported the use of any other supplement together with garlic were brewer's yeast $(26.3 \%)$, vitamin $C(5.3 \%)$, vitamin B complex $(10.5 \%)$ and vitamin $E(10.5 \%)$. 
Table 1. Distribution of lung carcinoma cases and subcohort members with complete dietary data by various nondietary baseline characteristics.

\begin{tabular}{|c|c|c|c|c|c|c|c|}
\hline \multirow[t]{2}{*}{ Characteristics } & & & \multicolumn{2}{|c|}{ Cases } & \multicolumn{3}{|c|}{ Subcohort } \\
\hline & & & 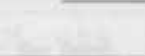 & n & $\%$ & $n$ & $\%$ \\
\hline Total & & 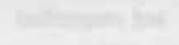 & 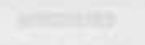 & 484 & 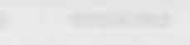 & 3123 & \\
\hline Gender & $=$ & $a^{2}+2$ & $y^{2}+x^{2}$ & s. & $x^{2}$ & & 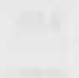 \\
\hline Men & & & & 430 & 88.8 & 1525 & 48.8 \\
\hline Women & 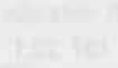 & $1+x=$ & t. & 54 & 11.2 & 1598 & 52.2 \\
\hline Age (years) & 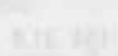 & 泟 & & & & & \\
\hline $55-59$ & 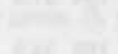 & & 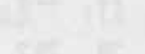 & 124 & 25.6 & 1198 & 38.4 \\
\hline $60-64$ & 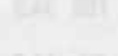 & $\sqrt{12}-2$ & 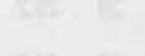 & 176 & 36.4 & 1082 & 34.6 \\
\hline 65.69 & $6+1=2$ & $2-1+2$ & $\sqrt{15}+2$ & 184 & 38.0 & 843 & 27.0 \\
\hline
\end{tabular}

Smoking habits

Never

Ex-cigarette/only pipe-cigar

Current cigarette smoker

- 1-9/day

- 10-19/day

- $\geq 20 /$ day

Highest educational level *

Primary school

Lower vocational

Second./medium vocational

University/higher vocational

History of COPD

No

Yes

Family history of lung cancer

No

Yes
14

178

21

143

128

147

125

155

51

400

82.6

2842

91.0

84

17.4

432

89.3

52

4.3

29.5

26.4

30.8

933

30.1

683

22.0

1080

34.8

406

13.1

281

9.0

6.1

13.1

8.8 $\%$ 
Table 2. Dnion and leek consumption and garlic supplement use among lung carcinoma cases with distinct histologicall characteristics and among subcohort members.

\begin{tabular}{|c|c|c|c|c|c|c|c|c|c|c|c|c|}
\hline \multirow[t]{3}{*}{ Category of consumption } & \multicolumn{10}{|c|}{ Cases } & \multicolumn{2}{|c|}{ Subcohort } \\
\hline & \multicolumn{2}{|c|}{$\begin{array}{l}\text { Squarnous cell } \\
\text { carcinoma }\end{array}$} & \multicolumn{2}{|c|}{$\begin{array}{l}\text { Adeno: } \\
\text { carcinoma }\end{array}$} & \multicolumn{2}{|c|}{$\begin{array}{l}\text { Small cell } \\
\text { carcinoma }\end{array}$} & \multicolumn{2}{|c|}{$\begin{array}{l}\text { Large cell, other } \\
\text { and unspecified }\end{array}$} & \multicolumn{2}{|c|}{ All } & & \\
\hline & n & 8 & $\mathrm{n}$ & $\%$ & n & \& & $n$ & $\%$ & ni & $\psi$ & $\mathrm{n}$ & $\%$ \\
\hline \multicolumn{13}{|c|}{ Onion consumption (number/day) } \\
\hline 0 & 43 & 20.5 & 21 & 20.0 & 28 & 31.5 & 15 & 18.8 & 107 & 22.1 & 646 & 20.7 \\
\hline$\leq 0.25$ & 70 & 33.3 & 37 & 35.2 & 23 & 25.8 & 24 & 30.0 & 154 & 31.8 & 920 & 29.5 \\
\hline $0.25 \cdot 0.5$ & 77 & 36.7 & 38 & 36.2 & 26 & 29.2 & 28 & 35.0 & 169 & 34.9 & 1098 & 35.2 \\
\hline$\geq 0.5$ & 20 & 9.5 & 9 & 8.6 & 12 & 13.5 & 13 & 16.3 & 54 & 11.2 & 459 & 14.7 \\
\hline
\end{tabular}

Leek consumption (freq/month)

\begin{tabular}{|c|c|c|c|c|c|c|c|c|c|c|}
\hline 0 & 78 & 37.1 & 38 & 36.2 & 25 & 28.1 & 33 & 41.3 & $174 \quad 36.0$ & 955 \\
\hline$\leq 2$ & 68 & 32.4 & 38 & 36.2 & 36 & 40.4 & 22. & 27.5 & 16433.9 & 1212 \\
\hline$>2$ & 64 & 30.5 & 29 & 27.6 & 28 & 31.5 & 25 & 31.3 & $146 \quad 30.2$ & 956 \\
\hline
\end{tabular}

Garlic supplement use

$\begin{array}{lrrrrrrrrrrrr}\text { No supplements } & 189 & 75.6 & 83 & 74.8 & 76 & 79.2 & 71 & 79.8 & 419 & 76.7 & 2373 & 71.0 \\ \text { Exclusively garlic } & 15 & 6.0 & 5 & 4.5 & 5 & 5.2 & 4 & 4.5 & 29 & 5.3 & 152 & 4.6 \\ \text { Any other supplement } & 37 & 14.8 & 20 & 18.0 & 12 & 12.5 & 10 & 11.2 & 79 & 14.5 & 675 & 20.2 \\ \text { Garlic + any other suppl. } & 9 & 3.6 & 3 & 2.7 & 3 & 3.1 & 4 & 4.5 & 19 & 3.5 & 140 & 4.2\end{array}$

$\because$ Numbers and proportions are presented for the total population available for analysis as described in the methods section. The categories of garlic supplement use are mutually exclusive.

The 140 subcohort members consumed vitamin C $(24.3 \%)$, vitamin B complex $(20.0 \%)$, vitamin $A D(9.3 \%)$ and vitamin $E(7.9 \%)$ together with garlic supplements. In the category in which we grouped users of any other dietary supplement the following supplement types. were reported by the 79 lung carcinoma cases and 675 subcohort members: vitamin $C$ $(27.8 \%$ and $25.3 \%)$, vitamin B complex $(25.3 \%$ and $26.8 \%)$, vitamin $A D(13.9 \%$ and $10.5 \%)$, and vitamin $E(10.1 \%$ and $7.3 \%)$, respectively. The proportion of users of exclusively garlic supplements in the different histologic subgroups was highest in squamous cell carcinoma cases $(6.0 \%)$ and lowest in adenocarcinoma and large cell carcinoma cases $(4.5 \%)$.

The proportions of subcohort members in the predefined categories of consumption of onions, leeks and garlic supplements were examined across strata of other lung carcinoma risk factors (table 3). Among the persons in the highest onion intake category were mare men and less never smokers. In the highest leek consumption category were more women and more never smokers and less persons with a history of COPD. Among consumers of garlic supplements were more women, never-smokers, persons with the highest education, 
Table 3. Association between Allium vegetable consumption and garlic supplement use and potential lung carcinoma risk factors among subcohort members.

\begin{tabular}{|c|c|c|c|c|c|c|c|c|c|}
\hline \multirow[t]{2}{*}{ Characteristics } & \multicolumn{4}{|c|}{ Onion consumption } & \multicolumn{3}{|c|}{ Leek consumption } & \multicolumn{2}{|c|}{ Garlic supplement } \\
\hline & 0 & $<0.25$ & $<0.5$ & $\geq 0.5$ & 0 & $\leq 2$ & $>2$ & $\mathrm{No}^{\mathrm{a}}$ & Yes $^{b}$ \\
\hline $\operatorname{Men}(\%)$ & 48.5 & 51.3 & 45.3 & 52.9 & 50.9 & 50.2 & 45.0 & 53.4 & 40.4 \\
\hline Never-smoking (\$) & 40.1 & 33.9 & 35.0 & 29.4 & 34.3 & 34.1 & 36.5 & 33.7 & 39.0 \\
\hline Universityhigh vocat. education (\%) & 13.1 & 13.7 & 12.5 & 13.3 & 11.1 & 15.4 & 12.1 & 10.9 & 11.5 \\
\hline History of COPD (\% yes) & 8.0 & 7.5 & 10.5 & 9.8 & 9.0 & 10.1 & 7.5 & 8.5 & 9.2 \\
\hline Family history of lung cancer ( $\%$ yes) & 7.3 & 10.0 & 11.4 & 10.7 & 8.9 & 9.8 & 11.4 & 10.4 & 11.3 \\
\hline \multicolumn{10}{|l|}{ Mean (SD) } \\
\hline \multirow[t]{2}{*}{ Age } & 61.7 & 61.4 & 61.2 & 61.2 & 61.7 & 61.3 & 61.2 & 61.3 & 61.8 \\
\hline & (4.1) & $(4.3)$ & (4.2) & (4.0) & (4.2) & $(4.3)$ & (4.2) & (4.2) & (4.1) \\
\hline \multirow[t]{2}{*}{ Vitamin C intake (mg/day) } & 93.4 & 97.0 & 107.8 & 120.2 & 96.4 & 100.9 & 113.7 & 92.5 & 112.6 \\
\hline & $(42.5)$ & $|39.1\rangle$ & $(42.4)$ & (47.2) & $(41.9)$ & $|39.6|$ & $(46.7)$ & (47.2) & $(52.7)$ \\
\hline \multirow[t]{2}{*}{$\beta$-carotene intake (mg eq vit A activity) } & 0.37 & 0.37 & 0.44 & 0.51 & 0.37 & 0.39 & 0.49 & 0.30 & 0.41 \\
\hline & $(0.23)$ & $(0.20)$ & $(0.25)$ & (0.28) & $(0.22)$ & $(0.21)$ & $(0.27)$ & $(0.42)$ & (0.42) \\
\hline
\end{tabular}

a: No supplements

b: Garlic with or without any other supplement

history of COPD and lung cancer in close relatives. In the highest onion and leek consumption category, and among users of garlic supplements the mean vitamin $C$ and $\beta$-carotene intakes were highest. The mean ages in the intake categories were almost similar.

In table 4 the observed Mantel-Haenszel rate ratios $\left(R_{R_{M H}}\right)$ and $95 \%$ confidence intervals (Cl) for lung carcinoma according to categories of onion and leek consumption are presented, stratified by age, gender and smoking status. No significant trends in the rate ratios of lung carcinoma were found for onion or leek consumption. However, the consumption of at least 0.5 onions per day was negatively associated with lung carcinoma ( $R R_{M H}=0.65,95 \% \mathrm{Cl}$ 0.45-0.95).

For squamous cell carcinoma and adenocarcinoma the associations with onion consumption were slightly higher than the null-value, except for the highest intake category, whereas the associations with leek consumption were negative for these histologic subtypes. Onion consumption was negatively associated with small cell carcinoma, with a $\mathrm{RR}_{\mathrm{MH}}$ in the category consuming $<0.25$ onions per day of $0.50(95 \% \mathrm{Cl} 0.28-0.88)$ and of $0.48(95 \%$ CI 0.24-0.97) in the highest intake category compared to subjects not consuming onions. The association of onion consumption with large cell, other and unspecified carcinoma varied between the intake categories. Leek consumption was positively associated with small cell 
Table 4. Mantel. Haenszel rate ratio $\left(\mathrm{RR}_{\text {wain }}\right)$ and $95 \%$ confidence intervals $(95 \% \mathrm{Cl})$ of lung carcinoma according to Allium vegetable consumption, adjusted for age, gender and smoking status in stratified analysis".

\begin{tabular}{|c|c|c|c|c|c|c|c|c|c|}
\hline \multirow[t]{2}{*}{ Characteristics } & \multicolumn{4}{|c|}{ Onion consumption (number/day) } & \multirow{2}{*}{$\begin{array}{l}\text { Trend test } x^{2} \\
-\quad \text { (p-value) }\end{array}$} & \multicolumn{3}{|c|}{ Leek consumption (freqimonth) } & \multirow{2}{*}{$\begin{array}{l}\text { Trend test } x^{2} \\
-\quad \text { (p-value) }\end{array}$} \\
\hline & 0 & $<0.25$ & $<0.5$ & $\geq 0.5$ & & 0 & $\leq 2$ & $>2$ & \\
\hline $\begin{array}{l}\text { Person years in } \\
\text { subcohort }\end{array}$ & 2071 & 2978 & 3554 & 1471 & 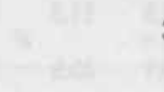 & 3096 & 3903 & 3092 & 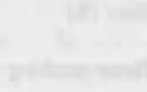 \\
\hline All carcinoma & 18 & 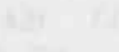 & & $y=$ & 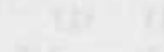 & 20 & $1=$ & 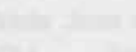 & 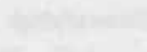 \\
\hline No. of cases & 107 & 154 & 169 & 54 & & 174 & 164 & 146 & 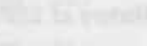 \\
\hline $\mathrm{RR}_{m-1}$ & $1.00 t$ & 0.95 & 0.97 & 0.65 & $3.64(0.06)$ & $1.00 \uparrow$ & 0.79 & 0.96 & $0.22(0.64)$ \\
\hline $95 \% \mathrm{Cl}$ & & $0.71 \cdot 1.28$ & $0.76-1.29$ & $0.45-0.95$ & & & $0.61 \cdot 1.01$ & $0.74-1.24$ & \\
\hline
\end{tabular}

Squamous cell carcinoma

$\begin{array}{lllllrllll}\text { No. of cases } & 43 & 70 & 77 & 20 & & 78 & 68 & 64 & \\ \text { RR }_{\text {mil }} & 1.00 \dagger & 1.09 & 1.18 & 0.63 & 1.09(0.30) & 1.00 \dagger & 0.78 & 0.97 & 0.04(0.84) \\ 95 \% \mathrm{Cl} & & 0.72 \cdot 1.65 & 0.79-1.78 & 0.36-1.11 & & & 0.55-1.10 & 0.67-1.38 & \end{array}$

\section{Adenocarcinoma}

$\begin{array}{llllllllll}\text { No. of cases } & 21 & 37 & 38 & 9 & & 38 & 38 & 29 & \\ \text { RR }_{\text {mat }} & 1.00 \dagger & 1.08 & 1.07 & 0.55 & 1.62(0.20) & 1.00 \dagger & 0.89 & 0.86 & 0.40 \text { (0.53) } \\ 95 \mathrm{Cl}_{\mathrm{Cl}} & & 0.62-1.85 & 0.62-1.83 & 0.26-1.17 & & & 0.57-1.39 & 0.53-1.41 & \end{array}$

Small cell carcinoma

\begin{tabular}{|c|c|c|c|c|c|c|c|c|c|}
\hline No. of cases & 28 & 23 & 26 & 12 & & 25 & 36 & 28 & \\
\hline $\mathrm{RP}_{\mathrm{M}}$ & $1.00 t$ & 0.50 & 0.61 & 0.48 & $3.61(0.06)$ & $1.00 \dagger$ & 1.27 & 1.30 & $0.92(0.34)$ \\
\hline 95\% CI & & $0.28-0.88$ & $0.36-1.04$ & $0.24-0.97$ & & & $0.76-2.10$ & $0.76 \cdot 2.24$ & \\
\hline \multicolumn{10}{|c|}{ arge cell, other and unspecified carcinoma } \\
\hline No. of cases & 15 & 24 & 28 & 13 & & 33 & 22 & 25 & \\
\hline $\mathrm{PR}_{\mathrm{M}}$ & $1.00 t$ & 0.87 & 1.07 & 1.05 & $007(0.79)$ & $1.00 t$ & 0.61 & 0.89 & $0.25(0.52)$ \\
\hline $95 \% \mathrm{Cl}$ & & $0.47 \cdot 1.64$ & $0.59-1.96$ & $0.51 \cdot 2.15$ & & & $0.36 \cdot 1.04$ & $0.53 \cdot 1.50$ & \\
\hline
\end{tabular}

$\because$ Age in three categories: $55-59,60-64,65-69$ years: smoking status categorized as never, ex and current smoker.

$t$ : Reference category 
carcinoma and negatively associated with large cell and other carcinoma, although not significantly. None of the tests for trend in the rate ratios reached statistical significance.

In multivariable analyses the associations between the risk of lung carcinoma and onion or leek consumption were adjusted for age (continuous variable), gender, packyears of past smokers and packyears of current smokers (both continuous), highest level of education, history of COPD, family history of lung cancer and dietary intake of vitamin $C$ and $\beta$-carotene (both continuous). As can be seen in table 5, only the rate ratio for the highest category of onion consumption stayed below the null-value $\{R R=0.80,95 \% \mathrm{Cl} 0.52-1.24\}$, the other RRs suggested a positive association. The associations for leek consumption were also higher than those found in the stratified analysis. Neither of the trends in the rate ratios was statistically significant. Exclusion of the lung carcinoma cases diagnosed in the first year after baseline did not alter the rate ratio estimates (results not shown). In analyses for men and women separately, none of the rate ratio estimates were significantly different from unity (results not shown).

The associations between onion and leek consumption and the risk of specific histologic subtypes of lung carcinoma are also being presented in table 5 . The RRs for squarnous cell carcinoma associated with onion consumption increased to 1.66 (95\% Cl 1.04-2.66) in the ' $0.25-0.5^{\prime}$ category, but was below the null-value in the highest intake category $(R R=0.86$, $95 \% \mathrm{Cl} \mathrm{0.45-1.64)}$. The RRs for squarnous cell carcinoma associated with leek consumption were similar to those found for all cases of lung carcinoma. For adenocarcinoma the associations with onion consumption were not very different from those found in the stratified analysis. However, the RRs for adenocarcinoma with leek consumption increased to 1.20 (95\% $\mathrm{Cl}$ 0.99-1.97) among subjects consuming leeks 2 times or less per month. All RRs for small cell carcinoma associated with onion consumption were below the null-value, whereas leek consumption was positively associated with small cell carcinoma. None of the RRs were significantly different from unity. The RRs for large cell, other and unspecified carcinoma associated with onion and leek consumption were somewhat higher than those found in the stratified analysis, but not significantly different from unity. None of the tests for trend in the rate ratios were significant.

The association between garlic supplement use with lung carcinoma is presented in table 6. Garlic supplement use was positively, but not significantly, associated with lung cancer after adjustment for age, gender and smoking status in stratified analysis. The relation with lung carcinoma was evaluated for those using exclusively garlic supplements with those not taking supplements as reference and for those using garlic together with any other supplement with those using any other supplement as reference. The RR ${ }_{M H}$ for those subjects using exclusively garlic supplements was higher than for subjects using garlic supplements with or without any other supplements $(1.29$ (95\% Cl 0.80-2..08) and $1.13(95 \% \mathrm{Cl}$ 0.79-1.62), respectively). The $R_{R_{M H}}$ for those using garlic with any other supplement was lower than for those in the reference category who consumed any other supplement $10.85,95 \% \mathrm{Cl} 0.44$ 1.62). In the multivariable analysis we show the results of two mode!s. The first model included all covariables also used in the analyses of onion and leek consumption. Compared to those not using supplements, the RR for those using garlic supplements with or without any other supplement was not significantly higher than the null-value. The positive association observed for exclusively garlic, however, was statisticaliy significantly $(R R=1.78,95 \%$ Cl 1.08-2.92). Lung carcinoma was negatively associated with garlic together with any other supplement use, compared to any other supplement use (RR $=0.93,95 \% \mathrm{Cl} 0.46-1.86$ ). Exclusion of cases diagnosed in the first year after baseline did not alter these results idata not shown). 
Table 5. Rate ratios and $95 \%$ confidence intervals of lung carcinoma according to onion and leek consumption in multivariable analysis.

\begin{tabular}{|c|c|c|c|c|c|}
\hline \multirow[t]{2}{*}{ Allium vegetable } & \multirow[t]{2}{*}{ All cases } & \multicolumn{4}{|c|}{ Histological type } \\
\hline & & $\begin{array}{l}\text { Squamous cell } \\
\text { carcinoma }\end{array}$ & Adenocarcinoma & Small cell carcinoma & $\begin{array}{l}\text { Large cell, other } \\
\text { unspecified carci }\end{array}$ \\
\hline 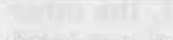 & $=$ & 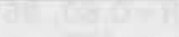 & 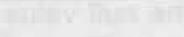 & 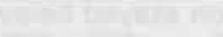 & . \\
\hline \multicolumn{6}{|c|}{ Onion (number/day) } \\
\hline 0 & $1.00 t$ & $1.00 \dagger$ & $1.00 t$ & $1.00 \uparrow$ & $1.00 t$ \\
\hline$\leq 0.25$ & $1.19(0.85 \cdot 1.67)$ & $1.51(0.94-2.45)$ & $1.03(0.58-1.85)$ & $0.67(0.35-1.26)$ & $0.95(0.49-1.84)$ \\
\hline $0.25 \cdot 0.5$ & $1.25(0.90-1.74)$ & $1.66(1.04 \cdot 2.66)$ & $1.08(0.61-1.91)$ & $0.87(0.48-1.58)$ & $1.26(0.67-2.3)$ \\
\hline$\geq 0.5$ & $0.80(0.52-1.24)$ & $0.86(0.45-1.64)$ & $0.57(0.24 \cdot 1.32)$ & $0.59(0.27-1.32)$ & $1.20(0.55 \cdot 2.5$ \\
\hline Trend $x^{2}(p)$ & $0.15(0.703)$ & $0.16(0.688)$ & $0.77(0.381)$ & $1.05(0.305)$ & $0.69(0.408)$ \\
\hline
\end{tabular}

Leak (freq/month)

$\begin{array}{llllll}0 & 1.00 t & 1.00 t & 1.00 \dagger & 1.00 \dagger & 1.00 \dagger \\ \leq 2 & 0.99(0.75-1.30) & 0.92(0.63-1.35) & 1.20(0.99-1.97) & 1.64(0.93-2.91) & 0.73(0.42-1.26) \\ >2 & 1.08(0.80-1.45) & 1.05(0.70-1.59) & 1.06(0.61-1.87) & 1.63(0.89-2.97) & 0.99(0.57-1.74) \\ \text { Trend } x^{2}(p) & 0.29(0.584) & 0.04(0.832) & 0.07(0.784) & 2.83(0.092) & 0.01(0.896)\end{array}$

-: Adjusted for age (c), gender, packyears of past-smokers (c), packyears of current smokers (c), highest level of education, history of COPD, family history of lung cancer, dietary intake of vitamin $\mathrm{C}(\mathrm{c})$ and $\beta$-carotene (c).

f: Peference category

In the analyses in strata of smoking status, we adjusted for fewer covariables than in the first model, and categorized highest educational level in three categories (low-medium-high). Among the never-smokers a higher RR was observed for those using exclusively garlic supplements (RF $=3.27,95 \% \mathrm{CI}$ 0.99-10.77) compared with the RRs among ex- or current smokers ( $\mathrm{RR}=1.37,95 \% \mathrm{Cl} 0.62-2.99$, and $\mathrm{RR}=1.47,95 \% \mathrm{Cl} 0.70-3.08$, respectively). Associations with garlic together with any other supplement use could only be evaluated within strata of ex-smokers and current smokers. Among ex-smokers the RR for lung carcinoma was lower than among current smokers (RP $=0.53,95 \% \mathrm{Cl} \mathrm{0.18-1.58}$ and $\mathrm{RR}=1.34,95 \% \mathrm{Cl} 0.55-3.28$ respectively). None of the associations with garlic supplement use within strata of smoking status were significant. 
Table 6. Rate ratios and $95 \%$ confidence intervals of lung carcinoma according to garlic supplement use in stratified and multivariable analyses.

\section{Garlic vs. no supplements}

No Garlic supplements Exclusively garlic
Garlic vs. any other supplement

Any other Garlic + any other

Stratified analysis ${ }^{a}$

Person years in subcohort

7671

939

489

2180

450

No. of cases

419

48

29

79

19

$\mathrm{RR}_{\text {wi }}(95 \% \mathrm{CI})$

$1.00 t$

$1.13(0.79-1.62)$

$1.29(0.80-2.08)$

$1.00+$

$0.85(0.44-1.62)$

Multivariable analysis

Person years in subcohort

7122

899

460

2069

440

All cases

323

36

23

65

13

RR $(95 \% \mathrm{Cl})$

$1.00 t$

$1.22(0.81-1.86)$

$1.78(1.08-2.92)$

$1.00+$

$0.93(0.46-1.86)$

Never smokers ${ }^{c}$

Person years in subcohort

$2376 \quad 345$

187

825

158

No. of cases

14.5

4

1

1

RR (95\% CI)

$1.00 t$

$2.42(0.83-7.11)$

$3.27(0.99-10.77)$

Ex smokers ${ }^{d}$

Person years in subcohort

$2702 \quad 329$

150

707

179

No. of cases

$124 \quad 14$

9

34

5

RR (95\% CI)

$1.00 t$

$1.03(0.32 \cdot 1.92)$

$1.37(0.62 \cdot 2.99)$

$1.00 t$

$0.53(0.18-1.58)$

Current smokerse

Person years in subcohon

$2044 \quad 226$

123

537

103

No. of cases

$219 \quad 20$

11

34

9

RR(95\% CI)

$1.00 t$

$1.02(0.57 \cdot 1.83)$

$1.47(0.70-3.08)$

$1.00 \dagger$

$1.34(0.55-3.28)$

t: Reference

a: Adjusted for age in three categories $(55-59,60-64,65-69$ years) and smoking habits (never-ex-current)

b: Adjusted, for age (c), gender, packyears of past smoking (c), packyears of current smoking (cl, highest educational level, history of $\mathrm{COPD}$, onion and leek consumption, and dietary intake of vitamin $\mathrm{C}(\mathrm{c})$ and $\beta$-catotene (c).

c: Adjusted for age (c), gender, highest educational level llow-medium-high), history of COPD.

d: Adjusted for age (c), gender, packyears of past smoking (c), highest educational level, history of COPD.

e: Adjusted, for age (c). gender, packyears of current smoking (c), highest educational level llow-medium-high), history of COPD. 


\section{Discussion}

In The Netherlands Cohort Study we found no evidence of an association between onion and leek consumption and the risk of lung carcinoma or any of its histologic subtypes after adjustment for confounders. The observed rate ratio estimates associated with garlic supplement use were inconsistent.

Evaluation of the risk of cancer associated with Allium consumption is important since the consumption of Allium vegetables has been suggested to have a negative effect on the risk of several cancer sites ${ }^{1,9}$. The relation with lung cancer has not been studied yet, although most evidence for a lower cancer risk associated with vegetable intake has been reported for lung cancer ${ }^{1,9}$, and lung cancer is an important cause of cancer morbidity and mortality. In the Dutch population lung cancer was the most frequent tumor in males and fourth most common cancer in females in $1989^{19}$. In two earlier studies on the association between consumption of vegetables and risk of lung cancer Allium vegetable intake was assessed, but in neither study the risk of lung cancer was specifically evaluated for Allium vegetable consumption. A recently published report from the lowa Women's Health Study, a prospective cohort study, showed a significantly lower lung cancer risk for high intake of all vegetables including leeks, scallions and fresh garlic: the age, smoking- and energyadjusted odds ratio (OR) was $0.50(95 \% \mathrm{Cl} 0.29-0.87)^{20}$. In 1992 , a case-control study from China was published on the risk of lung cancer associated with fresh green vegetables (Chinese chives, strip onions and fragrant flowered garlic as well as Chinese cabbage, green chilli, mint and bean sprouts). A lower lung cancer risk was observed for the more frequent consumers of fresh green vegetables after adjustment for age group, respondent type, study site, education and income $(O R=0.24)$, and within strata of smoking status ${ }^{21}$.

Absence of an association between Allium vegetable consumption and lung carcinoma risk may be explained by factors associated with the design and conduct of the study, as well as with the proposed mechanism of action of the potential anticarcinogenic compounds in Alliums. Selection bias due to loss of follow-up is unlikely since the completeness of follow-up of vital status in the subcohort was $100 \%$ and of cancer incidence $95 \%{ }^{15}$. By including many other, nondietary as well as dietary, known determinants of lung carcinoma in the multivariable models, we thoroughly controlled for potential confounding: the RR of $0.65(95 \% \mathrm{Cl} 0.45-0.95)$ observed in the stratified analysis for users of at least 0.5 onions per day increased to $0.80(95 \% \mathrm{Cl} 0.52-1.21)$ in the multivariable analysis by including packyears for past and current smokers as continuous variables in the model, instead of using smoking status categorized as never, ex or current smoking. The RR stayed below the null-value after controlling for the other potential risk factors, but was not significantly different from unity. Another explanation for absence of an association might be that the follow-up period is still relatively short $(3.3$ years). Preclinical symptoms of disease might have influenced the intake of Allium vegetables. Exclusion of cases diagnosed in the first year of follow-up, however, did not change the results. It is uncertain whether the absence of a relation between Allium vegetable consumption and lung carcinoma risk might have been caused by misclassification of exposure, since the validity of the semiquantitative food frequency questionnaire has not been assessed for the questions on onion and leek consumption specifically ${ }^{16}$. Unfortunately, we were not able to evaluate if fresh garlic use was associated with the risk of lung carcinoma, since a separate question on fresh garlic consumption was not included in the semi-quantitative food frequency questionnaire administered in 1986. However, consumption of fresh garlic was probably not very high. In a questionnaire that was completed by members of the subcohort four years after the baseline, $71 \%$ of the respondents reported that they never used fresh garlic, $12.5 \%$ used up to one garlic clove per week, and only $1.6 \%$ consumed at least one clove per day. The 
elevated risk for lung carcinoma associated with daily consumption of garlic supplements was unexpected, since garlic supplements are claimed to contain detectable amounts of antimutagenic or even anticarcinogenic garlic compounds ${ }^{10}$. The relative risk of lung carcinoma was notably higher in the never-smoking stratum then in the other smoking strata, although not significantly. However, since the number of cases was not very high, we had to define broader categories of education and exclude other determinants from the analyses per smoking stratum. Misclassification of exposure is a less plausible explanation for the higher risk, since recall of intake of garlic supplements was $77.8 \%$, which may provide enough precision to correctly classify individuals into distinctive categories of intake ${ }^{17}$. Excluding cases from the first year after baseline did not change the results, suggesting no influence of preclinical disease on the consumption of garlic supplements. Garlic supplement use in combination with any other supplement compared with the use of any other supplement as reference, was associated with a lower risk for lung carcinoma in nonsmokers and ex-smokers, while for those using exclusively garlic supplements a higher risk was observed in these strata. This discrepancy cannot simply be explained by differences in distribution of the other dietary supplement types, since cases and subcohort members consumed roughly the same types of other supplements. Although we cannot easily explain the observed risk of lung carcinoma for garlic supplement use, it can be concluded that garlic supplements are not associated with a lower risk of lung carcinoma.

Other possible explanations for the absence of a relation between onion and leek consumption and lung carcinoma incidence are related to the biological activity of the potential chemopreventive compounds once consumed. Quercetin, the principal flavonol present in onions, might act as anticarcinogen ${ }^{22}$, although quercetin and related flavonols are also reported to be mutagenic ${ }^{6,23}$. Kaempferol, predominantly present in leeks ${ }^{24}$, inhibits aflatoxin $B_{1}$-induced mutagenesis ${ }^{25}$, but might also act as anticarcinogen ${ }^{7}$. The level of flavonols in onions and leeks, however, varies by variety, season, storage conditions, method of preparation, and by part of the plant ${ }^{26-30}$. For instance, the outer dark green leaves of leek have a higher kaempferol content than the inner leaves ${ }^{30}$, and the dry skin of onions have a higher quercetin content than the inner rings. In some onion varieties, quercetin is not even detectable in the inner rings ${ }^{24}$. In garlic only traces of flavonols have been found ${ }^{27}$. Glutathione, another compound present in Allium vegetables, is also reported to be anticarcinogenic ${ }^{4,5}$. Both flavonols and glutathione are widely distributed in foods ${ }^{5,27}$.

Onions are the second most important contributors of quercetin intake in adults in The Netherlands ${ }^{31}$. However, the ingested amount of potential chemopreventive compounds contributed by eating Allium vegetables might not be high enough to have a detectable effect on the risk of lung carcinoma in humans. Organosulfur compounds are predominantly present in Alitum vegetables and account for their typical odor and flavor ${ }^{3,32}$. The principal groups of organosulfur compounds are the propyl-, methyl- and allyl-containing compounds, formed when the vegetables are cut. Onions and leeks have large proportions propyl derivatives, while garlic has mainly allyl-containing compounds ${ }^{33}$. However, the quantity of organosulfur compounds also depends on temperature, storage conditions, soil conditions, climate, chemical treatment and variety ${ }^{34,35}$.

To exert its potentia! chemopreventive action on lung cancer a potential anticarcinogen has to be absorbed after consumption. A study in four volunteers showed that less than $1 \%$ of quercetin when given in high doses (four times the estimated daily intake) did reach the general circulation ${ }^{36}$. The uptake of glutathione, which is normally present in interalveolar cells in the lung (not in alveolar cells) ${ }^{4}$ has to our knowledge only been tested in animals ${ }^{37}$. Specific data on the bioavailability of organosulfur compounds from onions, leeks and garlic supplements are also not available for humans. The possibility that the potential chemopreventive compounds in Alliums act only or predominantly in a very early stage in 
carcinogenesis or against specific chemical carcinogens ${ }^{7,38}$, might also explain the absence of a lower risk associated with onion and leek consumption, since its action must. then prevent initiation-related activities, which occur quickly and take place at a specific time and place in the presence of specific carcinogens ${ }^{39,40}$. For flavonols and garlic compounds both anti-initiating as well as anti-promoting activity has been demonstrated ${ }^{2.22}$.

In conclusion, we found no evidence of a relation between the consumption of onions or leeks and the risk of lung carcinoma or any histologic subtype of lung carcinoma. Although the increased rate ratio estimates for garlic supplement use cannot easily be interpreted, we conclude that garlic supplements are not associated with a lower risk of lung carcinoma.

\section{References}

1. Steinmetz K, Potter JD. Vegetables, fruit, and cancer. I. Epidemiology. Cancer Causes Control 1991;2:325-357.

2. Dorant E, Van den Brandt PA, Goldbohm RA, Hermus RJJ, Sturmans F. garlic and its significance for the prevention of cancer in humans: a critical view. Br J Cancer 1993;67:424-429.

3. Whitaker JR. Development of flavor, odor, and pungency in onion and garlic. Adv Food Res $1976: 22: 73-133$

4. Coles B, Ketterer B. The role of glutathione and glutathione transferases in chemical carcinogenesis. Crit Rev Biochem Mol Biol 1990;25:47-70.

5. Jones DP, Coates RJ, Flagg EW, Eley JW, Block G, Greenberg RS, Gunter EW, Jackson B. Glutathione in foods listed in the National Cancer Institute's Health Habits and History Food Frequency Questionnaire. Nutr Cancer 1992;17:57-75.

6. Ames BN. Dietary carcinogens and anticarcinogens. Science 1983;221:1256-1264.

7. Newmark HL. Plant phenolics as inhibitors of mutational and precarcinogenic events. Can J Physiol Pharmacol 1987:65:461-466.

8. Steinmetz K, Potter JD. Vegetables, fruit, and cancer. II. Mechanisms. Cancer Causes Control $1991 ; 2: 427-442$

9. Block G, Patterson B, Subar A. Fruit, vegetables, and cancer prevention: a review of the epidemiological evidence. Nutr Cancer 1992;18:1-29.

10. Lawson LD, Wang ZYJ, Hughes BG. Identification and HPLC Quantification of the sulfides and dialk(en)yl thiosulfinates in commercial garlic products. Planta Med 1991;57:363-370.

11. Dorant E, Van den Brandt PA, Hamstra AM, Feenstra MH, Goldbohm RA, Hermus RJJ, Sturmans F. The use of vitamins, minerals and other dietary supplements in The Netherlands. Int J Vit Nutr Res 1993;63:4-10.

12. Van den Brandt PA, Goldbohm RA, Van 't Veer P, Volovics A, Hermus RJJ, Sturmans F. A largescale prospective cohort study on diet and cancer in The Netherlands. J Clin Epidemiol $1990 ; 43: 285-295$

13. Van den Brandt PA, Schouten LJ, Goldbohm RA, Dorant E, Hunen PMH. Development of a record linkage protocol for use in the Dutch Cancer registry for epidemiological research. Int $J$ Epidemial 1990;19:553-558.

14. International Classification of diseases for Oncology. First edition. Geneva: World health Organization, 1976.

15. Van den Brandt PA, Van 't Veer P, Goldbohm RA, Dorant E, Volovics A, Hermus RJJ, Sturmans F. A prospective cohort study on dietary fat and the risk of postmenopausal breast cancer. Cancer Res 1993;53:75-82.

16. Goldbohm RA, Van den Brandt PA, Brants HAM, Van't Veer P, AI M, Sturmans F, Hermus RJJ. Validation of a dietary questionnaire used in a large-scale prospective cohort study on diet and cancer. Eur J Clin Nutr 1994;48:253-265.

17. Dorant E, Van den Brandt PA, Goldbohm RA, Hermus RJJ, Sturmans F. Agreement between interview data and a self-administered questionnaire on dietary supplement use. Eur J Clin Nutr 1994;48:180-188.

18. Stichting NEVO. NEVO table; Dutch food composition table 1986-1987. The Hague, Netherlands: Voorlichtingsbureau voor de Voeding, 1986.

19. De Winter GA, Coebergh JWW, Van Leeuwen FE, Schouten L (eds.). Incidence of cancer in the. Netherlands, 1989. First report of The Netherlands cancer registry. Coordinating Council of Comprehensive Cancer Registries, Utrecht, 1993. 
20. Steinmetz KA, Potter JD, Folsom AR. Vegetables, fruit, and lung cancer in the lowa Women's Health Study. Cancer Res 1993;53:536-543.

21. Swanson CA, Mao BL, Li YI, Lubin JH, Yao SX, Wang JZ, Cai SK, Hou Y, Blot WJ. Dietary determinants of lung cancer risk: results from a case-control study in Yunnan Province, China. Int J Cancer 1992;50:876-880.

22. Wattenberg LW. Chemoprevention of cancer. Cancer Res 1985;45:1-8.

23. Jurado J, Alejandre-Duran E, Alonso-Moraga A, Pueyo C. Study on the mutagenic activity of 13 bioflavonoids with the Salmonella Ara test. Mutagenesis 1991;6:289-295.

24. Herrmann K. Flavonols and flavones in food plants: a review. J Food Technol 1976;11:433-448.

25. Francis AR, Shetty TK, Bhattacharya RK. Modifying role of dietary factors on the mutagenicity of aflatoxin $B_{1}$ : in vitro effect of plants flavonoids. Mutat Res 1989;222:393-401.

26. Bylik A, Cooper PL, Sapers GM. Varietal differences in distribution of quercetin and kaempferol in onion (Allium cepa L.) tissue. J Agric Food Chem 1984;32:274-276.

27. Bilyk A, Sapers GM. Distribution of quercetin and kaempferol in lettuce, kale, chive, garlic chive, leek, horseradish, red radish, and red cabbage tissues. J Agric Food Chem 1985;33:226-228.

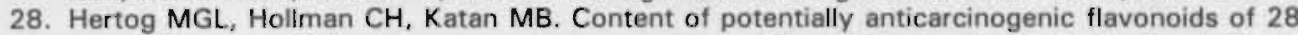
vegetables and 9 fruits commonly consumed in The Netherlands. J Agric Food Chem 1992;40:2379-2383.

29. Starke H, Herrmann K. Flavonols and flavones of vegetables. VI. On the changes of flavonols of onions. Z Lebensm Unters Forsch 1976;161:137-142.

30. Starke $\mathrm{H}$, Herrmann K. Flavonols and flavones of vegetables. VII. Flavonols of leek, chive and garlic. Z Lebensm Unters Forsch 1976;161:25-30.

31. Hertog MGL, Hollman PCH, Katan MB, Kromhout D. Intake of potentially anticarcinogenic flavonoids and their determinants in adults in The Netherlands. Nutr Cancer 1993:20:21-29.

32. Fenwick GR, Hanley AB. The genus Allium, part 2. CRC Crit Rev Food Sci Nutr 1985;22:273377.

33. Bernhard RA. The sulfur components of Allium species as flavoring matter. Qual Plant Mater Veg $1969 ; 1-3: 72-84$.

34. Block E. The organosulfur chemistry of the Genus. Allium - Implications for the organic chemistry of sulfur. Angew Chem Int Ed Engl 1992;31:1135-1178.

35. Block E, Naganathan S, Putman D, Zhao SH. Allium chemistry: HPLC analysis of thiosulfinated from onion, garlic, wild garlic (ramsoms), leek, scallion, shallot, elephant (great-headed) garlic, chive, and Chinese chive. Uniquely high allyl to methyl ratios in some garlic samples. J Agric Food Chem 1992;40:24.18-2430.

36. Gugier R, Leschik M, Dengler HJ. Disposition of Quercetin in man afetr single oral and intravenous doses. Eur J Clin Pharmacol 1975;9:229-234

37. Hagen TM, Wierzbicka GT, Sillau AH, Bowman BB, Jones DP. Bioavailability of dietary glutathione: effect on plasma concentration. Am J Physiol 1990;259:G524-G529.

38. Wargovich MJ. New dietary anticarcinogens and prevention of gastrointestinal cancer. Dis Colon Rectum 1988;31:72-75.

39. Malone WF. Chemopreventive research. In: Mechanisms of carcinogenesis. EK Weisburger ed., Kluwer Academic Publishers, Dordrecht, The Netherlands, 1989.

40. Bertram JS, Kononel LN, Meysekens FL. Rationale and startegies for chemoprevention of cancer in humans. Cancer Res 1987;47:3012-3031. 



\title{
Chapter 6
}

\section{Allium vegetable consumption, garlic supplement intake and female breast carcinoma incidence}

\author{
Elisabeth Dorant; Piet A. van den Brandt; R. Alexandra Goldbohm
}

\begin{abstract}
The risk of female breast carcinoma in relation to onion and leek consumption ancl the use of garlic supplements, was evaluated in the Netherlands Cohort Study on diet and cancer. Onions, leeks and garlic contain specific compounds which might act as antimutagens. Animal experiments also suggest a possible role for these compounds in inhibition of mammary carcinogenesis.

The Netherlands Cohort Study was started in 1986 among 120,852 Dutch men and women, aged 55-69 years, with collecting information on usual diet and important lifestyle characteristics. After 3.3 years of follow-up, 469 incident female breast carcinoma cases and 1713 female members of a randomly sampled subcohort were available for analysis. Intake of onions or leeks was not associated with breast carcinoma risk after controlling for dietary and nondietary risk factors: the rate ratios in the highest intake categories were $0.95195 \%$. confidence interval $0.61-1.47)$ and 1.08 (95\% confidence interval $0.79-1.48$ ), respectively, compared with the lowest intake categories. The tests for trend in the rate ratios were neither significant. Garlic supplement use was also not associated with breast carcinomai incidence (rate ratio $=0.87,95 \%$ confidence interval $0.58-1.31$ ).

In conclusion, we found no association between the consumption of onions or leeks, or garlic supplement use and the incidence of female breast carcinoma.
\end{abstract}




\section{Introduction}

Breast cancer is the most frequent cancer among women in The Netherlands. In 1989 , $30.7 \%$ of all new malignant tumors in women were breast tumors ${ }^{1}$. In reviews of epidemiological studies, it was concluded that a high consumption of certain vegetables and fruit might reduce the risk of breast cancer ${ }^{2-4}$. Most evidence for an inverse association has. been reported primarily in studies in which intake of a few selected micronutrients, mostly vitamin $C$ and $\beta$-carotene, as marker for fruit or vegetable intake, was investigated ${ }^{3,4}$. Nevertheless, other compounds present in vegetables and fruit, such as glutathione and flavonols, might be protective as well ${ }^{3,5-8}$.

Onions, leeks, garlic and other vegetables belonging to the Allium genus (e.g. shallots and chives) contain not only the flavonols quercetin and kaempferol ${ }^{9-11}$, and the cysteinecontaining tripeptide glutathione ${ }^{12}$, but also a wide variety of specific organic sulfur compounds, which are accountable for the typical odor of these plants ${ }^{13,14}$. Some of the organosulfur compounds (e.g. diallyl sulphide) act as antimutagen in in vitro laboratory experiments, and might even act as anticarcinogen in vivo ${ }^{15}$. One of the other potentially chemopreventive compounds, quercetin, has been shown to reduce the incidence and number of mammary tumors in rats induced with 7,12-dimethylbenz[a]anthracene (DMBA) and with $\mathrm{N}$-nitrosomethylurea ${ }^{16}$. Notably, the combination of diallyl sulphide and quercetin was more effective in reducing the number of mammary tumors than single administration of these compounds in the DMBA-induced mammary carcinogenesis model ${ }^{17}$.

Organosulfur compounds have also been detected in garlic supplements ${ }^{18}$, the most widely used dietary supplements in elderly women in The Netherlands ${ }^{19}$. In the DMBAinduced mammary tumor model, increasing quantities of garlic powder from dietary supplements delayed the onset of tumors and also reduced the total number of tumors per rat. The in vivo binding of DMBA with DNA was depressed, while the activity of glutathione S-transferase, an enzyme important for detoxification of carcinogens, was enhanced ${ }^{20}$. In another experiment, DMBA-DNA adduct formation in mammary tissue was significantly suppressed by several types of garlic supplements, but varied depending on the processing method ${ }^{21}$.

Recently, two case-control studies have investigated the association between Allium vegetable consumption and breast cancer risk. No significant association was found between the consumption of onions or leeks and the risk of breast cancer in Greek women ${ }^{22}$. In the other study, performed in Switzerland, no association was detected for fresh garlic. However, a significantly decreased risk was observed with increasing consumption of onions, which persisted after controlling for age, education and total energy intake lodds ratio $=0.3$ in the highest versus the lowest tertile) ${ }^{23}$.

We have examined the association between onion and leek consumption, garlic supplement use and the incidence of female breast carcinoma in the Netherlands Cohort Study (NLCS), a prospective cohort study on diet and cancer that was starteci in 1986 among 120,852 persons, aged $55-69$ years.

\section{Materials and methods}

A description of the design of the NLCS and the characteristics of the cohort has been published ${ }^{24}$. In brief, the NLCS has been started in 1986 among 58,279 men and 62,573. women aged 55-69 years, originating from 204 municipalities in The Netherlands with computerized population registries. Accumulation of person-time in the cohort has been estimated by follow-up of a randomly selected subcohort of 1688 men and 1812 women. Information on cancer incidence has been collected for the entire cohort by record linkage 
with all nine cancer registries in The Netherlands and with PALGA, the Dutch network and National Database for Pathology. The method of record linkage has been published ${ }^{25}$. The present analysis is restricted to female breast carcinoma incidence in the first 3.3 years of follow-up (from baseline in September 1986 to December 1989). Completeness of follow-up in this period is estimated to be $95 \%{ }^{26}$.

After excluding those subjects from the entire group of breast cancer cases, who reported any prevalent cancer other than skin cancer, and those with incident in situ breast cancer, breast cancer other than carcinoma (sarcoma, lymphoma, unspecified morphology), or without at least a microscopically confirmed diagnosis, 469 incident primary breast carcinoma cases were available for analysis. From the 1812 women in the subcohort, 1716 did not report prevalent cancer (excl. skin) at the start of the study.

A 150-item semi-quantitative food frequency questionnaire was used to collect information on the usual intake of foods and beverages in the year preceding the start of the study $^{27}$. Questionnaire data of all cases and subcohort members have been key-entered twice and processed blinded with respect to case/subcohort status to prevent random and systematic coding errors. Subjects were categorized into four categories of onion consumption $(0, \leq 0.25,0.25-0.5$, and $\geq 0.5$ onions per day) and three categories of leek consumption $(0, \leq 2$ and $>2$ times per month) based on information collected by asking how many onions they usually consumed per week and how often they consumed leeks in summer and winter. A question on the consumption of fresh garlic was not included in the questionnaire. The semiquantitative food frequency questionnaire has been validated against three 3-day diet records ${ }^{27}$. Garlic supplement users were defined as those women who reported daily use of any garlic supplement for at least one year in the five-year period before baseline. Recall of garlic supplement use was evaluated by comparing questionnaire data with information from three personal interviews as reference ${ }^{28}$.

Analyses on onion and leek consumption are based on cases and subcohort members with complete dietary data ${ }^{26}$, while analyses on garlic supplement use are based on subjects with complete information on dietary supplement use. As potentia! confounders we considered: age, parity, age at menarche, age at first birth, age at menopause, artificiallyinduced menopause, oral contraceptive use, history of benign breast disease, breast cancer in mother or sister(s), alcohol consumption, Quetelet index, highest level of education, smoking status, and dietary intake of vitamin $C$ and $\beta$-carotene (computed by using the Dutch food composition table ${ }^{29}$ ). Case-cohort analyses were performed based on the assumption that survival times were exponentially distributed in this follow-up period ${ }^{26}$. In age-adjusted stratified analyses, we computed Mantel-Haenszel rate ratios and $95 \%$. confidence intervals for each category of onion and leek consumption and for garlic supplement use. In the multivariable analyses, we further adjusted for other covariables. The rate ratios for garlic supplement use were not only computed for all consumers of garlic, supplements, but also for those who exclusively consumed garlic supplements (i.e. without othei supplements) and for those who consumed garlic supplements together with any other supplement. The $95 \%$ confidence intervals (Cl) of the estimated rate ratios (RR) were corrected for the additional variance introduced by using a subcohort instead of the complete cohort. Tests for trend in the rate ratios were based on likelihood ratio tests. Since prediagnostic disease symptoms might have influenced dietary habits, analyses were not only conducted for all cases diagnosed in 3.3 years of follow-up, but also for those diagnosed after the first year.

\section{Results}

As is presented in table 1, the proportion of subjects not consuming onions was slightly higher among cases than in the subcohort, while the proportions of subjects in the two. 
highest intake categories were somewhat lower in the case group. The differences between the distributions of onion consumption in cases diagnosed after the first year of follow-up and in the subcohort were smaller. The frequency of leek consumption was equally distributed in cases and subcohort. No differences were seen between cases and subcohort regarding overall use of dietary supplements. Nearly $35 \%$ of the cases used dietary supplements, $10.2 \%$ used garlic supplements and $24.6 \%$ any other supplement. Twenty-four of the 48 garlic supplement users took also other supplements: vitamin B $(9.4 \%)$, vitamin C $(7.8 \%)$, brewer's yeast $(10.9 \%)$, calcium $(9.4 \%)$ and multivitamins/minerals $(7.9 \%)$. Cases using any other supplement took vitamin B $(21.1 \%)$, vitamin C $(15.8 \%)$, brewer's yeast $(14.0 \%)$, calcium $(12.3 \%)$ and multivitamins/minerals $(12.2 \%)$. The $5.1 \%$ of the subcohort who used garlic together with any other supplement took vitamin B $(7.8 \%)$, vitamin C $(8.8 \%)$, brewer's yeast $(7.5 \%)$, calcium and multivitamin/minerals (both $7.0 \%)$. The distribution of supplements among subcohort members who used any other supplement was: vitamin $B(24.4 \%)$, vitamin $C(15.9 \%)$, calcium $(12.0 \%)$ and multivitamins/minerals $(13.4 \%)$.

Table 1. Onion and leek consumption and garlic supplement use among breast carcinoma cases and subcohort members.

\begin{tabular}{|c|c|c|c|c|}
\hline \multirow[t]{2}{*}{ Allium consumption } & \multicolumn{2}{|c|}{ Cases } & \multicolumn{2}{|c|}{ Subcohort } \\
\hline & All $(\%)$ & Excl. first year & $n(\%)$ & Person Years ${ }^{a}$ \\
\hline \multicolumn{5}{|l|}{ Onion (number/day) ${ }^{b}$} \\
\hline 0 & $105(24.1)$ & $72(22.2)$ & $333(20.8)$ & 1078 \\
\hline$\leq 0.25$ & $123(28.3)$ & $90(28.0)$ & $448(28.0)$ & 1453 \\
\hline $0.25-0.5$ & $150(34.5)$ & $117(36.0)$ & $601(37.6)$ & 1957 \\
\hline$\geq 0.5$ & $57(13.1)$ & $46(14.2)$ & $216(13.5)$ & 692 \\
\hline \multicolumn{5}{|l|}{ Leek (freq/month) ${ }^{b}$} \\
\hline 0 & $130(29.9)$ & $90(28.0)$ & $469(29,3)$ & 1523 \\
\hline$\leq 2$ & $161(37.0)$ & $124(38.2)$ & $603(37.7)$ & 1950 \\
\hline$>2$ & $144(33.1)$ & $11)(34.2)$ & $526(32.9)$ & 1707 \\
\hline \multicolumn{5}{|l|}{ Garlic supplement ${ }^{\mathrm{c}}$} \\
\hline No supplements & $305(65.2)$ & $228(65.5)$ & $1105(64.5)$ & 3583 \\
\hline Exclusively garlic & $24(5.1)$ & $17(4.9)$ & $86(5.0)$ & 281 \\
\hline Any other supplement & $115(24.6)$ & $83(23.9)$ & $434(25.3)$ & 1402 \\
\hline Garlic + any other suppl. & $24(5.1)$ & $20(5.7)$ & $88(5.1)$ & 284 \\
\hline
\end{tabular}

a: Person years in the subcohort (multiplication with the inverse of the sampling fraction (62573/1812) gives the estimated person-time-at-risk for the entire cohort).

b: Data presented for 435 cases and 1698 subcohort members with complete dietary data.

c: Data presented for 468 cases and 1713 subcohort members with complete data on dietary supplement use. The categories are mutually exclusive. 
Age-adjusted Mantel Haenszel rate ratios according to various known risk factors have already been published ${ }^{26}$. In short, breast cancer risk was positively associated with early menarche and late menopause, a history of benign breast disease, and breast cancer in mother or sisters(s). No association was observed for artificially induced menopause, oral contraceptive use, education, current cigarette smokingl or Quetelet Index. A decreasing risk. was observed with parity and early age at first birth ${ }^{26}$.

Associations among subcohort members between these and other potential risk factors on the one hand and onion or leek consumption and the use of garlic supplements on the other hand, are presented in table 2. We observed no association between onion or leek intake and age, age at menarche or menopause, Quetelet index, breast cancer in mother or artificially induced menopause. Compared to the lower consumption categories, more women. in the highest categories of onion and leek consumption had a higher mean intake of vitamin $\mathrm{C}$ and $\beta$-carotene, a history of benign breast disease and did not have a sister with a history of breast cancer. A larger proportion of women in the lowest consumption categories were nulliparous, did not consume alcohol, and had never smoked. Garlic supplement use was not associated with age or age at menarche or menopause. The mean vitamin $\mathrm{C}$ or $\beta$-carotene intake and Quetelet index were higher among garlic supplement users than among those not consuming dietary supplements. A higher percentage of garlic supplement users was nulliparous, had ever been diagnosed with benign breast disease, or had a mother with a history of breast cancer, while a lower percentage had never smoked, did not use alcohol, had an artificially induced menopause, a sister with breast cancer, or reported the use of oral contraceptives.

Table 2. Association between onion and leek consumption and garlic supplement use and important risk factors among subcohort members.

\begin{tabular}{|c|c|c|c|c|c|c|c|c|c|}
\hline \multirow{2}{*}{ Characteristics } & \multicolumn{4}{|c|}{ Onion consumption (number/day) } & \multicolumn{3}{|c|}{$\begin{array}{l}\text { Leek. consumption } \\
\text { (freq/month) }\end{array}$} & \multicolumn{2}{|c|}{$\begin{array}{c}\text { Garlic } \\
\text { supplement use }\end{array}$} \\
\hline & 0 & $<0.25$ & $<0.5$ & $\geq 0.5$ & 0 & $\leq 2$ & $>2$ & no suppl. & yes \\
\hline Age (mean yrs) & 61.9 & 61.5 & 61.0 & 61.4 & 61.8 & 61.4 & 61.1 & 61.5 & 61.5 \\
\hline Age at menarche (mean yrs) & 13.6 & 13.8 & 13.8 & 13.6 & 13.8 & 13.7 & 13.6 & 13.7 & 13.6 \\
\hline Age at menopause (mean yrs) & 48.9 & 48.8 & 49.0 & 48.9 & 48.6 & 48.9 & 48.9 & 48.6 & 48.8 \\
\hline Vitamin C (mean intake mg/day) & 101 & 102 & 112 & 124. & 100 & 106 & 119 & 96 & 113 \\
\hline$\beta$-carotene (mean intake $\mathrm{mg} \mathrm{E}_{\mathrm{q}}$ vit A) & 0.38 & 0.38 & 0.46 & 0.51 & 0.37 & 0.41 & 0.50 & 0.30 & 0.41 \\
\hline Quetelet Index (mean $\mathrm{kg} / \mathrm{m}^{2}$ ) & 25.2 & 25.1 & 25.2 & 25.1 & 25.3 & 25.0 & 25.2 & 25.4. & 27.7 \\
\hline Smoking $(\% \mathrm{no})$ & 65.2 & 60.3 & 57.1 & 52.3 & 60.6 & 57.0 & 59.9 & 61.4 & 58.6 \\
\hline Alcohol use (\% no) & 42.4 & 30.6 & 29.2 & 28.4 & 40.0 & 29.2 & 28.6 & 33.7 & 28.8 \\
\hline Children $(\%$ no) & 20.1 & 16.9 & 15.7 & 18.6. & 18.8 & 15.9 & 17.7 & 16.6 & 20.1 \\
\hline Oral contraceptive use (\% yes) & 21.7 & 24.7 & 28.3 & 21.6 & 19.6 & 27.2 & 27.4 & 24.1 & 20.6 \\
\hline Artificial menopause ( $\$$ yes) & 17.1 & 15.9 & 14.7 & 19.2 & 14.1 & 19.3 & 1.4 .3 & 15.9 & 15.3 \\
\hline Breast cancer in mother ( $\%$ yes) & 3.3 & 2.7 & 3.5 & 2.8 & 2.8 & 3.5 & 3.0 & 2.5 & 3.4 \\
\hline Breast cancer in sister(s) (\% yes) & 6.0 & 5.8 & 4.8 & 3.7 & 6.2 & 5.1 & 4.4 & 5.2 & 4.6 \\
\hline Benign breast disease $1 \%$ yes) & 8.1 & 8.0 & 6.5 & 9.3 & 7.7 & 6.1 & 9.3 & 6.4 & 8.0. \\
\hline
\end{tabular}


In age-stratified analysis, lower risks were seen for those women who consumed onions, compared to those not consuming onions (table 3). However, none of the Mantel-Haenszel rate ratios were significantly different from one. After further adjustment for other risk factors in multivariable analysis, the rate ratios stayed below the null-value, but were also not statistically significant. Onion consumption was not associated with breast carcinoma risk after exclusion of cases diagnosed during the first year of follow-up (results not shown). None of the tests for trend in the rate ratios were statistically significant. Leek consumption was also not associated with breast carcinoma risk: none of the rate ratios, both in the ageadjusted stratified analysis, as well as in the multivariable analysis, were different from unity. The tests for trend were not statistically significant. Exclusion of cases diagnosed in the first year of follow-up did not alter the results (data not shown). The use of garlic supplements was not associated with breast carcinoma risk (RR $=0.87,95 \% \mathrm{Cl} 0.58-1.31$ ). When the association with garlic supplement use was evaluated for each of the two subcategories fexclusively garlic supplements with no supplements as reference category, or garlic supplements plus any other supplement with any other supplement as reference), none of the rate ratios (in stratified and multivariable analysis) were statistically significant. After entering parity, age at menarche, Quetelet index and education in the model, the rate ratio associated with exclusively garlic supplement use decreased to 0.77 (95\% $\mathrm{Cl} 0.49-1.23$ ). The rate ratio was estimated at $0.75(95 \% \mathrm{Cl} 0.41-1.38)$ after further adjustment for other risk factors.

\section{Discussion}

The NLCS is the first prospective cohort study investigating the association between Allium vegetable consumption, garlic supplement use and breast cancer risk in postmenopausal women. We found no evidence that consumption of onions or leeks, or the use of garlic supplements is associated with a lower risk of female breast carcinoma.

Our results correspond with outcomes from a hospital-based case-control study in Greece, in which no association was observed between consumption of onions or leeks and breast cancer risk ${ }^{22}$. In contrast, in a case-control study in Switzerland, a significant protective effect was reported for increasing onion intake. The investigators noticed, however, that their results should be viewed with caution, since they did not collect complete dietary information and used hospital controls. Comparison of our results with those found in Switzerland is further complicated by the fact that in the Swiss study the association between onion consumption and breast cancer risk was not evaluated for preand postmenopausai women separately ${ }^{23}$.

Unfortunataly. we were not able to evaluate in the NLCS if fresh garlic consumption is associated with breast carcinoma risk, since a question on fresh garlic consumption was not included in the baseline questionnaire. However, consumption of fresh garlic by female subcohort members was probably not very high: in a follow-up questionnaire mailed in 1990 to subcohort members only, $69.7 \%$ of the subjects reported that they never used fresh garlic, $12.9 \%$ consumed up to 1 clove of garlic per week. Only $1.4 \%$ of the subcohort members consumed at least 1 garlic clove per day. In the Swiss case-control study, fresh garlic consumption was not associated with breast cancer risk lage-adjusted odds ratios for garlic consumption in increasing frequency consumption tertiles (low, intermediate, high) were 1.0, 0.7, and 0.6 (trend test $\left.\left.\chi^{2}=1.7\right)\right)^{23}$. There is no reason to assume that selection bias is responsible for not finding an association: completeness of follow-up of cancer incidence in the entire cohort was estimated at $95 \%$, and certification of person time in the subcohort was $100 \%{ }^{26}$. We also adjusted for confounding by including known risk factors (dietary and nondietary) in the analysis. If preclinical symptoms of breast carcinoma had an 
Table 3. Rate ratios and $95 \%$ confidence intervals of breast carcinoma according to Allium vegetable consumption and garlic supplement use.

\begin{tabular}{|c|c|c|}
\hline \multirow{2}{*}{ Allium consumption } & Stratified analysis ${ }^{\mathrm{a}}$ & Multivariable analysis ${ }^{\mathrm{b}}$ \\
\hline & $\mathrm{RR}_{\mathrm{MH}}(95 \% \mathrm{Cl})$ & RR $(95 \% \mathrm{Cl})$ \\
\hline \multicolumn{3}{|l|}{ Onion (number/day) } \\
\hline 0 & $1.00 t$ & $1.00 t$ \\
\hline$\leq 0.25$ & $0.91(0.67 .1 .22)$ & $1.02(0.72-1.44)$ \\
\hline $0.25-0.5$ & $0.82(0.62-1.09)$ & $0.87(0.62-1.27)$ \\
\hline$\geq 0.5$ & $0.86(0.60-1.24)$ & $0.95(0.61-1.47)$ \\
\hline Trend test $x^{2}$ (p-value) & $1.40(0.24)$ & $0.65(0.42)$ \\
\hline \multicolumn{3}{|l|}{ Leek (freq/month) } \\
\hline 0 & $1.00 t$ & $1.00 t$ \\
\hline$\leq 2$ & $0.98(0.75-1.27)$ & $0.96(0.71-1.30)$ \\
\hline$>2$ & $1.01(0.77-1.31)$ & $1.08(0.79-1.48)$ \\
\hline Trend test $x^{2}$ (p-value) & $0.004(0.95)$ & $0.32(0.57)$ \\
\hline \multicolumn{3}{|l|}{ Garlic supplement use } \\
\hline No supplements & $1.00 t$ & $1.00 t$ \\
\hline Garlic supplements & $1.00(0.71-1.41)$ & $0.87(0.58-1.31)$ \\
\hline No supplements & $1.00 t$ & $1.00 t$ \\
\hline Exclusively garlic & $1.01(0.63-1.61)$ & $0.75(0.41-1.38)$ \\
\hline Any other supplement & $1.00 t$ & $1.00 t$ \\
\hline Garlic + any other & $0.98(0.59-1.63)$ & $1.12(0.63-1.99)$ \\
\hline
\end{tabular}

\footnotetext{
I: Reference

a: Adjusted for age in three categories $(55-59,60-64,65-69)$.

b: Adjusted for age (continuous), parity, age at menarche, age at first birth, age at menopause, artificially-induced menopause, oral contraceptive use, history of benign breast disease, breast cancer in mother, breast cancer in sister(s), alcohol consumption, Quetelet index, highest level of personal education, smoking status, dietary intake of vitamin $\mathrm{C}$ and $\beta$-carotene (both continuous).
}

effect on the habitual intake of Allium vegetables or garlic supplements, we might have observed other RRs after excluding cases diagnosed during the first year of follow-up. However, the results were similar to those observed for the entire case group. A potential 
limitation of our study is that we are not entirely sure that the absence of a relation between onion and leek consumption and breast carcinoma risk has not been caused by nondifferential misclassification of exposure. Although the validity of the semiquantitative food frequency questionnaire has been assessed for vegetables, information on its validity regarding onion and leek consumption is not available ${ }^{27}$. Estimates on dietary supplement use and intake of garlic supplements, however, were considered to be accurate enough to classify individuals as user ${ }^{28}$.

The strongest indication up to now that Allium vegetable consumption might be inversely associated with cancer development is derived from case-control studies. Most of these studies reported a decreasing risk with increasing intake of Allium vegetables, mainly for cancer in the digestive tract ${ }^{2,3}$. Experimental research indicates that certain specific Allium compounds (e.g. diallyl sulphide) act antimutagenic, and may even act anticarcinogenic in vivo against several carcinogens ${ }^{15}$. Antimutagenic and anticarcinogenic action have also been suggested for other compounds detected in Allium vegetables, such as the flavonols quercetin and kaempferol, and the tripeptide glutathione ${ }^{7,8,12,16}$. However, there is only little information on the absorption, metabolism and bioavailibility of the potentially chemopreventive com-pounds in humans. A few studies have been published on the bioavailability of flavonols ${ }^{30,31}$, but the uptake of glutathione has to our knowledge only been evaluated in animals ${ }^{32}$. Specific data on the bioavailability of organosuifur compounds from onions, leeks and garlic supplements are also not available for humans. If these compounds are not absorbed in the intestinal tract, as is the case with quercetin ${ }^{30.31}$, they can only act anticarcinogenically by detoxifying or scavenging ingested carcinogens or preventing formation of carcinogens from precursor compounds within the digestive tract ${ }^{5}$. The strongest inhibitory action might then be expected for intestinal cancers, not for hormone related sites such as breast cancer.

In conclusion, this study did not provide evidence that either onion and leek consumption, or the use of garlic supplements protects against breast carcinoma in postmenopausal women.

\section{References}

1. De Winter GA, Coebergh JWW, Van Leeuwen FE, Schouten L. (eds.). Incidence of cancer in the Netherlands, 1989. First report of The Netherlands cancer registry. Coordinating Council of Comprehensive Cancer Registries, Utrecht, 1993.

2. Steinmetz K, Potter JD. Vegetables, fruit, and cancer. I. Epidemiology. Cancer Causes Control $1991 ; 2: 325-357$.

3. Block G, Patterson B, Subar A. Fruit, vegetables, and cancer prevention: a review of the epidemiological evidence. Nutr Cancer 1992;18:1-29.

4. Howe G, Hirohata T, Hislop G, Iscovich JM, Yuan JM, Katsouyanni K, Lubin F, Marubini E, Modan B, Rohan T, Tonioli P, Shunzhang Y. Dietary factors and risk of breast cancer: combined analysis of 12 case-control studies. J Natl Cancer Inst 1990;82:561-569.

5. Wattenberg LW. Chemoprevention of cancer. Cancer Res 1985:45:1-8.

6. Ames BN. Dietary carsinogens and anticarcinogens. Science 1983;221:1256-1264.

7. Steinmetz K, Potter JD. Vegetables, fruit, and cancer. II. Mechanisms. Cancer Causes Cantrol $1991 ; 2: 427-442$.

8. Newmark HL. Plant phenolics as inhibitors of mutational and precarcinogenic events. Can J Physiol Pharmacol 1987;65:461-466.

9. Herrmann K. Flavonols and flavones in food plants: a review. J Food Technol 1976;11:433-448.

10. Biiyk A, Sapers GM. Distribution of quercetin and kaempferol in lettuce, kale, chive, garlic chive, leek, horseradish, red radish, and red cabbage tissues. J Agric Food Chem 1985;33:226-228.

11. Hertog MGL, Hollman $\mathrm{CH}$, Katan MB. Content of potentially anticarcinogenic flavonoids of 28 vegetables and 9 fruits commonly consumed in The Netherlands. J Agric Food Chem $1992 ; 40: 2379-2383$. 
12. Coles B, Ketterer B. The role of glutathione and glutathione transferases in chemical carcinogenesis. Crit Rev Biochem Mol Biol 1990;25:47-70.

13. Whitaker JR. Development of flavor, odor, and pungency in onion and garlic. Adv. Food Res $1976 ; 22: 73-133$.

14. Block $E$. The organosulfur chemistry of the Genus Allium - Implications for the organic chemistry of sulfur. Angew Chem Int Ed Engl 1992:31:1135-1178.

15. Dorant E, Van den Brandt PA, Goldbohm RA, Hermus RJJ, Sturmans F. Garlic and its significance for the prevention of cancer in humans: a critical view. Br J Cancer 1993;67:424-429.

16. Verma AK, Johnson JA, Gould MN, Tanner MA. Inhibition of 7,12-dimethylbenzla]anthraceneand $\mathrm{N}$-nitrosomethylurea-induced rat mammary cancer by dietary flavonol quercetin. Cancer Res 1998;48:5754-5758.

17. Ip C, Ganther HE. Combination of blocking agents and suppressing agents in cancer prevention. Carcinogenesis 1991;12:365-367.

18. Lawson LD, Wang ZYJ, Hughes BG. Identification and HPLC Quantification of the sulfides and dialk(en)yl thiosulfinates in commercial garlic products. Planta Med 1991;57:363-370.

19. Dorant E, Van den Brandt PA, Hamstra AM, Feenstra MH, Goldbohm RA, Hermus RJJ, Sturmans $\mathrm{F}$. The use of vitamins, minerals and other dietary supplements in The Netherlands. Int J Vit Nutr Res 1993;63:4-10.

20. Liu J, Lin RI, Milner JA. Inhibition of 7,12-dimethylbenzlalanthracene-induced mammary tumors and DNA adducts by garlic powder. Carcinogenesis 1992;13:1847-1851.

21. Amagase H, Milner JA. Impact of various sources of garlic and their constituents on 7,12 . dimethylbenzla]anthracene binding to mammary cell DNA. Carcinogenesis 1993;14:1627-1631.

22. Katsouyanni K, Trichopoulos D, Boyle P. Xirouchaki E, Trichopoulou A, Lisseos B, Vasilaros S, MacMahon B. Diet and breast cancer: a case-control study in Greece. Int J Cancer 1986;38:815820.

23. Levi F, La Vecchia C, Gulie C, Negri E. Dietary factors and breast cancer risk in Vaud, Switzerland. Nutr Cancer 1993;19:327-335.

24. Van den Brandt PA, Goldbohm RA, Van 't Veer P, Volovics A, Hermus. RJJ, Sturmans F, A largescale prospective cohort study on diet and cancer in The Netherlands. J Clin Epidemiol 1990;43:285-295.

25. Van den Brandt PA, Schouten LJ, Goldbohm RA, Dorant E, Hunen PMH. Development of a record linkage protocol for use in the Dutch Cancer registry for epidemiological research. Int $J$ Epidemiol 1990;19:553-558.

26. Van den Brandt PA, Van 't Veer P, Goldbohm RA, Dorant E, Volovics A, Hermus RJJ, Sturmans F. A prospective cohort study on dietary fat and the risk of postmenopausal breast cancer. Cancer Res 1993;53:75-82.

27. Goldbohm RA, Van den Brandt PA, Brants HAM, Van 't Veer P, Al M, Sturmans F, Hermus RJJ. Validation of a dietary questionnaire used in a large-scale prospective cohort study on diet and cancer. Eur J Clin Nutr 1994:48:253-265.

28. Dorant E, Van den Brandt PA, Goldbohm RA, Hermus RJJ, Sturmans F, Agreement between interview data and a self-administered questionnaire on dietary supplement use. Eur J Clin Nutr 1994;48:180-188.

29. Stichting NEVO. NEVO table; Dutch food composition table 1986-1987. The Hague, Netherlands: Voorlichtingsbureau voor de Voeding, 1986.

30. Gugler R, Leschik M. Dengler HJ. Disposition of Quercetin in man after single oral and intravenous doses. Eur J Clin Pharmacol 1975;9:229-234.

31. Clark WG, MacKay EM. The absorption and excretion of rutin and related flavonoid substances. JAMA 1950;143:1411-1415.

32. Jones DP, Coates RJ, Flagg EW, Eley JW, Block G, Greenberg RS, Gunter EW, Jackson B. Glutathione in foods listed in the National Cancer Institute's Health Habits and History Food Frequency Questionnaire. Nutr Cancer 1992;17:57-75. 


$$
70
$$




\title{
Chapter 7
}

\section{A prospective cohort study on the relation between onion and leek consumption, garlic supplement use and the risk of colon and rectum carcinoma in The Netherlands}

\author{
Elisabeth Dorant; Piet: A. van den Brandt; R. Alexandra Goldbohm
}

\begin{abstract}
The association between onion and leek consumption, garlic supplement use and colon and rectum carcinoma among men and women was evaluated in the Netherlands Cohort Study, a large-scale prospective cohort study on diet and cancer. Onions, leeks and garlic belong to the Allium genus and contain large amounts of potentially chemopreventive compounds. The Netherlands Cohort Study was started in 1986 among 120,852 men and women, aged 55-69. Dietary intake was measured with a 150-item food frequency questionnaire. After 3.3 years of follow-up, 150 and 143 incident male and female cases of colon carcinoma and 93 and 57 cases of rectum carcinoma, respectively, with complete dietary data were available for analysis. Dietary data were available for 1525 men and 1598 women of a randomly selected subcohort, that was followed up to estimate persontime in the entire cohort.

In men, the adjusted rate ratios (RRs) in multivariable analysis for colon and rectum carcinoma in the highest compared to the lowest, onion consumption categories were 0.87 (95\% confidence interva! ( $\mathrm{Cl}) 0.48-1.65)$, and $0.66(95 \% \mathrm{Cl} 0.28-1.52)$, respectively. The RPis for proximal colon carcinoma were lower than for distai colon carcinoma. Leek consumption was not associated with colon and rectum carcinoma incidence in men. None of the RRs were significantly different from unity and no trends in the RRs were detected. A lower risk was found for rectum carcinoma in women consuming less than 0.25 onions per day (RR=0.36 95\%, Cl 0.13-0.99), but the trend in the RRs was not statistically significant $(p=0.25)$. All other RRs for colon and rectum carcinoma associated with onion consumption were slightly higher than one. Leek consumption was not associated with colon and rectum carcinoma incidence.

The use of garlic supplements was not associated with colon and rectum carcinoma in men and women combined.

This study does not support an inverse association between the consumption of onions and leeks, or the use of garlic supplements and the incidence of male and female colon and rectum carcinoma.
\end{abstract}




\section{Introduction}

Vegetables have long been recognized as important exogenous factors in the etiology of cancer of colon and rectum. High intake of vegetables might reduce the risk considerably '. Recent reviews on the role of vegetables and fruit on cancer risk emphasized the strong evidence for a protective effect of vegetable and fruit consumption on risk of colorectal cancer. Certain vegetables, such as cruciferous vegetables and carrots, may be particularly promising in this respect ${ }^{2-6}$. However, in a recently published Australian case-control study on vegetable and fruit consumption and male and female colon cancer, the strongest inverse associations were with onions. In women, all odds ratios in increasing quartiles of consumption were significantly below unity. In men, the inverse risk was stronger for proximal than for distal colon cancer?

Onions, but also leeks, garlic, chives and shallots belong to the Allium genus. Experimental research suggests an inhibitory role in colon carcinogenesis by certain sulphur containing compounds, such as diallyl sulphide, S-allylmercaptocystein and S-allylcystein, present in Allium vegetables ${ }^{8}$. Diallyl disulphide, a garlic compound, has recently been shown to reduce the incidence and multiplicity of invasive colon adenocarcinoma in experimental animals ${ }^{9}$. Some of the potentially chemopreventive sulphur containing compounds are also present in garlic supplements ${ }^{10}$, the most widely used type of dietary supplement by elderly persons in The Netherlands ${ }^{11}$. Onions are also important contributors of the flavonol quercetin ${ }^{12}$. Flavonols, such as quercetin and kaempferol (present in leeks ${ }^{13,14}$ ), and the cysteinecontaining tripeptide glutathione, which has been detected in onions ${ }^{15}$, might act as anticarcinogens as well ${ }^{16-20}$.

Results from earlier case-control studies also suggest that high intake of onions or other vegetables belonging to the Allium genus may reduce the risk for colon and rectum cancer. In Japan, a decreased risk for colorectal cancer as well as for the subset of cancers in the lower part of the rectum (less than $5 \mathrm{~cm}$ from the anus) was observed with high consumption of Japanese leeks. In a preceding study in Hawaii, the risk for colorectal cancer among Hawaiian Japanese was also lower than unity with high consumption of leeks ${ }^{21,22}$. High consumption of onions was associated with a significantly reduced risk for colon cancer in a case-control study in the USA ${ }^{23}$. In Belgium, both the consumption of leeks and the consumption of onions and/or shallots were inversely associated with the risk for colon cancer and for rectum cancer ${ }^{24}$. However, onion and leek consumption were not associated. with risk for colorectal cancer in Greece ${ }^{25}$. Only in one case-control study, in Japan, higher risks for colon and rectum cancer were observed with onion consumption ${ }^{26}$. Garlic consumption was associated with a lower rectum cancer risk in women in China, while nc association was found for rectum cancer in men, and also not for male or female colon cancer in this study ${ }^{27}$. To date, there has been no report examining associations between Allium vegetable consumption and colon and rectum cancer risk in a prospective study.

In 1986, the Netherlands Cohort Study (NLCS), a large-scale prospective cohort study on diet and cancer, was started among 120,852 men and women ${ }^{28}$. We have investigated the relation between onion and leek consumption, the use of garlic supplements and the risk of colon and rectum cancer after 3.3 years of follow-up.

\section{Methods}

\section{The Netherlands Cohort Study}

A description of the design of the NLCS and the characteristics of the cohort has been published ${ }^{28}$. In brief, the NLCS has been started in 1986 among 58,279 men and 62,573 women aged 55-69 years, originating from 204 municipalities in The Netherlands with 
computerized population registries. A self-administered mailed questionnaire was used to collect information on usual diet, lifestyle characteristics, medical history, dietary supplement use and other important risk factors for cancer. Accumulation of person-time in the cohort has been estimated by follow-up of a randomly selected subcohort of 1688 men and 1812 women.

\section{Identification of cases of colon and rectum cancer}

Information on cancer incidence has been collected for the entire cohort by record linkage with all nine cancer registries in The Netherlands and with PALGA, the Dutch network and National Database for Pathology. The method of record linkage has been published ${ }^{29}$. The present analysis is restricted to cancer incidence in the first 3.3 years of follow-up (from baseline in September 1986 to December 1989). Completeness of follow-up in this period is estimated to be $95 \%{ }^{30}$.

\section{Study population}

After excluding those subjects from the entire group of colon and rectum cancer cases, who reported any prevalent cancer other than skin cancer at baseline, and those with incident in situ carcinoma, colon and rectum cancer other than carcinoma (sarcoma, lymphoma, unspecified morphology), or without at least a microscopically confirmed diagnosis, 258 incident male and 220 incident female colon and rectum carcinoma cases were available for analysis. Of the subcohort, 1630 men and 1716 women without a previous history of cancer other than skin cancer were included.

\section{Questionnaire}

A 150-item semiquantitative food frequency questionnaire was used to collect information on the usual intake of foods and beverages in the year preceding the start of the study. Questionnaire data of all cases and subcohort members have been key-entered twice and processed blinded with respect to case/subcohort status to prevent random and systematic. coding errors ${ }^{31}$. Two of the questions on vegetable intake specifically focused on the consumption of Allium vegetables in the preceding year: ' How many onions did you usually eat per week?', and 'How often have you consumed leek in summer and how often in winter ?'. The latter question asked, for each season, to choose from one of six categories ranging from 'never or less than once per month' to '3-7 times per week', including leeks consumed in mixed vegetable dishes. A question on the consumption of other Allium vegetables (e.g. garlic, chives) was not included in the baseline questionnaire. The food and beverage part of the questionnaire has been validated against three 3 -day diet records ${ }^{31}$.

Information on type of dietary supplement, brand name, dose per day, as well as the specific period in which the consumption took place, could be listed in an open-ended question on dietary supplement use. Recal! of garlic supplement use was evaluated by comparing questionnaire data with information from three personal interviews as reference ${ }^{32}$.

\section{Data analysis}

For the analysis of onion and leek consumption, we used cases and subcohort members with dietary data that were considered as complete ${ }^{30}$. Subjects were categorized into four categories of onion consumption $(0, \leq 0.25,0.25-0.5$, and $\geq 0.5$ onions per day) and three. categories of leek consumption $(0, \leq 2$ and $>2$ times per month). In the first 3.3 years of follow-up, 150 colon (ICD-O topography code 153.0-9) and 93 rectosigmoid and rectum (ICD-O topography codes 154.0 and 154.1 ) carcinoma cases with complete dietary data were detected in male cohort members. Of all 150 malignant tumours in the colon, 65 originated in the proximal part (ICD-O topography codes 153.0-1, 153.4-6), 71 in the distal 
part (ICD-O topography codes $153.2-3$ and 153.7), 13 were unspecified (ICD-O topography code 153.9) and one had overlapping boundaries (ICD-O topography code 153.8$)^{33}$. Of the 143 female colon carcinoma cases with complete dietary data, 68 had a carcinoma in the proximal and 56 in the distal colon. Fifteen carcinomas were not specified and four had overlapping boundaries. In 57 women, the primary lesion was found in the rectosigmoid junction and rectum. Analyses of garlic supplement use are based on subjects with complete information on dietary supplement use. Garlic supplement users were defined as those subjects who reported daily use of any garlic supplement for at least one year in the five-year period before baseline. When garlic supplement users also took other dietary supplements in the same period, we separately examined the relation with colon and rectum carcinoma for users of exclusively garlic supplements with nonusers of dietary supplements as reference, and for those consuming garlic together with other supplements. For this analysis, subjects taking any other supplement were used as reference.

To determine whether onion and leek consumption, or the use of garlic supplements was associated with other potential risk factors for colon and rectum cancer, we compared for male and female subcohort members, the mean age, Quetelet index, alcohol intake, and dietary intake of vitamin $C$ or $\beta$-carotene between the categories of consumption. The dietary intake of vitamin $C$ and $\beta$-carotene was calculated by using the computerized Dutch food composition table ${ }^{34}$. The proportions of nonsmokers, subjects with a personal history of chronic intestinai disease or cholecystectomy, or with a family history of intestinal cancer and the proportion nulliparous women (for female subcohort members) were also compared between the exposure categories.

Case-cohort analyses were performed based on the assumption that survival times were exponentially distributed in this follow-up period ${ }^{30}$. In age-adjusted stratified analyses, we computed Mantel-Haenszel rate ratios and $95 \%$ confidence intervals for each category of onion and leek consumption and for garlic supplement use, and tests for trend in the rate ratios. In the multivariable analyses, we further adjusted for other covariables.

All $95 \%$ confidence intervals were corrected for the additional variance introduced by using a subcohort instead of the complete cohort. Tests for trend in the rate ratios were based on likelihood ratio tests. Separate analyses were conducted for male and female colon and rectum carcinoma. Since there is evidence of subsite-specific differences in colon cancer risk associated with vegetable consumption ${ }^{7.35}$, we also evaluated whether the role of onion and leek consumption differs or varies for proximal and distal colon cancer. To evaluate a potential influence of preclinical symptoms of large intestinal cancer on dietary habits, analyses were also performed for cases diagnosed after the first year of follow-up.

\section{Results}

In table 1, we present the distributions of onion and leek consumption and garlic supplement use in cases and subcohort. Male colon carcinoma cases consumed not as many onions as male subcohort members. The proportions of male rectum carcinoma cases, however, were both in the lowest as well as in the highest category of onion consumption smaller than in the subcohort. The proportions of the subjects consuming leeks more than twice per month were larger among male colon carcinoma cases and smaller among male rectum carcinoma cases than among subcohort members. The proportions of users of exclusively garlic supplements were larger in the two case groups, while only a small proportion of the male colon carcinoma cases took garlic supplements together with any other supplement.

In women, the proportions of cases in the lowest as well as in the highest onion consumption categories were larger than in the subcohort. The proportions of subjects in the highest leek consumption category were larger among female colon carcinoma cases and 
smaller among female rectum carcinoma cases than among female subcohort members. The proportions of users of garlic supplements without any other supplement were smaller among female cases than among subcohort members.

Table 1. Proportions of onion and leek consumption and garlic supplement use among male andi female colon and rectum carcinoma cases and among subcohort members ${ }^{a}$.

\begin{tabular}{|c|c|c|c|c|c|c|}
\hline \multirow[t]{2}{*}{ Allium consumption } & \multicolumn{3}{|c|}{ Men } & \multicolumn{3}{|c|}{ Women } \\
\hline & Colon & Rectum & Subcohort & Colon & Rectum & Subcohort \\
\hline & $(n=150)$ & $(n=93)$ & $(n=1525)$ & $(n=143)$ & $(n=57)$ & $(n=1598)$ \\
\hline
\end{tabular}

Onions (number/day)

$\begin{array}{lllllll}0 & 22.7 & 19.4 & 20.5 & 23.1 & 28.1 & 20.8 \\ <0.25 & 31.3 & 34.4 & 31.0 & 28.0 & 14.0 & 28.0 \\ 0.25-0.5 & 32.0 & 34.4 & 32.6 & 32.2 & 40.4 & 37.6 \\ >0.5 & 14.0 & 11.8 & 15.9 & 16.8 & 17.5 & 13.5\end{array}$

Leeks (freq/month)

\begin{tabular}{lllllll}
0 & 34.7 & 35.5 & 31.9 & 32.2 & 29.8 & 29.3 \\
$>2$ & 34.0 & 41.9 & 39.9 & 33.6 & 38.6 & 37.7 \\
\hline 2 & 31.3 & 22.6 & 28.2 & 34.3 & 31.6 & 32.9
\end{tabular}

Garlic supplement use ${ }^{b}$

$\begin{array}{lrrrrrr}\text { No } & 74.4 & 82.8 & 77.9 & 57.8 & 67.7 & 64.5 \\ \text { Exclusively garlic } & 6.4 & 7.1 & 4.1 & 3.9 & 3.1 & 5.0 \\ \text { Garlic + any other } & 1.9 & 0 & 3.2 & 7.8 & 4.6 & 5.1 \\ \text { Any other } & 17.3 & 10.1 & 14.8 & 30.5 & 24.6 & 25.3\end{array}$

a: Percentages are presented for the total population available for analysis as described in the methods section.

b: The categories of garlic supplement use are mutually exclusive.

Baseline characteristics of the population are presented in table 2. Compared with male subcohort members, male colon and rectum cancer cases were older at baseline. A higher percentage of male cases were ex-smokers, had a history of cholecystectomy or a family history of intestinal cancer. A higher proportion of subjects with chronic intestinal disease (e.g. Crohn's disease, colitis uicerosa) was seen in male colon carcinoma cases, and a lower proportion in rectum carcinoma cases. The distributions of educational level were nearly equal in cases and subcohort. 
Female colon and rectum carcinoma cases were older than subcohort members. Furthermore, higher percentages of cases had a history of chronic intestinal disease or cholecystectomy. The percentage of female subjects with a family history of intestinal cancer was nearly twice as high in colon carcinoma cases as in the subcohort, whereas the percentages in rectum carcinoma cases and subcohort were nearly equal. The distributions of female cases according to smoking status, educational level and parity were somewhat different from those in the subcohort.

Table 2. Distribution (\%) of male and female colon and rectum carcinoma cases and subcohort members with complete dietary data, by selected baseline characteristics.

\begin{tabular}{|c|c|c|c|c|c|c|}
\hline \multirow[t]{2}{*}{ Characteristics } & \multicolumn{3}{|c|}{ Men } & \multicolumn{3}{|c|}{ Women } \\
\hline & $\begin{array}{c}\text { Colon } \\
n=150\end{array}$ & $\begin{array}{c}\text { Rectum } \\
n=93\end{array}$ & $\begin{array}{l}\text { Subcohort } \\
n=1525\end{array}$ & $\begin{array}{c}\text { Colon } \\
n=143\end{array}$ & $\begin{array}{c}\text { Rectum } \\
n=57\end{array}$ & $\begin{array}{c}\text { Subcoho } \\
n=159\end{array}$ \\
\hline \multicolumn{7}{|l|}{ Age (years) } \\
\hline 55-59 & 24.7 & 25.8 & 38.2 & 27.3 & 21.1 & 38.5 \\
\hline $60-64$ & 40.7 & 45.2 & 35.0 & 36.4 & 38.6 & 34.3 \\
\hline $65-69$ & 34.7 & 29.0 & 26.8 & 36.4 & 40.0 & 27.2 \\
\hline
\end{tabular}

Smoking status

Never

Ex-smoker

Current smoker
8.0

56.0

36.0

Previous history of

Chronic intestinal disease

Cholecystectomy

Intestinal cancer in family

Highest educational level

Primary school

Lower vocational

Second./medium yoc.

University/higher voc.

$\begin{array}{lll}4.0 & 2.2 & 3.1 \\ 9.3 & 7.5 & 5.4 \\ 6.7 & 9.7 & 5.3\end{array}$

9.6

58.0

63.2

59.0

58.1

48.4

23.1

15.8

20.2

42.0

18.9

21.1

20.8

33.3

18.9

7.0

5.3

4.6

21.0

19.3

14.6

9.1

5.3

5.4

Parity

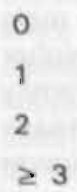

$\begin{array}{lll}22.8 & 25.8 & 25.9 \\ 20.8 & 19.4 & 21.2 \\ 36.2 & 36.7 & 35.0 \\ 20.1 & 17.2 & 17.9\end{array}$

33.8

28.1

34.0

$21.1 \quad 31.6$

22.8

$33.8 \quad 29.8$

34.7

$11.3 \quad 10.5$

8.5

0

1

2

$20.4 \quad 15.8$

17.5

$9.9 \quad 12.3$

8.2

26.8

28.1

22.0

43.0

43.9 
Associations between onion and leek consumption and potential confounders are presented in table 3, for male and female subcohort members in the lowest and highest consumption categories. Associations between garlic supplements use and other risk factors are presented for those not using dietary supplements and for those using garlic supplements with or without any other supplement. In men, the mean ages were slightly higher in the lowest onion and leek consumption categories than in the highest categories. No differences in the mean Quetelet index were observed, whereas the mean alcohol intake was lowest in the lowest consumption categories and the mean vitamin $C$ and $\beta$-carotene intakes highest in the highest consumption categories. Both in the lowest onion and leek consumption categories, a higher proportion of nonsmokers and subjects with a history of chronic intestinal disease or cholecystectomy was observed. The proportion of male subcohort members with a family history of intestinal cancer was higher in those not consuming onions, and lower in those not eating leeks. The mean age, Quetelet index and alcohol intake were nearly identical in male garlic supplement users and nonusers of dietary supplements. Compared with nonusers of dietary supplements, higher mean intakes of vitamin $C$ and $\beta$ carotene, higher proportions of nonsmokers and subjects with a family history of intestinal cancer, and lower proportions of those with a history of chronic intestinal disease or cholecystectomy, were found in male garlic supplement users. In women, a higher mean age and a lower mean alcohol intake were seen in the lowest onion and leek consumption category. The mean vitamin $\mathrm{C}$ and $\beta$-carotene intakes were higher in highest consumption categories. A higher percentage of nonsmokers, women with a history of chronic intestinal disease or cholecystectomy, or without children was seen in lowest consumption categories. The percentages of women with a family history of intestinal cancer were lower in the lowest consumption categories. In female garlic supplement users a higher mean Quetelet index, mean vitamin $C$ and $\beta$-carotene intake, and percentage of women with a history of cholecystectomy was seen, compared with nonusers of dietary supplements, and a lower proportion of nonsmokers, female subcohort members with a family history of intestinal cancer, or without children.

Table 4 presents rate ratios (RR) and $95 \%$ confidence intervals ( $\mathrm{Cl}$ ) of male colon and rectum carcinoma associated with onion and leek consumption, controlled for age in stratified analysis and further controlled for other variables in multivariable analysis. A decreasing colon carcinoma risk was observed with increasing onion consumption. The RR in the highest onion intake category was $0.87(95 \% \mathrm{Cl} \mathrm{0.48-1.65)}$. RRs for carcinoma in the proximal colon were lower than for carcinoma in the entire colon, except for the RR in the highest consumption category. All RRs for distai colon carcinoma were higher than one, but none, of them significantly. The RR for rectum carcinoma associated with onion consumption was lower than one in the highest category $(R R=0.66,95 \% \mathrm{Cl} 0.28-1.52)$. None of the RRs for colon carcinoma associated with leek consumption were significantly different from unity. The RFs for rectum carcinoma were lower in higher leek consumption categaries. None of the RRs for rectum carcinoma with each consumption category and none of the tests for trend were statistically significant. In women, the Mantel-Haenszel RR for colon carcinoma was higher than one in the highest onion consumption category (Table 5). When all other risk factors were included in the model, the RR increased to 1.49 (95\% $\mathrm{Cl} 0.79-2.81)$. The highest RRs were found for carcinama in the distal colon (RR 1.78, 95\% $\mathrm{Cl} 0.68-4.64$ in the highest onion consumption category). The RR for rectum carcinoma associated with onion consumption was higher than one in the highest intake category, but lower than one in the categary ${ }^{\prime}<0.25$ onions per day' $(\mathrm{RR}=0.36,95 \% \mathrm{Cl} 0.13-0.99)$. Leek consumption was not associated with female colon or rectum carcinoma. None of the RRs were significantly different from unity and none of the tests for trend were statistically significant. 
Table 3. Associations between onion and leek consumption, garlic supplement use and potential confounders in male and female subcohort members.

\begin{tabular}{|c|c|c|c|}
\hline \multirow[t]{2}{*}{ Characteristics } & 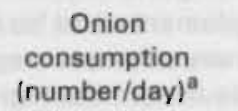 & $\begin{array}{l}\text { Leek consumption } \\
\text { (freq/month) }{ }^{a}\end{array}$ & $\begin{array}{c}\text { Garlic supplement } \\
\text { use }\end{array}$ \\
\hline & $0 \quad \geq 0.5$ & $>2$ & No suppl. \\
\hline
\end{tabular}

Men

Age (mean years)

61.5

61.1

61.6

61.4

61.2

62.3

Quetelet Index (mean $\mathrm{kg} / \mathrm{m}^{2}$ )

$25.1 \quad 25.3$

$25.1 \quad 25.0$

$25.1 \quad 25.2$

Alcohol (mean g/day)

$11.7 \quad 20.3$

13.6

15.7

$14.1 \quad 14.2$

Vitamin C (mean mg/day)

$85.6 \quad 116.9$

$93.3 \quad 106.9$

$89.4 \quad 112.1$

$\beta$-carotene (mean $\mathrm{mg}$ Eq vit A)

0.36

0.37

0.41

0.30

0.42

Never smoking (\%)

13.4

9.1

9.1

7.9

$9.5 \quad 10.2$

Chron. intest. disease (\%)

$6.1 \quad 2.1$

4.7

2.6

2.4

1.7

Cholecystectomy (\%)

$5.4 \quad 2.9$

4.9

3.5

5.6

3.4

Intest. cancer in family (\%)

$6.7 \quad 4.5$

5.1

6.0

5.0

6.8

Women

Age (mean years)

$61.9 \quad 61.4$

61.8

61.1

61.5

61.5

Quetelet Index (mean $\mathrm{kg} / \mathrm{m}^{2}$ )

$25.2 \quad 25.1$

$25.3 \quad 25.2$

25.4

25.7

Alcohol (mean g/day)

4.3

8.4

4.8

6.4

5.4

5.5

Vitamin C (mean mg/day)

$100.7 \quad 123.8$

$99.7 \quad 119.2$

$96.1 \quad 112.9$

$\beta$-carotene (mean $\mathrm{mg} E q$ vit $\mathrm{A}$ )

0.38

0.51

0.37

0.50

0.30

0.41

Never smoking (\%)

$65.2 \quad 52.3$

$60.6 \quad 59.9$

$61.4 \quad 58.6$

Chron. intest. disease (\%)

7.5

3.2

5.5

3.8

3.3

3.4

Cholecystectomy (\%)

$13.2 \quad 12.5$

$14.3 \quad 12.7$

12.9

15.5

Intest. cancer in family (\%)

5.1

6.5

4.3

5.5

5.3

4.6

Nulliparous (\%)

$20.2 \quad 18.8$

$19.1 \quad 17.8$

16.6

11.7

a: The proportions and means are shown for the lowest and highest consumption categories.

b: Users of garlic supplements with or without any other dietary supplement. 
Table 4. Rate ratios and $95 \%$ confidence intervals of male colon and rectum carcinoma according to onion and leek consumption, in stratified ${ }^{2}$ and multivariablet analysis.

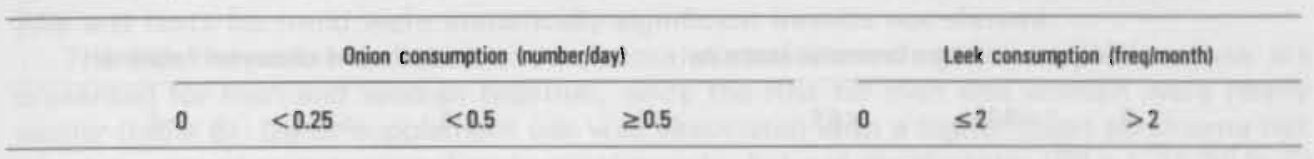

Coion

$\begin{array}{lllll}\text { PY in subcohort } & 1007 & 1521 & 1597 & 768 \\ \text { No. of cases } & 34 & 47 & 48 & 21 \\ \text { RR }_{\text {We }}(95 \% \text { CI) } & 1.00 \dagger & 0.92(0.58 \cdot 1.46) & 0.89(0.56 \cdot 1.41) & 0.81(0.46 \cdot 1.43) \\ \text { RR (95\% CI) } & 1.00 t & 1.01(0.62 \cdot 1.64) & 0.97(0.59 \cdot 1.59) & 0.87(0.48-1.65)\end{array}$

$$
\text { Trend test } x^{2}-0.53(p-0.47)
$$

$\begin{array}{lll}1568 & 1946 & 1379 \\ 52 & 51 & 47 \\ 1.00 t & 0.79(0.53-1.18) & 1.03(0.68-1.56) \\ 1.00 t & 0.77(0.50-1.17) & 1.10(0.71-1.70) \\ & & \text { Trend test } x^{i}=0.006(p-0.94)\end{array}$

Proximal colon

$\begin{array}{lllll}\text { No. of cases } & 17 & 22 & 17 & 9 \\ \text { RR }_{\text {Men }} \text { (95\% CI) } & 1.00 t & 0.88(0.46 \cdot 1.68) & 0.63(0.32-1.26) & 0.86(0.40 \cdot 1.85) \\ \text { RR (95\% CI) } & 1.00 t & 0.97(0.49 \cdot 1.93) & 0.67(0.31-1.43) & 0.93(0.39-2.23)\end{array}$

$$
\text { Trend test } x^{2}-0.43(p-0.51)
$$

Distal colon

$\begin{array}{lllll}\text { No. of cases } & 13 & 21 & 26 & 11 \\ \text { RR }_{\text {Ma }}(95 \% \text { Cl) } & 1.00 t & 1.12(0.55-2.26) & 1.23(0.62 .2 .44) & 1.16(0.51-2.64) \\ \text { AR (95\% Cl) } & 1.00 t & 1.29(0.61-2.71) & 1.48(0.71 \cdot 3.09) & 1.47(0.61-3.53) \\ & & & \text { Trend test } x^{2}-1.07(p-0.30)\end{array}$

\begin{tabular}{|c|c|c|c|c|}
\hline PY in subcohort & 1007 & 1522 & 1595 & 772 \\
\hline No. of cases & 18 & 32 & 32 & 11 \\
\hline $\mathrm{RR}_{\operatorname{Man}}(95 \% \mathrm{Cl})$ & $1.00 t$ & $1.19(0.65-2.17)$ & $1.11(0.61 \cdot 2.01)$ & $0.81(0.37 \cdot 1.77)$ \\
\hline RR $(95 \%$ CI $)$ & $1.00 \%$ & $1.12(0.61-2.08)$ & $0.99(0.53 \cdot 1.85)$ & $0.66(0.28) 1.52)$ \\
\hline
\end{tabular}

Rectum

$\begin{array}{lll}20 & 24 & 21 \\ 1.00 t & 0.98(0.54-1.78) & 1.18(0.63-2.20) \\ 1.00 t \quad 0.88(0.46-1.66) & 1.32(0.67-2.54) \\ & & \text { Trend test } x^{2}=0.70(p=0.40)\end{array}$

$\begin{array}{lll}25 & 24 & 22 \\ 1.00 t & 0.80(0.45-1.41) & 0.97(0.54-1.73) \\ 1.00 t & 0.84(0.47-1.50) & 0.97(0.52-1.82) \\ & & \text { Trend test } x^{2}=0.02(p-0.89)\end{array}$

$\begin{array}{lll}1570 & 1946 & 1379 \\ 33 & 39 & 21 \\ 1.00 t & 0.97(0.60-1.57) & 0.73(0.42-1.29) \\ 1.00+ & 0.99(0.60-1.63) & 0.72(0.40-1.30) \\ & & \text { Trend test } x^{2}=1.18(p-0.28)\end{array}$

a. Stratified by age in three categories: $55-59,60-64,65-69$ years.

b: Adjusted for age, Quetelet index, alcohol intake, vitamin $\mathrm{C}$ and $\beta$-carotene as continuous variables, and smoking status, education, family history of large intestinal cancer, history of cholecystectomy and chronic intestinal disease as categorical variables.

c: PY: Persons years in the subcohort.

t: Reference category. 
Table 5. Rate ratios and $95 \%$ confidence intervals of female colon and rectum carcinoma according to onion and leek consumption, in stratified ${ }^{3}$ and multivariable analysis.

\begin{tabular}{|c|c|c|c|c|c|c|}
\hline \multicolumn{4}{|c|}{ Onion consumption (numberiday) } & \multicolumn{3}{|c|}{ Leek consumption (freq/month) } \\
\hline 0 & $<0.25$ & $<0.5$ & $\geq 0.5$ & 0 & $\leq 2$ & $>2$ \\
\hline
\end{tabular}

Colon

\begin{tabular}{|c|c|c|c|c|c|c|c|}
\hline PY in subcohort ${ }^{t}$ & 1081 & 1458 & 1960 & 698 & 1521 & 1958 & 1715 \\
\hline No. of cases & 33 & 40 & 46 & 24 & 46 & 48 & 49 \\
\hline $\mathrm{RR}_{\mathrm{Me}}(95 \% \mathrm{Cl})$ & $1.00 t$ & $0.91(0.56-1.49)$ & $0.81(0.50-1.31)$ & $1.13(0.65 \cdot 1.97)$ & $1.00 t$ & $0.82(0.54-1.25)$ & $0.99(0.65-1.52)$ \\
\hline BR $(85 \% \mathrm{Cl})$ & $1.00 t$ & $1.21(0.70-2.09)$ & $1.11(0.65-1.90)$ & $1.49(0.79-2.81)$ & $1.00 t$ & $0.91(0.57-1.45)$ & $1.18(0.73-1.89)$ \\
\hline
\end{tabular}

Trend test $x^{2}-0.97(0-0.32)$

Trend test $x^{2}=0.55(p=0.46)$

Proximal colon

\begin{tabular}{|c|c|c|c|c|c|c|c|}
\hline No. of cases & 16 & 19 & 20 & 13 & 22 & 20 & 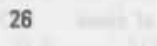 \\
\hline $\mathrm{RH}_{\mathrm{wa}}(95 \% \mathrm{Cl})$ & $1.00 t$ & $0.83(0.42 \cdot 1.65)$ & $0.72(0.36-1.41)$ & $1.19(0.56-2.51)$ & $1.00 t$ & $0.65(0.36 \cdot 1.19)$ & $1.02(0.57-1.80)$ \\
\hline RR (95\% Cl) & $1.00 t$ & $1.09(0.50-2.36)$ & $1.05(0.49 .2 .23)$ & $1.50(0.62 .3 .60)$ & $1.00 t$ & $0.77(0.39-1.53)$ & $1.28(0.67-2.46)$ \\
\hline
\end{tabular}

Distal colon

\begin{tabular}{|c|c|c|c|c|c|c|c|}
\hline No. of cases & 10 & 15 & 21 & 10 & 15 & 25 & 16 \\
\hline $\mathrm{RR}_{\mathrm{Me}}(95 \% \mathrm{Cl})$ & $1.00 t$ & $1.02(0.47 \cdot 2.21)$ & $1.07(0.52-2.20)$ & $1.31(0.56 \cdot 3.08)$ & $1.00 t$ & $1.33(0.71 \cdot 2.50)$ & $0.99(0.50-1.97)$ \\
\hline RR (95\% Cl) & $1.00 t$ & $1.21(0.51-2.84)$ & $1.27(0.56-2.91)$ & $1.78(0.68-4.64)$ & $1.00 t$ & $1.25(0.63-2.46)$ & $0.98(0.46 \cdot 2.10)$ \\
\hline
\end{tabular}

Rectum

\begin{tabular}{|c|c|c|c|c|c|c|c|}
\hline PY in subcohort & 1083 & 1457 & 1960 & 698 & 1525 & 1957 & 1716 \\
\hline No. of cases & 16 & - & 23 & 10 & 17 & 22 & 18 \\
\hline $\mathrm{RR}_{\mathrm{am}}$ (95S Cl) & $1.00 t$ & $0.39(0.16-0.94)$ & $0.87(0.45-1.68)$ & $1.00(0.44 .2 .25)$ & $1.00 t$ & $1.03(0.54-1.96)$ & $0.99\{(0.50-1.98)$ \\
\hline RR $(95 \$$ C1) & $1.00 t$ & $0.36,(0.13-0.99)$ & $1.00(0.47 \cdot 2.12)$ & $1.34(0.55-3.31)$ & $1.00 t$ & $1.18(0.56-2.50)$ & $1.31(0.60-2.85)$ \\
\hline
\end{tabular}

a: Stratified by age in three categories: 55-59, 60-64, 65-69 years.

b: Adjusted for age, Quetelet index, alcohol intake, vitamin $C$ and $\beta$-carotene as continuous variables, and smoking status, education, family history of large intestinal cancer, history of cholecystectomy and chronic intestinal disease as categorical variables.

c: PY: Persons years in the subcohort.

t: Reference category. 
All analyses have also been carried out for those cases diagnosed after the first year of follow-up. All RRs were nearly similar to those found for the entire case group. None of the RRs and tests for trend were statistically significant (results not shown).

The RRs for colon and rectum carcinoma associated with garlic supplement use are presented for men and women together, since the RRs for men and women were nearly similar (table 6). Garlic supplement use was associated with a higher colon carcinoma risk when compared to not using dietary supplements, but not significantly $\{R R=1.2695 \% \mathrm{C} \mid$ 0.84-1.91). When cases using other dietary supplements were excluded, the RR of colon carcinoma increased to $1.36(95 \% \mathrm{Cl} 0.79-2.35)$. We observed a slightly lower risk for colon carcinoma with the use of garlic supplements together with other supplements: $R R=0.93$ (95\% $\mathrm{Cl}$ 0.51-1.71). The RR for rectum carcinoma associated with use of garlic supplements was lower than one (RR $=0.77,95 \% \mathrm{Cl} 0.41-1.46)$, but when users of other supplements than garlic were excluded the RR was higher than one (RR=1.28 95\% Cl 0.63-2.60). None of the RRs were significantly different from unity. The number of rectum carcinoma cases using garlic supplements together with other supplements was too low to provide meaningful estimates.

Table 6. Rate ratios and $95 \%$ confidence intervals of colon and rectum carcinoma according to garlic supplement use, in stratified ${ }^{a}$ and multivariable ${ }^{\mathrm{b}}$ analysis.

Garlic vs. no supplement

Garlic vs. any other supplement

No Garlic supplements Exclusively garlic Any other Garlic + any other other"

Colon

$\begin{array}{llllll}\text { No. of cases } & 205 & 31 & 16 & 94 & 15 \\ \text { PY in subcohort } & 7270 & 937 & 488 & 2178 & 449 \\ \text { RR }_{\text {MH }}(95 \% \text { CI) } & 1.00 t & 1.21(0.81 \cdot 1.80) & 1.20(0.70-2.05) & 1.00 \dagger & 0.93(0.53-1.63) \\ \text { RR }(95 \% \text { CI) } & 1.00 \dagger & 1.26(0.84-1.91) & 1.36(0.79-2.35) & 1.00 \dagger & 0.93(0.51-1.71)\end{array}$

Rectum

$\begin{array}{llllll}\text { No. of cases } & 126 & 12 & 9 & 16 & 3 \\ \text { PY in subcohort } & 7672 & 565 & 490 & 1406 & 283 \\ \text { RR }_{\text {MH }} \text { (95\% CI) } & 1.00 \dagger & 0.80(0.43 \cdot 1.47) & 1.16(0.57-2.34) & & \\ \text { RR }(95 \% \text { CI) } & 1.00 \dagger & 0.77(0.41-1.46) & 1.28(0.63-2.60) & & \end{array}$

a: Stratified by gender and age in three categories: 55.59, 60.64 and $65-69$ years.

b: Adjusted for age, vitamin C and $\beta$-carotene as continuous variables, and gender, smoking status, education, family history of intestinal cancer, previous history of chronic intestinal disease or cholecystectomy as categorical variables.

c: PY: Persons years in the subcahort.

d: The distributions of 'any other dietary supplements', mentioned by colon carcinoma cases and subcohort members, were: vitamin AD $11.7 \%$ and $8.7 \%$; vitamin B $26.2 \%$ and $22.2 \%$; vitamin $\mathcal{C} 17.5 \%$ and $18.2 \%$; vitamin $E$. $5.8 \%$ and $5.2 \%$; multivitamins/minerals 8.8 and $13.6 \%$; calcium $7.8 \%$ and $9.6 \%$; brewer's yeast $4.9 \%$ and $7.5 \%$.

e: Other supplements used rogether with garlic supplements by colon carcinoma cases and subcohort members, were: vitamin $\mathrm{AO} \quad 4.5 \%$ and $4.2 \%$; vitamin $\mathrm{B} \quad 11.4 \%$ and $8.9 \%$; vitamin $\mathrm{C} 4.5 \%$ and $9.4 \%$; vitamin $\mathrm{E} 2.3 \%$ and $3.0 \%$; multivitamins/minerals $2.3 \%$ and $6.4 \%$; catcium $11.4 \%$ and $6.1 \%$; brewer's yeast $9.8 \%$ and $8.3 \%$.

t: Reference category. 


\section{Discussion}

In the Netherlands Cohort Study, we have found no evidence of an inverse association between the consumption of onions and leeks, the use of garlic supplements, and the incidence of colon and rectum carcinoma in men and women. We also found no evidence for a lower risk of carcinoma in the proximal and distal part of the colon, or for cases diagnosed after the first year of follow-up.

Our results do not support the findings from a number of case-control studies of Allium vegetable consumption and colon and rectum cancer risk. Of the eight case-control studies that investigated the association with Allium vegetables as individual food group, six reported an inverse association with colon and rectum cancer ${ }^{7.21-25}$. In the most recently published case-control study, by Steinmetz and Potter, the consumption of onions was associated with the lowest colon adenocarcinoma risk of all vegetable groups. In women, all odds ratios (OR) in increasing quartiles of consumption were significantly below unit $(1.00,0.39,0.38,0.42$, after controlling for protein intake, age at first live birth, Quetelet index and alcohol intake). In men, a stronger inverse association was observed for proximal colon (protein-adjusted $\mathrm{OR}=0.23$, with $95 \% \mathrm{Cl} 0.07-0.83$ in the highest quartile of consumption), than for distal colon cancer ${ }^{2}$. One study reported no association between onion and leek consumption and colorectal cancer ${ }^{25}$, and one showed a positive association between onion consumption and colon and rectum cancer ${ }^{26}$. However, this higher risk may have been caused by the selection of hospital patients with severe gastric and intestinal disorders as controls. Patients suffering from gastric complaints may have avoided the consumption of Allium vegetables. In the other studies that used hospital controls, patients with orthopaedic diseases ${ }^{25}$ or any other diseases except gastrointestinal disorders ${ }^{21,22,27}$ were selected. In the case-control studies by Tuyns ${ }^{24}$ and Steinmetz and Potter ${ }^{7}$ population controls were selected, while Graham et al. selected neighbourhood controls ${ }^{23}$.

A potential problem in prospective cohort studies is the possibility of selection bias if there is exposure-related loss to follow-up ${ }^{39}$. In the NLCS, however, selection bias is unlikely since the completeness of follow-up of cancer incidence was estimated at $95 \%{ }^{30}$. One of the potential limitations of our study is that we are not entirely sure that the absence of a relation between onion and leek consumption and colon and rectum carcinoma risk has not been caused by nondifferential misclassification of exposure. Although the validity of the semiquantitative food frequency questionnaire has been assessed for food groups, information on its validity regarding onion and leek consumption is not available ${ }^{31}$. Recall of garlic supplement use was $77.8 \%$, which may provide enough precision to classify individuals into distinctive categories of intake ${ }^{32}$. Unfortunately, we did not inquire after the consumption of other Allium vegetables, such as fresh garlic, in the baseline questionnaire. However, in a later version of the questionnaire that was completed by members of the subcohort in 1990 , only $1.8 \%$ of the men and $1.4 \%$ of the women reported daily consumption of fresh garlic. The proportions of garlic supplement users at baseline were much higher: $7.3 \%$ of the male and $10.1 \%$ female subcohort members took at least one garlic supplement per day. We included many other, nondietary as well as dietary, determinants of colon and rectum carcinoma as potential confounders in the multivariable models. However, it might still be possible that another factor than we controlled for in our analysis, might be involved. Regarding the published studies, only in the study by Steinmetz and Potter ${ }^{7}$, adjustment was made for other variables than age, gender or place of residence.

Another reason for finding no association between onion and leek consumption, garlic supplement use and incidence of colon and rectum carcinoma in our study, could be that the contrasts between the highest and lowest consumption categories within our study population, or the level of intake of potentially anticarcinogenic compounds from Allium 
vegetables, are not high enough to detect an association. It has been shown that the amount of potentially anticarcinogenic compounds in Allium vegetables depends on variety, growing conditions, storage and preparation methods ${ }^{36-38}$. However, since in some of the case-control studies contrasts between the comparison groups were simply yes/no ${ }^{24,27}$, high/low ${ }^{21,22}$, or not specified ${ }^{23,25}$, it is not clear whether the consumption levels differ between the study populations. In two studies, cases and controls were categorized in quantiles, with low frequency of consumption as reference category ${ }^{7,26}$.

In contrast with retrospective case-control studies, prospective cohort studies are considered not to be biased by differential recall of past dietary intake due to awareness of the disease status ${ }^{39}$. However, it is not very likely that this type of recall bias is accountable for the difference between results from case-control studies and our prospective cohort study, since differential recall of Allium vegetable intake by cases and controls leads to the observed inverse associations only if cases recall their consumption not as frequently or accurately as controls. Nevertheless, cases and controls might have recalled their past dietary intake differently, when their recall was influenced by current dietary habits ${ }^{40}$.

Also, the difficulty to measure exposure in the relevant period is a plausible explanation. Dietary habits might have been changed by vague or nonspecific symptoms prior to the diagnosis of cancer. Only in the study by Steinmetz and Potter, the investigators tried to eliminate a potential influence of disease symptoms on dietary intake. Subjects were asked to report their diet 12 months before the interview, if they had made recent dietary changes (in $26 \%$ of the cases and $13 \%$ of the controls) ${ }^{?}$. Although in some of the other case-control studies the investigators specifically asked information on dietary habits before the onset of disease $24,25,27$, it is not clear whether the cases were able to remember the exact time of onset of symptoms associated with the disease. In the study by Tajima and Tominaga, dietary habits one or two years before visiting the hospital were asked, disregarding the time between interview and the diagnosis of cancer ${ }^{26}$. Haenszel et al $^{21}$ did not specify the time reference, and Graham et al $^{23}$ measured current diet. In the NLCS, we have examined the possibility of an effect of preclinical symptoms on dietary habits by excluding cases diagnosed in the first year of follow-up. The RRs were practically similar to those observed for the entire follow-up period.

In conclusion, we found no evidence of an association between onion and leek consumption, the use of garlic supplements and the incidence of male and female colon and rectum carcinoma.

\section{References}

1. Tomatis L. (ed). Cancer. causes, occurrence and control. IARC Scientific Publication No. 100. Lyon: International Agency for Research on cancer, 1990.

2. Willett $W$. The search for the causes of breast and colon cancer. Nature. 1989;338:389-394.

3. Trock B, Lanza E, Greenwald P. Dietary fiber, vegetables, and colon cancer: critical review and meta-analysis of the epidemiologic evidence. JNCl 1990;82:650-661.

4. Miller AB. Diet and cancer. A review. Rev Oncol 1990;3:87-95.

5. Steinmetz K, Potter JD. Vegetables, fruit, and cancer. I. Epidemiology. Cancer Causes Control $1991 ; 2: 325-357$.

6. Block G. Patterson B, Subar A. Fruit, vegetables, and cancer prevention: a review of the epidemiological evidence. Nutr Cancer 1992;18:1-29.

7. Steinmetz K, Potter JD. Food group consumption and colon cancer in the Adelaide case-control study. I. Vegetables and fruit. Int J Cancer 1993;53:711-7.19.

8. Dorant E, Van den Brandt PA. Goldbohm RA, Hermus RJJ, Sturmans F. Garlic and its significance for the prevention of cancer in humans: a critical view. Br J Cancer 1993;67:424429.

9. Reddy BS, Rao CV, Rivenson A, Kelloff G. Chemoprevention of colon carcinogenesis by organosulfur compounds. Cancer Res 1993:53:3493-3498. 
10. Lawson LD, Wang ZYJ, Hughes BG. Identification and HPLC Quantification of the sulfides and dialk(en)yl thiosulfinates in commercial garlic products. Planta Med 1991;57:363-370.

11. Dorant E, Van den Brandt PA, Hamstra AM, Feenstra MH, Goldbohm RA, Hermus RJJ, Sturmans F. The use of vitamins, minerals and other dietary supplements in The Netherlands. Int J Vit Nutr Res 1993;63:4-10.

12. Hertog MGL, Hollman PCH, Katan MB, Kromhout D. Intake of potentially anticarcinogenic flavonoids and their determinants in adults in The Netherlands. Nutr Cancer 1993;20:21-29.

13. Starke H, Herrmann K Flavonols and flavones of vegetables, VII. Flavonols of leek, chive and garlic. Z Lebensm Unters Forsch 1976;161:25-30.

14. Hertog MGL, Hollman $\mathrm{CH}$, Katan MB. Content of potentially anticarcinogenic flavonoids of 28 vegetables and 9 fruits commonly consumed in The Netherlands. J Agric Food Chem 1992; $40: 2379-2383$.

15. Jones DP, Coates RJ, Flagg EW, Eley JW, Block G, Greenberg RS, Gunter EW, Jackson B. Glutathione in foods listed in the National Cancer Institute's Health Habits and History Food Frequency Questionnaire. Nutr Cancer 1992;17:57-75.

16. Wattenberg LW. Chemoprevention of cancer. Cancer Res 1985;45:1-8.

17. Newmark HL. Plant phenolics as inhibitors of mutational and precarcinogenic events. Can J Physiol Pharmacol 1987;65:461-466.

18. Coles B, Ketterer B. The role of glutathione and glutathione transferases in chemical carcinogenesis. Crit Rev Biochem Mol Biol 1990;25:47-70.

19. Steinmetz K, Potter JD. Vegetables, fruit, and cancer. II. Mechanisms. Cancer Causes Control $1991: 2: 427-442$.

20. Morse MA, Stoner GD. Cancer chemoprevention: principles and prospects. Carcinogenesis 1993;14:1737-1746.

21. Haenszel W, Locke FB, Segi M. A case-control study of large bowel cancer in Japan. JNCI 1980;64:17-22.

22. Haenszel W, Berg JW, Segi M, Kurihara M, Locke F. Large-bowel cancer in Hawaiian Japanese. JNCl 1973;51:1765-1779.

23. Graham S, Marshall J, Haughey B, Mittelman A, Swanson M, Zielezny M, Byers T, Wilkinson G, West D. Dietary epidemiology of cancer of the colon in western New York. Am J Epidemiol 1988;128:490-503.

24. Tuyns AJ, Kaaks R, Haelterman $\mathbf{M}$. Colorectal cancer and the consumption of foods: a casecontrol study in Belbium. Nutr Cancer 1988;11:189-204.

25. Manousos O, Day NE, Trichopoulos D, Gerovassilis F, Tzonou A, Polychronopoulou A. Diet and colorectal cancer: a case-control study in Greece. Int J Cancer 1983;32:1-5.

26. Tajima K, Tominaga S. Dietary habits and gastro-intestinal cancers: a comparative case-control study of stomach and large intestinal cancers in Nagoya, Japan. Jpn J Cancer Res 1985:76:705716.

27. Hu J, Liu $Y, Y u Y$, Zhao $T$, Liu S, Wang $Q$. Diet and cancer of the colon and rectum: a casecontrol study in China. Int J Epidemiol 1991;20:362-367.

28. Van den Brandt PA, Goldbohm RÂ, Van't Veer P, Volovics A, Hermus RJJ, Sturmans F. A largescale prospective cohort study on diet and cancer in The Netherlands. J Clin Epidemiol 1990; 43:285-295.

29. Van den Brandt PA, Schouten LJ, Goldbohm RA, Dorant E, Hunen PMH. Development of a record linkage protocol for use in the Dutch Cancer registry for epidemiological research. Int J Epidemiol 1990; 19:553-558.

30. Van den Brandt PA, Van 't Veer P, Goldbohm RA, Dorant E, Volovics A, Hermus RJJ, Sturmans F. A prospective cohort study on dietary fat and the risk of postmenopausal breast cancer. Cancer Res 1993;53:75-82.

31. Goldbohm RA, Van den Brandt PA, Brants HAM, Van ' $t$ Veer P, Al M, Sturmans F, Hermus RJJ. Validation of a dietary questionnaire used in a large-scale prospective cohort study on diet and cancer. Eur J Clin Nutr 1994;48:253-265.

32. Dorant E, Van den Brandt PA, Goldbohm RA, Hermus RJJ, Sturmans, F. Agreement between interview data and a self-administered questionnaire on dietary supplement use. Eur $\mathrm{J}$ Clin Nutr, 1994; $48: 180-188$.

33. International Classification of diseases for Oncology. First edition. Geneva: World health Organization, 1976.

34. Stichting NEVO. NEVO table; Dutch food composition table 1986-1987. The Hague, Netherlands: Voorlichtingsbureau voor de Voeding, 1986. 
35. Peters RK, Garabrant DH, Yu MC, Mack TM. A case-control study of occupational and dietary factors in colorectal cancer in young men by subsite. Cancer Res 1989;49,5459-5468.

36. Block $E$. The organosulfur chemistry of the Genus Allium - Implications for the organic chemistry of sulfur. Angew Chem Int Ed Engl 1992;31:1135-1178.

37. Herrmann K. Flavonols and flavones in food plants: a review. J Food Technol 1976;11:433-448.

38. Bilyk A, Sapers GM. Distribution of quercetin and kaempferol in lettuce, kale, chive, garlic chive, leek, horseradish, red radish, and red cabbage tissues. J Agric Food Chem 1985;33:226-228.

39. Rothman KJ. Modern epidemiology. Boston: Little, Brown and Company, 1986.

40. Moller Jensen O, Wahrendorf J, Rosenqvist A, Geser A. The reliability of qeustionnaire-derived historical dietary information and temporal stability of food habits in individuals. Am J Epidemial $1984 ; 120: 281-290$. 


\title{
Chapter 8
}

\section{Consumption of onions and a reduced risk of stomach carcinoma}

Elisabeth Dorant; R. Alexandra Goldbohm; Ferd Sturmans; Piet A. van den Brandt

\begin{abstract}
Results from case-control studies indicate that consumption of Allium vegetables (onions, leek and garlic) may reduce the risk for stomach cancer considerably.

The association between onion and leek consumption, garlic supplement use and the incidence of stomach carcinoma was investigated in the Netherlands Cohort Study, a large-scale prospective study on diet and cancer, that started in 1986 among 120,852 men and women aged 55-69. Dietary data, collected with a self-administered food frequency questionnaire, were available for 139 stomach carcinoma cases who were diagnosed during 3.3 years of follow-up and for 3123 subjects of the randomly selected subcohort that was followed up to estimate the person time in the entire cohort.

The rate ratio for stomach carcinoma in the highest onion consumption category $(\geq 0.5$ onions per day) was 0.50 (95\% confidence interval $0.26-0.95)$, compared to the lowest category $(0$ onions/day), after adjustment for age, gender, alcohol, vitamin $C$ and $\beta$ carotene intake, smoking, education, history of stomach disorders and family history of stomach cancer. Analysis per subsite revealed that the reduction in risk was restricted to carcinoma in the non-cardia part of the stomach (rate ratio $=0.31,95 \%$ confidence interval $0.14-0.70$ in the highest category, $p$-trend $=0.002$ ). A reduction in risk was also seen among subjects without a stomach disorder in their history ( $p$-trend $=0.01)$. Neither the consumption of leeks ( $p$-trend $=0.23$ ), nor the use of garlic supplements were significantly associated with stomach carcinoma risk. Exclusion of cases diagnosed during the first year of follow-up did not change the results.
\end{abstract}

Submitted for publication 


\section{Introduction}

The consumption of vegetables and fruits is associated consistently with a reduced risk of stomach cancer. In recent reviews of the literature, it was concluded that the most: abundant evidence for an inverse association is available for fruit and lettuce. However, Allium vegetables, particularly onions, may be protective as well ${ }^{1.4}$.

Allium vegetables, such as garlic and onions, are traditionally known for their antibacterial and fungicidal properties. Most of their prophylactic and therapeutic effects are ascribed to specific sulfur containing compounds, which are responsible for the typical odor and flavor of these plants ${ }^{5-7}$. Some of these so-called organosulfur compounds also act as antimutagen in in-vitro models and even as anticarcinogen in invivo test systems ${ }^{8}$. Organosulfur compounds have been detected in raw and cooked. Allium vegetables, and in commercial preparations, such as garlic supplements, the most widely used type of dietary supplement by elderly persons in The Netherlands ${ }^{9-11}$. Other potentially anticarcinogenic compounds in Allium vegetables are the flavonols quercetin (onions) and kaempferol (leek, garlic), and the cysteine-containing tripeptide glutathione (onions), which plays an important role in the detoxification of carcinogens ${ }^{12-17}$.

Evidence that Allium vegetable consumption is associated with a reduction of stomach cancer risk in humans, is at present based on results from case-control studies conducted in different parts of the world, that have evaluated Allium vegetables as a distinct vegetable category. Most of these case-control studies reported a decreasing risk for stomach cancer with increasing consumption of Allium vegetables, although not for all subsites or histological subtypes of stomach cancer ${ }^{18-28}$. Two studies found no association with onions, chives or garlic ${ }^{29,30}$, and one case-control study reported a higher risk for stomach cancer with increasing frequency of onion intake ${ }^{31}$.

However, the resuits from case-control studies can be biased by differential recall of dietary intake due to awareness of the disease status ${ }^{32}$. Recall of dietary intake could also have been influenced by current dietary habits ${ }^{33}$, which may be different from those in the relevant reference period due to symptoms of the disease ${ }^{34,35}$. Prospective studies are less susceptible to recall bias, since dietary intake is measured before the presence of disease is known. In the Netherlands Cohort Study (NLCS), a large-scale prospective cohort study on diet and cancer that was started in 1986 among 120,852 men and women, we have examined the association between the consumption of onions and leeks, the use of garlic supplements, and the subsequent risk of carcinoma in the stomach and subsites within the stomach after 3.3 years of follow-up. To evaluate whether the results were biased due to changes in dietary habits caused by prediagnostic cancer-related symptoms, we also performed analysis with exclusion of cases diagnosed during the first year after baseline.

\section{Materials and methods}

\section{The Netherlands Cohort Study}

A description of the design of the NLCS and the characteristics of the cohort have been published ${ }^{36}$. In brief, the NLCS has been started in 1986 among 58,279 men and 62,573 women aged 55-69 years, originating from 204 municipalities in The Netherlands with computerized population registries. A self-administered mailed questionnaire was used to collect information on usual diet, lifestyle characteristics, medical history, dietary supplement use and other important risk factors for cancer. 
Following the case-cohort approach for analysis of the study, a subcohort of 3500 subjects (1688 men and 1812 women) was randomly sampled from the large cohort and followed up for vital status. The entire cohort has been followed-up for the incidence of cancer.

\section{Follow-up for the incidence of cancer}

Information on cancer incidence has been collected for the entire cohort by record linkage with all nine cancer registries in The Netherlands and with PALGA, the Dutch network and National Database for Pathology. The method of record linkage has been published $^{37}$. The present analysis is restricted to cancer incidence in the first 3.3 years of follow-up (from baseline in September 1986 to December 1989). Completeness of follow-up in this period was estimated to be $95 \%{ }^{38}$.

\section{Population for analysis}

After excluding subjects reporting any prevalent cancer other than skin cancer, or with incident in situ carcinoma, stomach cancer other than carcinoma (sarcoma, lymphoma, unspecified morphology), or without a microscopically confirmed diagnosis, 155 incident primary stomach carcinoma cases were available for analysis. From the subcohort, 3346 persons remained for analysis after excluding prevalent cancer cases other than skin cancer.

\section{Questionnaire}

A 150-item semi-quantitative food frequency questionnaire was used to collect information on the usual intake of foods and beverages in the year preceding the start of the study ${ }^{39}$. Questionnaire data of all cases and subcohort members have been keyentered twice and processed blinded with respect to case/subcohort status to prevent random and systematic coding errors. Two of the questions on vegetable intake specifically focused on the consumption of Allium vegetables: ' How many onions did you usually eat per week ?', and 'How often have you consumed leek in summer and how often in winter ? '. Consumption of leeks was estimated on a scale of six categories per season, ranging from 'never or less than once per month' to '3-7 times per week', including leeks consumed in mixed vegetable dishes. A question on the consumption of other Allium vegetables, such as garlic, chives of shallots, was not included in the baseline questionnaire. The questionnaire has been validated against three 3-day diet records ${ }^{39}$. Information on the use of dietary supplements was collected with an open-ended question that was formulated as follows: 'During the past five years did you use vitamin tablets, drops, or other preparations (for example tonics, vitamins, garlic pills, brewer's yeast, calcium) ?'. For each of the maximal four supplements that could be listed, information on type of supplement, brand name. dose per day, and the period in which the consumption tock place, could be listed. Recall of garlic supplement use was evaluated by comparing questionnaire data with information from three personal interviews as reference ${ }^{40}$.

\section{Data analysis}

For the analysis of onion and leak consumption, we used the data of 139 cases (106 men and 33 women) and 3123 subcohort members (1525 men and 1598 women) for whorn complete dietary data were available ${ }^{38}$. Subjects were categorized into four categories of onion consumption $(0, \leq 0.25,0.25-0.5$, and $\geq 0.5$ onions per day) and 
three categories of leek consumption $10, \leq 2$ and $>2$ times per month). Analyses of garlic supplement use are based on 152 cases (119 men and 33 women) and 3340 subcohort members (1627 men and 1713 women) with complete information on dietary supplement use. Garlic supplement users were defined as those subjects who reported daily use of any garlic supplement for at least one year in the five-year period before baseline. When garlic supplement users also took other dietary supplements in the same time period, we separately examined the relation with stomach carcinoma for users of exclusively garlic supplements with nonusers as reference, and for those consuming garlic supplements together with other supplements. For the latter analysis we used subjects taking any other supplement as reference. Case-cohort analyses were performed based on the assumption that survival times were exponentially distributed in this follow-up period ${ }^{38}$. In age-gender-stratified analyses, we computed Mantel-Haenszel rate ratios and $95 \%$ confidence intervals for onion and leek consumption and for garlic supplement use, and tests for trend in the rate ratios. In the multivariable analyses, we further adjusted for alcohol intake, dietary intake of vitamin $\mathrm{C}$ and $\beta$-carotene, smoking status, educational level, a history of stomach disorders and a family history of stomach cancer. The dietary intake of vitamin $C$ and $\beta$-carotene was computed by using the Dutch food composition table ${ }^{41}$. All $95 \%$ confidence intervals were corrected for the additional sampling variance introduced by using a subcohort instead of the complete cohort. Tests for trend in the rate ratios were based on likelihood ratio tests. Since the pathogenesis of carcinoma in the proximal part of the stomach (cardia and gastroesophageal junction) is different from that in the other part of the stomach ${ }^{42}$, and there may be subsite-specific differences in stomach carcinoma risk associated with Allium vegetable consumption ${ }^{25}$, we also evaluated whether the role of onion and leek consumption varies for the cardia (ICD-O topography code 1510) and the other subsites (ICD-O topography codes 1511 to 1519$)^{43}$. To evaluate a potential influence of prediagnostic symptoms of stomach carcinoma on dietary habits, analyses were also performed for cases diagnosed after the first year of follow-up. Because other gastric diseases (e.g. ulcer disease, gastritis) might have influenced dietary habits as well ${ }^{35}$, and may also play a role in gastric cancer etiology ${ }^{44}$, analysis were also performed for those subjects who did not report to have suffered from any gastric disorder requiring medical attention.

\section{Results}

Table 1 shows the distribution of onion and leek consumption among subcohort members and cases ranked by year of follow-up. Overall, the consumption of onions was lower among cases than among subcohort members. The proportion of cases not consuming onions was higher in each of the follow-up years, and although the proportion of cases in the highest consumption category increased somewhat, the proportions in later follow-up years were still lower than in the subcohort. Leeks were less frequently consumed by cases than by subcohort members. No clear trends were seen after categorization of the cases by year of follow-up. A slightly larger proportion of cases than of subcohort members used garlic supplements $19.2 \%$ and $8.8 \%$, respectively). Of all cases, $5.9 \%$ used exclusively garlic supplements while $3.3 \%$ also took other dietary supplements. These percentages were $4.6 \%$ and $4.2 \%$, respectively, in subcohort members. The proportion of cases using garlic supplements varied 
Table 1. Distribution (\%) of stomach carcinoma cases and subcohort members across categories of onion and leek consumption and garlic supplement use.

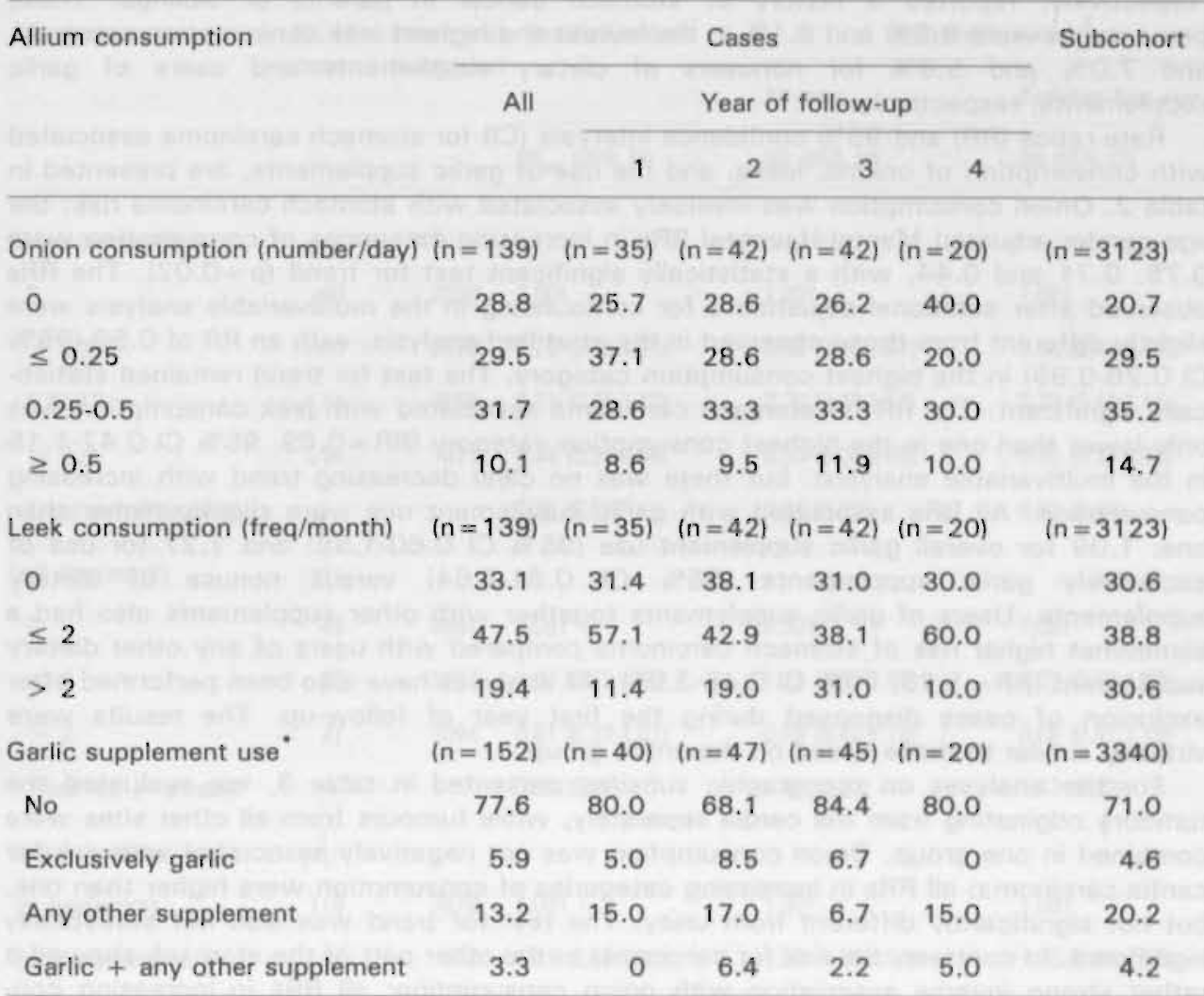

*: Percentages are presented for the total population available for analysis as described in the methods section. The categories of garlic supplement use are mutually exclusive.

considerably between the follow-up years, with no indication of an association with prediagnostic symptoms of stomach carcinoma.

Associations between onion and leek consumption, garlic supplement use and potential risk factors for stomach cancer (age, gender, dietary intake of vitamin $\bar{C}$ and $\beta$ carotene, alcohol intake, smoking status and educational level) were reported earlier ${ }^{45}$. One of the two other risk factors for stomach cancer, a personal history of stomach disorders (defined as any stomach disease in the past that required medical attention), was associated with onion and leek consumption or the use of garlic supplements. A higher proportion of subcohort members who did not consume onions, leeks or garlic supplements reported to have suffered from a stomach disorder $(11.9 \%, 11.2 \%$ and $10.3 \%$ respectively). compared to subjects in the highest onion and leek intake categories and among users of garlic supplements $(9.4 \%, 8.7 \%$ and $7.2 \%$ respectively). 
The associations were less marked for a family history of stomach cancer : $7.7 \%$ and $8.1 \%$ of the subcohort members in the lowest and highest onion consumption category, respectively, reported a history of stomach cancer in parents or siblings. These percentages were $6.6 \%$ and $6.1 \%$ in the lowest and highest leek consumption category, and $7.0 \%$ and $5.8 \%$ for nonusers of dietary supplements and users of garlic supplements, respectively.

Rate ratios (RR) and $95 \%$ confidence intervals $(\mathrm{Cl})$ for stomach carcinoma associated with consumption of onions, leeks, and the use of garlic supplements, are presented in table 2. Onion consumption was inversely associated with stomach carcinoma risk: the age-gender adjusted Mantel-Haenszel RRs in increasing categories of consumption were $0.75,0.71$ and 0.44 , with a statistically significant test for trend $(p=0.02)$. The RRs observed after additional adjustment for confounding in the multivariable analysis were slightly different from those observed in the stratified analysis, with an RR of $0.50195 \%$ $\mathrm{Cl} 0.26-0.95)$ in the highest consumption category. The test for trend remained statistically significant. The RR for stomach carcinoma associated with leek consumption was only lower than one in the highest consumption category $(\mathrm{RR}=0.69,95 \% \mathrm{Cl} 0.42-1.15$ in the multivariable analysis), but there was no clear decreasing trend with increasing consumption. All RRs associated with garlic supplement use were slightly higher than one: 1.09 for overall garlic supplement use $(95 \% \mathrm{Cl} 0.60-1.96)$ and 1.27 for use of exclusively garlic supplements $(95 \% \mathrm{Cl} \quad 0.61-2.64)$ versus nonuse of dietary supplements. Users of garlic supplements together with other supplements also had a somewhat higher risk of stomach carcinoma compared with users of any other dietary supplement ( $\mathrm{RR}=1.28,95 \% \mathrm{Cl} 0.45-3.66$ ). All analyses have also been performed after exclusion of cases diagnosed during the first year of follow-up. The results were virtually similar to those based on the entire group.

For the analyses on topographic subsites presented in table 3 , we evaluated the tumours originating from the cardia separately, while tumours from all other sites were combined in one group. Onion consumption was not negatively associated with risk for cardia carcinoma: all RRs in increasing categories of consumption were higher than one, but not significantly different from unity. The test for trend was also not statistically significant. In contrast, the risk for carcinoma in the other part of the stomach showed a rather strong inverse association with onion consumption: all RRs in increasing consumption categories were significantly below unity $(0.54,0.54$, and 0.31$)$ with a highly significant trend test $(p=0.002)$. Table 3 also shows the rate ratios and $95 \%$ confidence intervals for those subjects who did not report a history of any severe gastric disorder. The RRs for cardia carcinoma were slightly higher than those for the entire group, but none of the RRs were significantly different from unity. All RRs for carcinoma in the other sites of the stomach stayed below one, but only the RR in the highest consumption category was significantly different from unity $(\mathrm{RR}=0.35,95 \% \mathrm{Cl} 0.15$ $0.86)$. The trend was statistically significant. Leek consumption was not associated with risk for carcinoma at either of these sites. The RRs for cardia carcinoma were somewhat lower than one, but none of the RRs were significantly different from unity and the trend was also not significant. For those never having suffered from a gastric disorder, the RRs were somewhat lower than those observed for the entire group. For carcinoma. at the other sites, only the RR in the highest consumption category was lower than one, both in the entire population as well as in the subgroup without gastric disorders in their medical history. However, none of the RRs were significantly different from one. Also the test for trend was not significant. Exclusion of cases from the first year of follow-up 
Table 2. Rate ratios and $95 \%$ confidence intervals of stomach carcinoma according to Allium vegetable consumption and garlic supplement use.

\begin{tabular}{|c|c|c|c|c|c|}
\hline \multirow[t]{2}{*}{ Allium consumption } & $\begin{array}{l}\text { No. of } \\
\text { cases }\end{array}$ & $\begin{array}{l}\text { Person years } \\
\text { in subcohort }\end{array}$ & Stratified analysis ${ }^{\circ}$ & \multicolumn{2}{|c|}{ Multivariable analysis ${ }^{9}$} \\
\hline & & & & All cases & Excluding first yeat \\
\hline & & & $\mathrm{RP}_{\text {ue }}$ (95\% Cl) & RR (95\% CI) & RR (95\% Cl) \\
\hline
\end{tabular}

Onions (number/day)

$\begin{array}{llllll}0 & 40 & 2090 & 1.00 t & 1.00 \dagger & 1.00 t \\ \leq 0.25 & 41 & 2978 & 0.75(0.48 \cdot 1.21) & 0.68(0.42-1.07) & 0.68(0.43-1.08) \\ 0.25 \cdot 0.5 & 44 & 3559 & 0.71(0.45 \cdot 1.12) & 0.70(0.44-1.11) & 0.70(0.44-1.11) \\ \geq 0.5 & 14 & 1471 & 0.44(0.23-0.86) & 0.50(0.26-0.95) & 0.50(0.26-0.96) \\ \text { Trend test } x^{2} \text { (p.value) } & & & 5.35(0.02) & 4.64(0.03) & 4.58(0.03)\end{array}$

Leek (frequmonth)

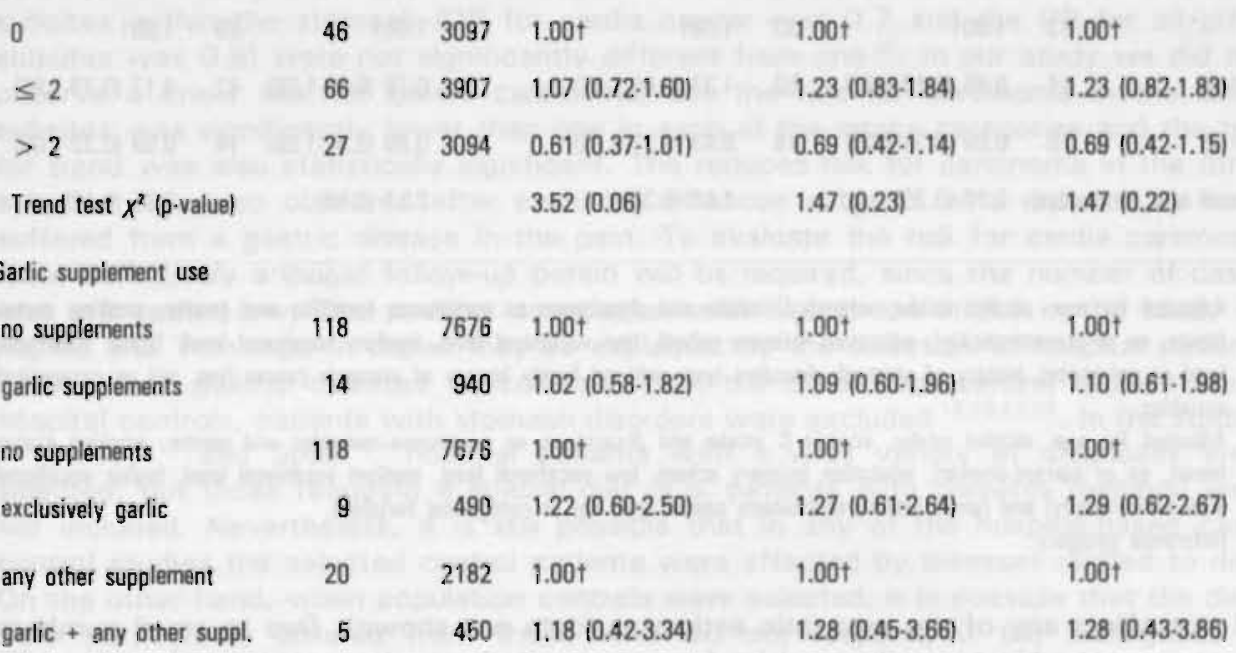

$\because$ Stratified by gender and age in three categories $(55-59,60-64,65-69$ years).

f: Adjusted for age, alcahol intake, vitamin $\mathbf{C}$ intake and $\beta$-carotene as continuous variables and gender, smoking status inever, ex or current-moker), education (primary school, low vocational level, medium vocational lẹvel, or higher vocational levelluniversity). history of stomach disorders (yes, no) and family history of stomach cancer (yes, no) as categorical variables. The RRs with garlic supplement use are atso adjusted for onion and leek consumption.

t: Reference category. 
Table 3. Rate ratios and $95 \%$ confidence intervals of cardia carcinoma and other subsites of stomach carcinoma according to onion and leek consumption.

\begin{tabular}{|c|c|c|c|c|c|c|c|c|c|}
\hline \multirow{3}{*}{$\begin{array}{l}\text { Allium } \\
\text { consumption }\end{array}$} & \multicolumn{5}{|c|}{ All ${ }^{*}$} & \multicolumn{4}{|c|}{ Without history of gastric disorders ${ }^{\mathfrak{}}$} \\
\hline & & Cardia & ant & & Other sites & & Cardia & & Other sites \\
\hline & $\mathbf{N}$ & RR $(95 \% \mathrm{Cl})$ & & N & RR (95\% Ci) & $\mathbf{N}$ & RR $(95 \%$ CI) & N & RR $(95 \%$ CI $)$ \\
\hline
\end{tabular}

Onions (number/day)

$\begin{array}{lrlrlrlll}0 & 5 & 1.00 \dagger & 35 & 1.00 \dagger & 4 & 1.00 \dagger & 25 & 1.00 t \\ \leq 0.25 & 12 & 1.39(0.51-3.77) & 29 & 0.54(0.32-0.91) & 9 & 1.30(0.42-3.93) & 25 & 0.64(0.35-1.15) \\ 0.25-0.5 & 13 & 1.57(0.58-4.27) & 31 & 0.54(0.32-0.91) & 11 & 1.60(0.53-4.81) & 27 & 0.60(0.33-1.07) \\ \geq 0.5 & 6 & 1.89(0.59-5.96) & 8 & 0.31(0.14-0.70) & 6 & 2.12(0.60-7.48) & 7 & 0.35(0.15-0.86) \\ \text { Trend test } x^{2} \text { (p-value) } & 1.26(0.26) & & 10.1(0.002) & & 1.57(0.21) & & 6.04(0.01)\end{array}$

Leek consumption (freq/month)

$\begin{array}{lllllllll}0 & 13 & 1.00 \dagger & 33 & 1.00 \dagger & 11 & 1.00 \dagger & 28 & 1.00 \dagger \\ \leq 2 & 14 & 0.85(0.40-1.81) & 52 & 1.37(0.86-2.17) & 12 & 0.79(0.37-1.70) & 42 & 1.17(0.73-1.86) \\ >2 & 9 & 0.89(0.38-2.05) & 18 & 0.63(0.34-1.16) & 7 & 0.86(0.37-1.98) & 14 & 0.59(0.32-1.09) \\ \text { Trend test } x^{2} \text { (p-value) } & 0.10(0.75) & & 1.46(0.23) & & 0.17(0.68) & & 2.25(0.13)\end{array}$

*: Adjusted for age, alcohol intake, vitamin $\mathrm{C}$ intake and $\beta$-carotene as continuous variables and gender, smoking status (never, ex or current-smoker), education (primary school, low vocational level, medium vocationail level, higher vocational level or university), history of stomach disorders (yes, no) and family history of stomach cancer (yes, no) as categorical variables.

f: Adjusted for age, alcohol intake, vitamin $\mathrm{C}$ intake and $\beta$-carotene as continuous variables and gender, smoking status (never, ex or current-smoker), education (primary school, low vocational level, medium vocational level, higher vocational fevel or university) and family history of stomach cancer (yes, no) as categorical variables.

t: Reference category.

did not affect any of the rate ratio estimates (data not shown). Due to small numbers we were not able to evaluate risks for cancer at these sites associated with garlic supplement use.

\section{Discussion}

The Netherlands Cohort Study is the first prospective cohort study evaluating the association between consumption of onions and leeks, the use of garlic supplements and the incidence of stomach carcinoma. We present evidence for a strongly decreased risk with increasing consumption of onions for carcinoma arising from the part of the stomach beyond the cardia. The reduced risk was also observed among those subjects 
who did not report to have suffered from a gastric disease. Leek consumption was not associated with a lower stomach carcinoma risk in our study and we also found no reduced risk with garlic supplement use.

To date, the evidence for a protective effect of onions on gastric cancer risk was only based on results from case-control studies mentioning Allium vegetables as a separate vegetable group. The results of these studies are summarized in table 4.

Onion consumption was associated with a reduced stomach cancer risk in most of the studies, with odds ratios (OR) ranging from 0.30 in a Belgian study ${ }^{28}$ and 0.31 among Hawaiian Japanese ${ }^{18}$ to 0.72 in Poland ${ }^{27}$. In a population-based case-control study by You et al ${ }^{20-22}$ in a province of China with high stomach cancer rates, not only overall Allium vegetable consumption was inversely related to stomach cancer risk $(O R=0.5$ in the highest compared to the lowest quartile of consumption) ${ }^{22}$, but also consumption of specific Allium vegetables after controlling for the consumption of other Alliums in the analysis ${ }^{21}$. The lowest risk was reported for Chinese chives: $O R=0.6$ in the highest intake category (>3.7 kg/year), while onion consumption was not associated with a lower stomach cancer risk in this study ${ }^{20-22}$. In Italy, increasing consumption of 'onions and/or garlic as condiments' was associated with a reduced risk for stomach carcinoma and despite the fact that only information from $27 \%$ of the cases and controls regarding garlic consumption was available, a statistically significant protective effect of cooked garlic on stomach cancer risk was also reportedi ${ }^{23}$. Aiso, the ORs for subsites within the stomach $10 R$ for cardia cancer was 0.7 and the OR for all other subsites was 0.8 ) were not significantly different from one ${ }^{25}$. In our study we did not observe a lower risk for cardia carcinoma, but the risk for carcinoma in the other subsites was significantly lower than one in each of the intake categories and the test for trend was also statistically significant. The reduced risk for carcinoma in the other subsites was aiso observed after exclusion of those subjects who reported to have suffered from a gastric disease in the past. To evaluate the risk for cardia carcinoma more definitively a longer follow-up period will be required, since the number of cases was still rather low. The positive association with high onion intake in the study by Tajima and Tominaga in Japan may be explained by the selection of hospital patients with severe gastric diseases as controls ${ }^{31}$. In the other case-control studies using hospital controls, patients with stomach disorders were excluded ${ }^{18,19,27,29}$. In the studies in Greece ${ }^{19}$ and Spain ${ }^{29}$ hospital patients, with a wide variety of diagnoses were selected, but those requiring a special diet (e.g. patients with diabetes mellitus) were not included. Nevertheless, it is still possible that in any of the hospital-based casecontrol studies the selected control patients were affected by diseases related to diet. On the other hand, when population cantrols were selected, it is possible that the diets from participants differed from those who did not respond, if the willingness to participate was related to dietary practices ${ }^{46}$.

One of the strengths of our cohort study is that the completeness of follow-up is very high ${ }^{38}$. Consequently, the results cannot be explained by exposure-related loss to follow-up. Furthermore, we controlled for potential confounding by including important nondietary as well as dietary (vitamin $C$ and $\beta$-carotene) risk factors of stomach carcinoma in the multivariable models. Since none of the rate ratio estimates were markediy changed, it is unlikely that residual confounding due to inaccuracies in the measurements of these factors explain the results. Nevertheless, it might still be possible that another factor is involved. In the studies by Trichopoulos et al ${ }^{19}$, You et al ${ }^{20-22}$, and Tuyns et al $^{28}$, showing significantly lower risks with Allium vegetable 
Table 4. Case-control studies of allium vegetables and stomach cancer.

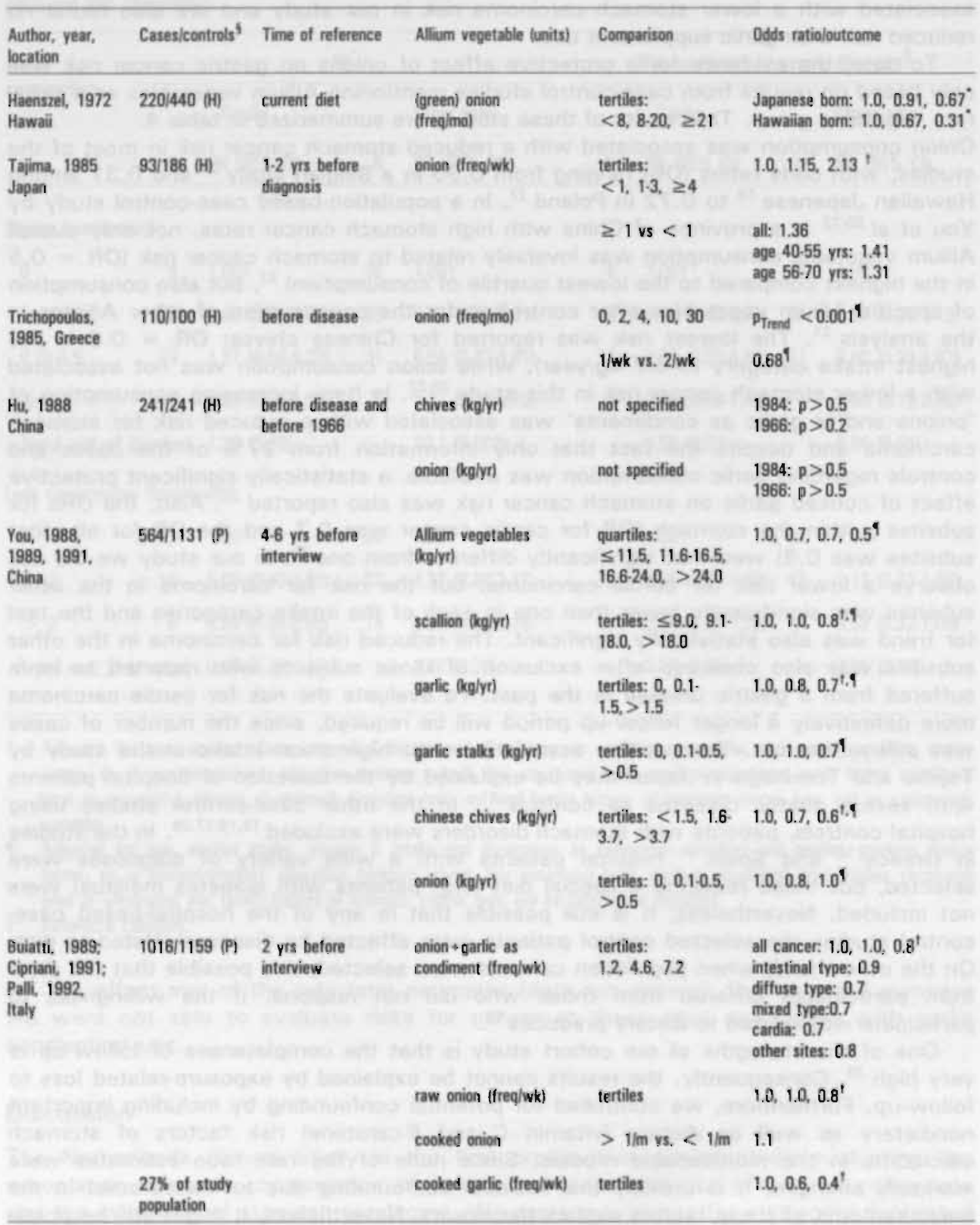


Table 4, continued

\begin{tabular}{|c|c|c|c|c|c|}
\hline $\begin{array}{l}\text { Author, year, } \\
\text { location }\end{array}$ & Cases/controls 5 & Time of reference & Allium vegetable (units) & Comparison & Odds ratio/outcome \\
\hline $\begin{array}{l}\text { Graham, } 1990 \\
\text { New York }\end{array}$ & $293 / 293(\mathrm{~N})$ & $\begin{array}{l}1 \mathrm{yr} \text { before } \\
\text { symptoms }\end{array}$ & $\begin{array}{l}\text { onion (cooked + raw) } \\
\text { (freq/mo) }\end{array}$ & not specified & $\begin{array}{l}\text { 'sign, decreasing risk in male } \\
\text { and female' }\end{array}$ \\
\hline $\begin{array}{l}\text { Boeing } 1991 \\
\text { Poland }\end{array}$ & $741 \mid 741(\mathrm{H})$ & before symptoms & onion (Ireq) & tertiles & $1.0,0.88,0.86^{9}$ \\
\hline \multirow[t]{2}{*}{$\begin{array}{l}\text { Gonzalez, } 1991 \\
\text { Spain }\end{array}$} & $354 / 354(H)$ & 1 yr before disease & raw onion & high vs. low & 0.9 \\
\hline & $\sqrt{3-2}=$ & $\sqrt{x}$ & garlic as seasoning & frequency & no association \\
\hline \multirow[t]{2}{*}{$\begin{array}{l}\text { Tuyns, } 1992 \\
\text { Belgium }\end{array}$} & $449 / 3524(P)$ & before disease & cooked onion & yes vs. no & $0.30^{*}: 4$ \\
\hline & & & cooked leek & yes vs. no & $0.29^{2} .1$ \\
\hline
\end{tabular}

5: $\mathrm{H}$ - hospital; P - population; N = neighborhood

$\because 95 \% \mathrm{Cl}$ does not include 1.00 ; $\mathrm{t}$ : statistically significant trend; $\mathbf{q}$ : adjusted for other food items.

consumption, the ORs were also adjusted for dietary risk factors. However, in a large case-control study in Italy, the ORs were only adjusted for nondietary risk factors ${ }^{23-25}$. In the study by Boeing et al $^{27}$, onion consumption was no longer significantly associated with a lower stomach cancer risk after additional adjustment for vegetables and fruit. One of the other strengths of our study is that we measured diet before the disease was diagnosed and thus avoided the problem of biased recall inherent in the case-control study design. A potential drawback is the still limited length of follow-up (3.3 years). Since duration of several years of preclinical symptoms of stomach carcinoma, most often abdominal discomfort of insidious onset, is not uncommon ${ }^{34}$, cases may have altered their dietary habits in the course of time before baseline. When we ranked the stomach carcinoma cases in our study according to the year of follow-up in which they were diagnosed, we indeed observed a greater similarity between the distribution of onion and leek consumption in the subcohort and in the cases diagnosed later in the follow-up period, than in cases diagnosed shortly after baseline. However, the proportions of cases in the lowest onion consumption category were higher than in the subcohort in al! follow-up years. Also, the conclusions regarding the effect of onion and leek intake and the use of garlic supplements on stomach carcinoma risk were not changed after exclusion of cases diagnosed during the first year of follow-up. Nevertheless, we will investigate this aspect further when we have completed a longer period of follaw-up. In case-control studies, it is equally important to measure dietary intake in the correct reference period. However, only in the studies by Graham et al ${ }^{26}$. and Boeing et al ${ }^{27}$, the reference period was defined as the time before onset of symptoms. In most of the other case-control studies, the period before onset of the disease ${ }^{19,28-31}$ or a fixed time interval before the interview took place ${ }^{18,20-25}$ was specified as reference period, irrespective of the duration of the symptoms or the time between diagnosis and interview. A potential limitation of our study is, that we can not rule out the possibility of nondifferential misclassification of exposure. Although the semiquartitative food frequenc.y questionnaire was validated, specific information on the validity of the report of onion and leek consumption is not available ${ }^{35}$. If nondifferential 
misclassification with respect to onion and leek consumption has occurred, the actual rate ratios may be stronger than those we have observed. For garlic supplements, it is unlikely that this explains absence of an effect of garlic supplements, because the agreement between interview data and the open-ended question on dietary supplement use was relatively high $(77.8 \% \text { recall })^{40}$.

Buiatti et al ${ }^{23}$ noticed that only raw onions, and not cooked onions, significantly reduced the risk for stomach carcinoma. In contrast, Gonzalez et al ${ }^{30}$ observed no association with raw onions, while Tuyns et al ${ }^{28}$ found that cooked onions and cooked leeks were significantly associated with a lower stomach cancer risk. In the NLCS cohort, we could not evaluate whether the risk for stomach carcinoma varied with raw or cooked onions and leeks, since we did not inquire after the preparation methods in our questionnaire, because onions and leeks are mostly eaten cooked in The Netherlands. Nevertheless, despite the fact that the results from case-control studies with respect to preparation methods are scarce and inconsistent, it might be important to collect information on preparation methods, since it has been shown that the level of potentially chemopreventive flavonols decreases considerably when these vegetables are cleaned and prepared ${ }^{47,48}$. On the other hand, the most promising compounds with respect to reduction of stomach carcinoma risk, the organosulfur compounds, are formed from pre-cursor compounds when the vegetables are crushed or cut, and probably also when they are cooked ${ }^{3,10}$. Garlic and onion extracts, but also synthetically produced organosulfur compounds, have not only been shown to inhibit mutagenesis, initiation and promotion, but also to induce enzymes important in the detoxification of carcinogens $8,49,50$. However, since the evidence that Helicobacter pylori is one of the important risk factors for stomach cancer is growing 4.51 .54 , the original observation that these compounds act antibacterially ${ }^{5}$ may be even more interesting and should be further investigated. The strongly reduced risk with onion consumption that we observed in our cohort study for other anatomic sites in the stomach than the cardia, also when subjects with a history of gastric disorders were excluded, is particularly interesting since Helicobacter pylori infection has been implicated as a strong independent etiologic factor for these sites specifically ${ }^{54}$.

In conclusion, we found evidence for a reduced risk for carcinoma in all parts of the stomach, except in the cardia, with increasing consumption of onions. The reduced risk. was also observed among those without a gastric disorder in their medical history. No association was observed for leek consumption or the use of garlic supplements. Exclusion of cases diagnosed during the first year of follow-up gave similar resuits as those based on the entire case group.

\section{References}

1. Steinmetz K, Potter JD, Vegetables, fruit, and cancer, I. Epidemiology. Cancer Causes Control 1991; 2:325-357.

2. Block G, Patterson B, Subar A. Fruit, vegetables, and cancer prevention: a review of the epidemiological evidence. Nutr Cancer 1992;18:1-29

3. Boeing $\mathrm{H}$. Epidemiological research in stomach cancer: progress over the last ten years. J Cancer Res Clin Oncol 1991;117:133-143.

4. Nomura A, Stemmermann GN. Helicobacter pylori and gastric cancer. I Gastroenterol Hepatol 1993;8:294-303.

5. Cavallito CJ. Bailey JH. Allicin, the antibacterial principle of allium sativum. I. Isolation, physical properties and antibacterial action. J Am Chem Soc 1944;66:1950-1951. 
6. Fenwick GR, Hanley AB. The genus Allium, part 3. CRC Crit Rev Food Sci Nutr 1986;23:1. 73.

7. Hughes BG, Lawson LD. Antimicrobial effects of Allium sativum L. (Garlic), Allium ampeloprasum L. (Elephant garlic), and Allium cepa L. (onion), garlic compounds and commercial garlic supplement products. Phytother Res 1991:5:154-158.

8. Dorant E, Van den Brandt PA, Goldbohm RA, Hermus RJJ, Sturmans F. Garlic and its significance for the prevention of cancer in humans: a critical view. $\mathrm{Br} J$ Cancer 1993;67:424-429.

9. Lawson LD, Wang ZYJ, Hughes BG. Identification and HPLC Quantification of the sulfides and dialk(en)yl thiosulfinates in commercial garlic products. Planta Med 1991;57:363-370.

10. Block $E$. The organosulfur chemistry of the Genus Allium - Implications for the organic chemistry of sulfur. Angew Chem Int Ed Engi 1992:31:1135-1178.

11. Dorant E, Van den Brandt PA, Hamstra AM, Feenstra MH, Goldbohm RA, Hermus RJJ, Sturmans $F$. The use of vitamins, minerals and other dietary supplements in The Netherlands. Int J Vit Nutr Res 1993;63:4-10.

12. Newmark HL. Plant phenolics as inhibitors of mutational and precarcinogenic events. Can J Physiol Pharmacol 1987;65:461-466.

13. Steinmetz K, Potter JD. Vegetables, fruit, and cancer. II. Mechanisms. Cancer Causes Control 1991;2:427-442.

14. Bilyk A, Sapers GM. Distribution of quercetin and kaempferol in lettuce, kale, chive, garlic chive, leek, horseradish, red radish, and red cabbage tissues. J Agric Food Chem 1985;33:226-228.

15. Jones DP, Coates RJ, Flagg EW, Eley JW, Block G, Greenberg RS, Gunter EW, Jackson B. Glutathione in foods listed in the National Cancer institute's Health Habits and History Food Frequency Questionnaire. Nutr Cancer 1992;17:57-75.

16. Coles B, Ketterer B. The role of glutathione and glutathione transferases in chemical carcinogenesis. Crit Rev Biochem Mol Biol 1990;25:47-70.

17. Hertog MGL, Hollman $\mathrm{CH}$, Katan $\mathrm{MB}$. Content of potentially anticarcinogenic flavonoids of 28 vegetables and 9 fruits commonly consumed in The Netherlands. J Agric Food Chem 1992;40:2379-2383.

18. Haenszel W, Kurihara M, Segi M, Lee RKC. Stomach cancer among Japanese in Hawaii. J Natl Cancer Inst 1972;49:969-988.

19. Trichopoulos D, Ouranos G, Day NE, Tzonou A, Manousos O, Papadimitriou Ch, Trichopoulos A. Diet and cancer of the stomach: a case-control study in Greece. Int J Cancer 1985;36:291-297.

20. You W, Blot WJ, Chang Y, Ershow AG, Yang Z, An Q, Henderson B, Xu G, Fraumeni JF, Wang T. Diet and high risk of stomach cancer in Shandong, China. Cancer Res. 1988:48:3518-3523.

21. You W, Blot WJ, Chang $Y$, Ershow AG, Yang Z, An Q, Henderson B, Xu G, Fraumeni JF, Wang $T$. Allium vegetabies and reduced risk of stoomach cancer. J Natl Cancer inst 1989:81:162-164.

22. You WC, Chang YS, Yang ZT, Zhang L, Xu GW, Blot WJ, Kneller R, Keefer LK, Fraumeni JF. Etiological research on gastric cancer and its precursor lesions in Shandong. China. In: Relevance to human cancer of $\mathrm{N}$-nitroso compounds, tobacco smoke and mycotoxins. Ed. IK O'Neill, J Chen, H Bartsch, Lyon International agency for research on cancer, 1991: pp 33-38.

23. Buiatti E, Palli D, Decarli A, Amadori D, Avellini C, Bianchi S, Biserni R, Cipriani $F$, Cocco P, Giacosa A, Marubini E, Puntoni R, Vindigni C, Fraumeni J, Blot W. A case-control study of gastric cancer and diet in Italy. Int J Cancer 1989;44:611-616.

24. Cipriani F, Buiatti E, Palli D. Gastric cancer in Italy. Ital J Gastroenterol 1991:23:429-435.

25. Palli D, Bianchi S, Decarli A, Cipriani F, Avellini C, Cocco P, Falcini F, Puntoni R, Fusso A, Vindigni C, Fraumeni JF, Blot WJ, Buiatti E. A case-control study of cancer of the gastric cardia in Italy. Br J Cancer 1992;65:263-266.

26. Graham S, Haughey B, Marshall J, Brasure J, Zielezny M, Freudenheim J. West D, Nolan J. Wilkinson G. Diet in the epidemiology of gastric cancer. Nutr Cancer 1990;13:19-34.

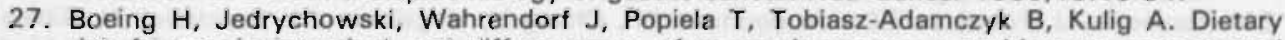
risk factors in intestinal and diffuse types of stomach cancer: a multicenter case-control study in Poland. Cancer Causes and Control 1991:2:227-233. 
28. Tuyns AJ, Kaaks R, Haelterman M, Riboli E. Diet and gastric cancer. A case-control study in Belgium. Int J Cancer 1992;51:1-6.

29. Hu J, Zhang S, Jia E, Wang E, Liu S, Liu Y, Wu Y, Cheng Y. Diet and cancer of the stomach: a case-control study in China. Int J Cancer 1988;41:331-335.

30. Gonzalez CA, Sanz JM, Marcos G. Pita S, Brullet E, Saigi E, Badia, A, Riboli E. Dietary factors and stomach cancer in Spain: a multi-centre case-control study. Int J Cancer 1991;49:513-519.

31. Tajima K, Tominaga S. Dietary habits and gastro-intestinal cancers: a comparative casecontrol study of stomach and large intestinal cancers in Nagoya, Japan. Jpn J Cancer Res (Gann) 1985:76:705-716.

32. Rothman KJ. Modern epidemiology. Boston: Little, Brown and Company, 1986.

33. Moller Jensen O, Wahrendorf J, Rosenquist A, Geser A. The reliability of qeustionnairederived historical dietary information and temporal stability of food habits in individuals. Am J Epidemiol 1984;120:281-290.

34. MacDonald WC, Rubin CE. Cancer, benign tumors, gastritis and other gastric disease. In: Isselbacher KJ, Adams RD, Braunwald E, Petersdorf RG and Wilson JD (eds). Harrison's Principles of internal medicine, 9th ed, McGraw-Hill Kogakusha Ltd, Tokyo, 1980.

35. Koch JP, Donaldson RM. A survey of food intolerances in hospitalized patients. New Engl J Med 1964;271:657-660.

36. Van den Brandt PA, Goldbohm RA, Van 't Veer P, Volovics A, Hermus RJJ, Sturmans F. A large-scale prospective cohort study on diet and cancer in The Netherlands. J Clin Epidemiol $1990 ; 43: 285-295$.

37. Van den Brandt PA, Schouten LJ, Goldbohm RA, Dorant E, Hunen PMH. Development of a record linkage protocol for use in the Dutch Cancer registry for epidemiological research. Int $J$ Epidemiol 1990:19:553-558.

38. Van den Brandt PA, Van 't Veer P, Goldbohm RA, Dorant E, Volovics A, Hermus RJJ, Sturmans F. A prospective cohort study on dietary fat and the risk of postmenopausal breast cancer. Cancer Res 1993;53:75-82.

39. Goldbohm RA, Van den Brandt PA, Brants HAM, Van 't Veer P, AI M, Sturmans F, Hermus RJJ. Validation of a dietary questionnaire used in a large-scale prospective cohort study on diet and cancer. Eur J Clin Nutr 1994;48:253-265.

40. Dorant E, Van den Brandt PA, Goldbohm RA, Hermus RJJ, Sturmans F. Agreement between interview data and a self-administered questionnaire on dietary supplement use. Eur $\mathrm{J}$ Clin Nutr 1994:48:180-188.

41. Stichting NEVO. NEVO table; Dutch food composition table 1986-1987. The Hague, Netherlands: Voorlichtingsbureau voor de Voeding, 1986.

42. MacDonald WC, MacDonald JB. Adenocarcinoma of the esophagus and/or gastric cardia. Cancer 1987:60:1094-1098.

43. International Classification of diseases for Oncology. First edition. Geneva: World health Organization, 1976.

44. Correa P. A human model of gastric carcinogenesis. Cancer Res 1988;48:3554-3560.

45. Dorant E, Van den Brandt PA, Goldbohm RA. A prospective cohort study on the relation between onion and leek consumption, garlic supplement use and the risk for colon and rectum carcinoma in The Netherlands. Carcinogenesis (in press).

46. Willett WC. Epidemiologic studies of diet and cancer. Med Oncol Tumor Pharmacol 1990;7:93-97.

47. Starke H, Herrmann K. Flavonols and flavones of vegetables. VI. On the changes of flavonols of onions. Z Lebensm Unters Forsch 1976;161:137-142.

48. Starke H, Herrmann K. Flavonols and flavones of vegetables. VII. Flavonols of leek, chive and garlic. Z Lebensm Unters Forsch 1976;161:25-30.

49. Maurya AK, Singh SV. Differential induction of glutathione transferase isoenzymes of mice stomach by diallyl sulfide, a naturally occurring anticarcinogen. Cancer Lett 1991;57:121129.

50. Shenoy NR, Choughuley ASU. Inhibitory effect of diet related sulphydryl compounds on the formation of carcinogenic nitrosamines. Cancer Lett 1992;65:227-232.

51. Parsonnet J, Friedman GD, Vandersteen DP, Chang Y, Vogelman JH, Orentreich N, Sibley RK. Helicobacter pylori infection and the risk of gastric carcinoma. New Engl J Med 1991;325:1127-1131. 
52. Nomura A, Stemmermann GN, Chyou PH, Kato I, Perez-Perez GI, Blaser MJ, Helicobacter pylori infection and gastric carcinoma among Japanese Americans in Hawaii. New Engl J Med 1991;325:1132-1136.

53. Hansson LE, Engstrand L, Nyren O, Evans DJ, Lindgren A, Bergstrōm R, Andersson B, Athlin L, Bendtsen O, Tracz P. Helicobacter pylori infection: Independent risk indicator of gastric adenocarcinoma. Gastroenterol 1993;105:1098-1103.

54. Parsonnet J, Samloff IM, Nelson LM, Orentreich $N$, Vogelman JH. Friedman GD. Helicobacter pylori, pepsinogen, and risk for gastric adenocarcinoma. Cancer Epidemiol Biomarker Prev 1993;2:461-466. 


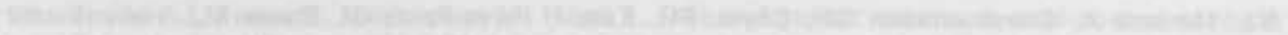

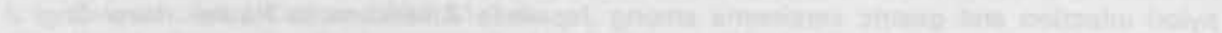

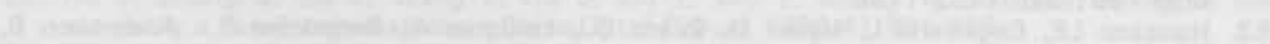

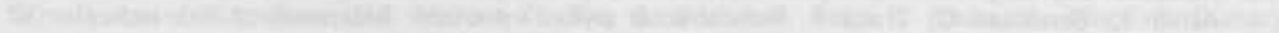

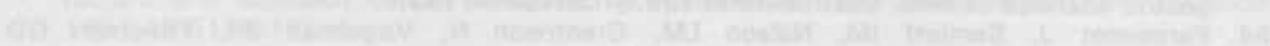

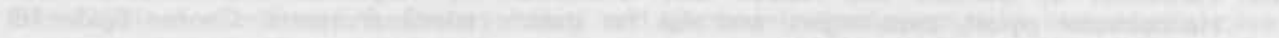




\section{Chapter 9}

\section{Epilogue}

In this chapter the results of the Netherlands Cohort. Study on diet and cancer with respect to the consumption of onions and leeks, the use of garlic supplements and risk of lung, breast, colon, rectum and stomach carcinoma will be discussed in connection with evidence from earlier epidemiologic studies on Allium vegetable consumption and the risk of cancer. In addition, the biological evidence will be addressed and recommendations for future research will be made.

\section{Evidence from case-control studies}

In view of the widespread use of Allium vegetables ' and the vast amount of research on vegetable consumption in relation with cancer risk ${ }^{2,3}$, it is surprising that only relatively few epidemiologic studies on diet and cancer have mentioned Allium vegetables. However, the hypothesis that Allium vegetables may reduce the risk of cancer is relatively new. Also, not many studies may have investigated this association specifically yet, but included Allium vegetables together with other vegetables in larger categories (e.g. ${ }^{4-6}$ ). For instance, in the lowa Women's Health Study, a large-scale prospective cohort study of postmenopausal women, the individual Allium vegetables garlic, leek and scallion were analyzed together with all other vegetables in one group, while the use of onions was not asked ${ }^{4}$.

The results of those case-control studies that specifically investigated associations between the consumption of Allium vegetables and the risk for cancer ${ }^{7-36}$ are listed in the table below. One study from China is not included in the table, since it was erroneously presented as retrospective cohort study, while it was actually a very inefficient type of casecontrol study lin this study no association was reported for esophageal cancer with garlic consumption) ${ }^{37}$. Most: of the case-control studies listed in the table reported negative associations with Allium vegetable consumption, primarily for stomach, colon and rectum cancer. The lowest risks for stomach cancer $(O R=0.30$ and $O R=0.29$ with 'yes' vs. 'no ' consumption of onions and leeks, respectively) were found in Belgium ${ }^{20}$. High consumption of Allium vegetables was also associated with a decreased risk for stomach cancer in most of the other populations, despite the probably large international differences in intake levels. The lowest risks for colorectal cancer were also found in Belgium: $O R=0.16$ for colon cancer with intake of onions and shallots, $O R=0.23$ for rectum cancer with intake of leeks ${ }^{25}$. Overall, it can be concluded that consumption of Allium vegetables may reduce the risk of cancer in various populations considerably. Potential difficulties associated with the casecontrol design will be considered later. 
Table. Case-control studies of Allum vegetables and cancer, listed by topographic site and year of publication.

\begin{tabular}{llll}
\hline First author, year, location & $\begin{array}{l}\text { Cases/ } \\
\text { controlst }\end{array}$ & $\begin{array}{l}\text { Allium vegetable } \\
\text { (units) }\end{array}$ & Comparison
\end{tabular}

\section{Stomach cancer}

Haenszel, 1972. Hawail

$220 / 440(H)$

green onion (freqimo) tertiles: $<8,8-20, \geq 21$

$93 / 186(H)$

onion (freqiwk)

tertiles: $<1,1 \cdot 3, \geq 4$

$0,2,4,10,30$

not specified

not specified

You, 1988, 1989, 1891,

Ching

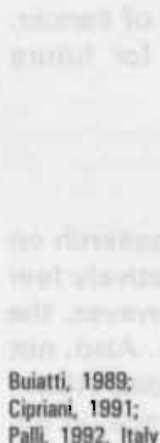

$1016 / 1159$ (P)

Palli, 1992, Italy

$564 / 1131(\mathrm{P})$

alliums (kg/vr)

quartiles: $\leq 11.5,11.6$

$16.5,16.6-24.0,>24.0$

scallion (kg/yr)

tertiles: $\leq 8.0,9.1-18.0$,

$>18.0$

garlic (kg/yr)

tertiles: $0,0.1 \cdot 1.5,>1.5$

$1.0,0.8,0.7^{b .6}$

garlic stalks (kg/ $/ \mathrm{rr}$

tertiles: $0,0.1-0.5,>0.5$

1.0. $1.0,0.7^{b . c}$

chinese chives $(\mathrm{kg} / \mathrm{yr})$ tertiles: $<1.5,1.6-3.7$, $>3.7$

onion (kg/yn)

tertiles: $0,0.1-0.5,>0.5$

$1.0,0.7,0.6^{\text {b.e }}$

onion+ garlic

(freq/wk)

tertiles: $1.2,4.6,7.2$

$1.0,0.8,1.0^{\circ}$

1.0. 1.0, $0.8^{\mathrm{b}}$ intestina! type: 0.9

diffuse type: 0.7

mixed type: 0.7

cardia: 0.7

other subsites: 0.8

onion (freq/wk) fertiles

tertiles

garlic (freg/wk)

not specified

Graham, 1990, New York

293/293 (N)

onion ifreqimo)

tertiles: low-med-high

high vs. laver

high vs. low

yes ys. no

yes ws. no raw: $1.0,1.0,0.8^{b}$ cooked: 1.1

cooked: $1.0,0.6,0.4^{b}$

'sign. reduced risk'

$1.0,0.88,0.86^{\mathrm{c}}$

0.8

no association

$0.30^{2.5}$

$0.29^{26}$ 
Table, continued

First author, year, location

\section{Colorectal cancer}

Haenszet, 1973, Hawaî

Haenszel, 1980, Japan

Manousos, 1983, Greece

\section{Colon cancer}

Tajima, 1985, Japan

Graham, 1988, USA

Tuyns, 1988, Belgium

$\mathrm{Hu}$, 1991, China

Steinmetz, 1993, Australia

\section{Rectum cancer}

Haenszel, 1980, Japan

Tạima, 1985, Japan

Tuyns, 1988, Belgium

Hu, 1991, China

\section{Larynx cancer}

Theng. 1992, China

\section{Esophagus cancer}

Cook-Mozaffari, 1979,Iran
Cases!

controls?

179/357 (H)

leek (freq)

high vs. low

Japanese: 0.63

Hawaiian: 0.66

$588 / 1176$ (H)

japanese leek (freg/mo) $\leq 1$ vs. $<1$

0.78 "

$100 / 100$ (H)

onion (fregimo)

$0,2,4,10,30$

leek (freqimo)

$0,2,4,10,30$

'no association'

'ne association'

\begin{tabular}{|c|c|c|c|}
\hline 42/186 (H) & onion (freq/wk) & tertiles: $<1,1 \cdot 3, \geq 4$ & $1.0,1.31,2.84^{b}$ \\
\hline 428/428. (N) & onion & not specified & 'sign. reduced risk \\
\hline $53 / 2851(\mathrm{P})$ & leek & yes vs. no & $0.34=$ \\
\hline & onion + shallot & yes vs. no & $0.16^{\prime \prime}$ \\
\hline
\end{tabular}

$111 / 336$ (H)

garlic (freg)

no vs. yes

'no association'

220/438 (P) onion lfreq/wk|

\section{quartiles:}

men: $<0.5,<1.0, \leq 2.9,>2.9$ men: $1.0,0.85 .0 .41,0.86^{\text {f }}$ women: $0,<1.0, \leq 2.5,>2.5$

$\begin{array}{llll}\text { ?11176 (H) } & \text { iapanese leek (freqimo) } \geq 1 \text { vs. }<1 & 0.65 \\ 51 / 186(\mathrm{H}) & \text { onion (freq/wk) } & \text { tertiles: }<1.1 .3, \geq 4 & 1.0,1.17,2.99^{\text {b }} \\ 368 / 2851 \text { (P) } & \text { leek: } & \text { yes vs, no } & 0.23^{\text {a }} \\ & \text { onion+shalloi } & \text { yes vs. no } & 0.17 \text { " }\end{array}$

$225 / 336$ (H)

garlic (freq)

no vs. yes

women: $4.82^{2}$

$201 / 414(P) \quad$ garlic tertiles: low-medhigh $\quad 1.0,0.6,0.5^{b}$

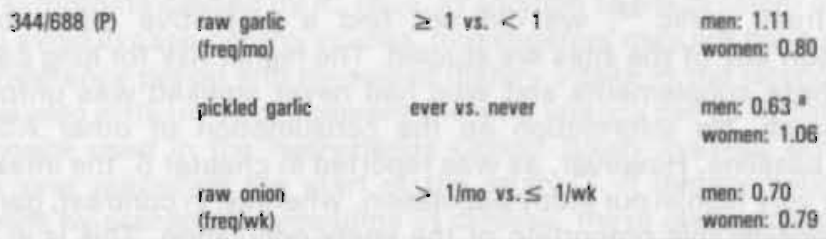


Table, continued

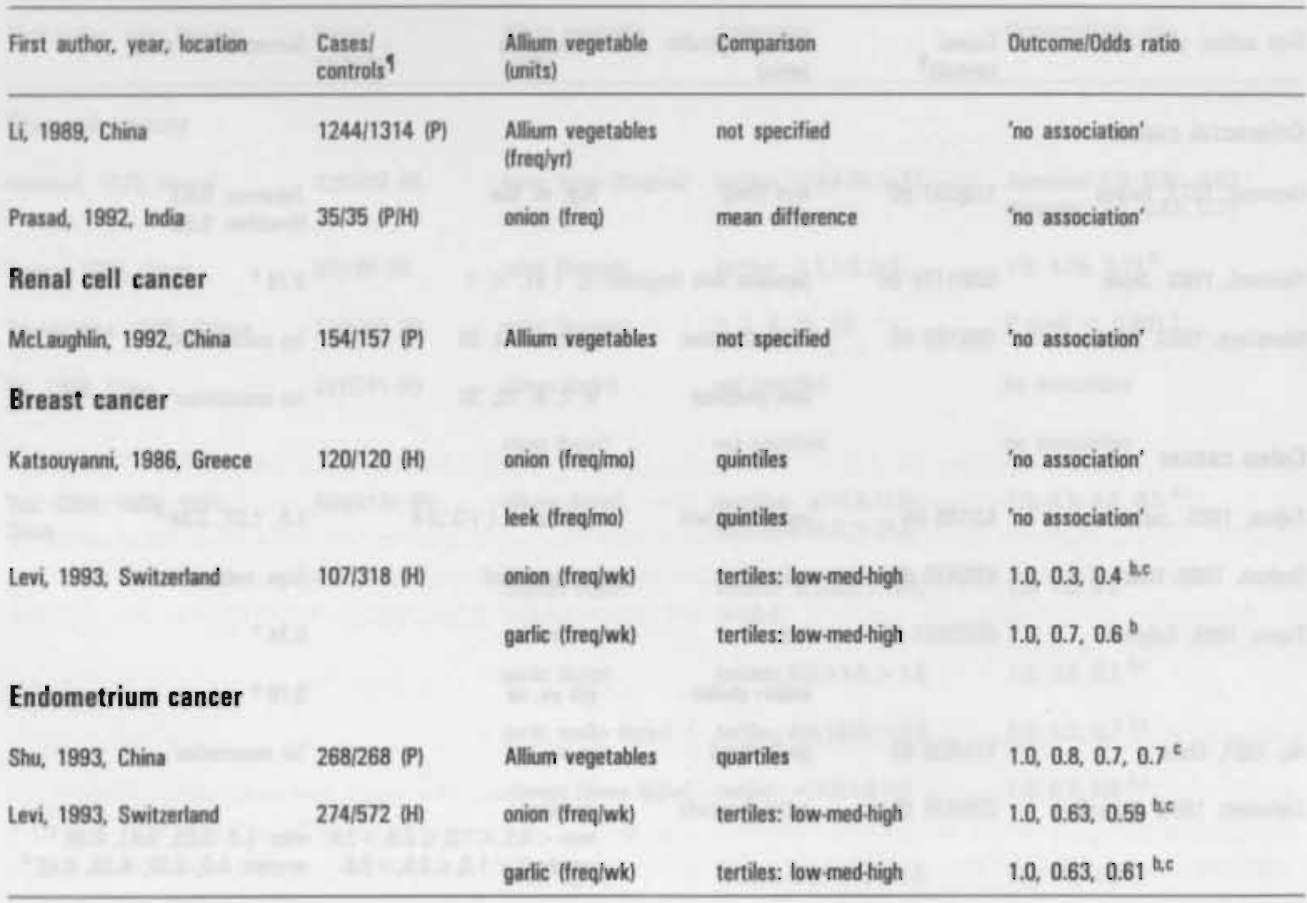

4. $\mathrm{H}$-Hospitat; P-Population; N-Neighborhood

a: $95 \%$ confidence interval does not include 1.0

b: statistically significant trend

c: adjusted for other lood items

\section{Results from the Netherlands Cohort Study on diet and cance?}

The Netherlands Cohort Study on diet and cancer is the first prospective cohort study in which the relation with onion and leek consumption, the use of garlic supplements, and risk for cancer was specifically investigated. After 3.3 years of follow-up, a significantly decreased risk for stomach carcinorna (excl. cardia) was observed with increasing consumption of onions. No protective effect of onion consumption was seen for cardia carcinoma, colon and rectum carcinoma, or for lung and breast carcinoma. Consumption of leeks was not associated with the risk of cancer at any of these sites. Although garlic supplements are reported to contain potentially chemopreventive compounds that are also present in fresh garlic ${ }^{38}$, we did not find a protective effect of the use of garlic supplementson any of the sites we studied. The higher risk for lung cancer among subjects who used these supplements and who had never smoked was unforeseen and warrants further research. No information on the consumption of other Allium vegetables was collected at baseline. However, as was reported in chapter 5, the intake of fresh garlic was probably not very high in our study population, whereas, in contrast, garlic supplements were used by a considerable proportion of the study population. This is in accordance with the results from the Dutch national Food Consumption Survey showing that garlic supplements 
are the most frequently used type of dietary supplement by eiderly persons in the Netherlands (chapter 3).

Overall, our results are not in line with those from most case-control studies, except for the lower risk for stomach carcinoma associated with onion consumption. Possible explanations for this discrepancy will be discussed below.

Selection bias in cohort studies may occur when loss to follow-up is related to exposure ${ }^{39}$. However, since the completeness of the follow-up in the Netherlands Cohort Study was very high ${ }^{40}$, the results cannot be considered to be explained by exposure-related loss to follow-up. On the other hand, it might be possible that selection bias in case-control studies is accountable for the negative associations observed in most of the case-control studies. Selection bias may be introduced by the investigators when cases and controls are selected differently with respect to the exposure under study. Although in most case-control studies that selected hospital controls patients with other gastrointestinal diseases (e.g. ${ }^{19.22}$ ) or with diseases that involved dietary recommendations, were not included (e.g. in ${ }^{9,19,23}$ ). it is still possible that the selected control-patients were affected by diseases related to diet. In the only study that showed a significantly higher risk for gastrointestinal cancer with onion consumption, patients with severe gastric disorders were selected as controls ${ }^{8}$. When population controls are selected, it is also possible that the diets of those who decided to participate in the study differ from the diets of nonresponders, especially when the willingness to participate is related to dietary practices ${ }^{41}$.

One of the major problems in retrospective studies is the possibility of recall bias due to knowledge of the disease status. Recall bias does not play a role in prospective studies, since exposure is measured in the study population before the disease is diagnosed ${ }^{39}$. However, this type of bias only leads to negative associations if cases recall their Allium intake less frequently than controls, which is not very plausible. Nevertheless, differential recall cannot be ruled out when cases could have changed their dietary habits as a consequence of their disease, since it has been shown that recall of past dietary intake can be influenced by current dietary habits ${ }^{42,43}$. This type of recall bias may be particularly important in retrospective studies of dietary habits in relation with diseases that cause symptoms of the digestive tract, such as gastrointestinal cancer. In a large survey by Koch and Donaldson, patients with complaints of dyspepsia often named onions as one of the foods causing aggravation of gastrointestinal symptoms ${ }^{44}$. Also, raw onions were shown to increase the number af heartburn episodes in patients with a chronic reflux symptoms, compared to a noonion diet ${ }^{45}$.

Specification of the correct reference period is also of major importance in case-control studies of diseases with a long latency period between occurrence and diagnosis. Most casecontrol studies, however, probed for dietary habits before diagnosis of the disease that was studied $9,10,19,20,23,25,26,33$ rather than before symptoms of disease ${ }^{17,18,34,36}$ or in the period before recent dietary changes, as was done in an Australian case-control study on foodgroup consumption and colon cancer ${ }^{27}$. Other çase-control studies used a fixed time interval before the interview ${ }^{8,11 \cdot 16.28 .30-32}$ or measured current diet ${ }^{7.21 .22 .29}$, irrespective of the duration of the disease or the symptoms caused by it. Thus, in addition to the problem of recall bias, which may be hard to avoid in case-contro! studies, investigators may not have specified the etiologically correct reference period and measured dietary intake in the latency or disease period. Of course, it is also difficult to circumvent the long latency period in cohort studies. The dietary questionnaire used in the Netherlands Cohort Study inquired after the usual dietary intake in the year preceding the start of the study ${ }^{46}$. If dietary habits had been changed before baseline by preclinical symptoms of disease, these dietary data may reflect the consequences of cancer on usual dietary intake instead of the diet in the etiologically, relevant period. To examine this possibility, cases diagnosed during the first year of follow-up 
were excluded from the analysis. In Chapters $5-8$, it is shown this exclusion only marginally altered the rate ratio estimates. However, a one-year period may not be long enough for this purpose, since symptoms of disease may have been present for a longer period before baseline. Especially in the case of stomach carcinoma, for which a significantly decreased risk with onion consumption was observed also after exclusion of cases from the first followup year, exclusion of cases from later years may provide more insight into this possibility. To study this in more detail a longer follow-up period will be required.

Correct ranking of subjects in distinct exposure categories is an important issue in epidemiologic research. Consequently, the instrument used in observational research to measure exposure has to be validated to define its ability to rank subjects adequately with respect to their true exposure. To assess the validity of the semiquantitative food frequency: questionnaire used in the Netherlands Cohort Study, a separate study has been carried out in a subgroup of the cohort by comparing the questionnaire with three 3 -day diet records ${ }^{44}$. However, the validity has not been assessed for individual vegatables such as onions and leeks, since a recording period of nine days may not be long enough to provide stable estimates of consumption of food items, that may show a large intraindividual day-to-day variation ${ }^{46-48}$. If nondifferential misclassification with respect to onion and leek consumption has occurred, the actual associations may be stronger than those we have reported. As part of the larger validation study, the interviewers also asked information on the use of clietary supplements. Although it was difficult to assess the validity of an open-ended question, we were able to show in chapter 4 , that our questionnaire has substantial relative validity in measuring overall use of dietary supplements. The highest agreement between interview information and the questionnaire was observed for garlic supplements.

With respect to garlic supplement use, the Netherlands Cohort Study is the first study to date that has evaluated the effect of these supplements on the risk for cancer. Thus, we cannot compare our results with those from other studies. To account for the possibility that dietary supplement users are different from persons not using supplernents, we also evaluated the risk associated with use of garlic supplements with other supplements, with subjects using other dietary supplements as reference. None of the associations we observed were different from unity. However, the higher risk for lung cancer among subjects who had never smoked was nearly significant and certainly deserves further attention when a larger number of cases is available.

Unlike in most published case-control studies on the Allium/cancer hypothesis, we have tried to rule out that other dietary and nondietary risk factors for cancer associated with the exposure explain our findings. Since none of the rate ratio estimates were markedly changed after inclusion of all important confounders in the analyses, it is unlikely that residual confounding due to inaccuracies in the measurements of these factors explain the results. Nevertheless, it might still be posșibie that another factor might be involved.

Finally, in trying to find an explanation for the consistencies as well as the discrepancies between results from case-control studies and our cohort study, it is important to consider the level and variability in consumption between study populations. However, it is practically impossible to compare these aspects: several case-control studies reported associations for increasing frequencies of consumption, other studies used consumed amount per year or week, some studies evaluated 'high' versus 'low' intake without further specification " or simply yes versus no consumption. Furthermore, some investigators categorized onions with garlic, or onions with shallots into one category. Most of the case-control studies categorized the subjects in quantiles, instead of using intake itself as starting point for categorization, as was done in our study and in some of the case-control studies $9,20,25,26$.

Since the level of presumed chemopreventive compounds varies by type of Allium vegetable, variety, growing conditions, storage and preparation methods ${ }^{49-53}$, it might be possible that 
differences in results between studies are (partly) caused by differences in, for instance, preparation methods. In one of the case-control studies, a protective effect was seen for raw onions and not for cooked onions ${ }^{14}$.

\section{Biological evidence}

Most experimental research with respect to the suggested chemopreventive properties of Allium vegetables has been focused on the role of the so-called organosulfur compounds. The theory of the consecutive steps in the carcinogenic process has proved very helpful in arranging the results from experimental research, reviewed in chapter 2. As was concluded, allyl-containing compounds of garlic possess antimutagenic properties and might even exhibit anticarcinogenic activity against a variety of carcinogens. However, as we also remarked, available evidence is far from complete. Also, compounds from other Allium vegetables have not been studied as extensively yet as those from garlic. The precise role of other potentially chemopreventive compounds present in Allium vegetables, flavonols and glutathione, is at present not clear, as was discussed in chapters 5-8.

One of the interesting aspects, however, is that compounds from garlic were being examined in laboratory experiments for their anticarcinogenic effect long before any study relating garlic and garlic compounds to a decreased risk for cancer in humans was published. These early studies were initiated after a publication reporting the selective inhibition of certain enzymes that were supposed to play a role in tumour growth ${ }^{54}$. The original aim of this study was to elucidate which compounds from garlic were responsible for the known antibacterial effect of garlic ${ }^{55}$. As was discussed in chapter 8 , this antibacterial effect may provide an interesting clue for explaining the protective effect of onions on the risk of carcinoma in that part of the stomach that is suggested to be related with infection Helicobacter pylori infection ${ }^{56,57}$.

\section{Recommendations for future research}

The evidence from the Netherlands Cohort Study on diet and cancer for a protective effect of onion consumption on the risk for stomach carcinoma warrants further research. To study the possible influence of preclinical symptoms of cancer in more detail, the association between onion consumption and stomach carcinoma risk will be investigated further in the Netherlands Cohort Study after a longer follow up period. Also, detailed analysis, focusing on topographic sites and histologica! subtypes, may be informative with respect to the role of Allium vegetables.

The higher risk for lung cancer among never-smokers associated with garlic supplement use also needs to be examined further. More detailed exposure information (duration of use, period of exposure, content of specific garlic supplementsi mav be required, as well as more detailed information on morphological characteristics of the tumours. Also, a longer follow-up period will be needed to assess the risk more definitively.

Future cohort studies on diet and cancer should measure the consumption of Allium vegetables to determine if our results can be reproduced in other study populations and to examine the association with other Allium vegetables, particularly with fresh garlic. Also, it might be worthwile to examine the influence of aspects that might change the leve! of potentially chemopreventive compounds, e.g. preparation methods.

To clarify the biological mechanisms, more systematic experimental research is needed to examine which Allium compounds, in realistic amounts, may be promising with respect 
to chemoprevention of cancer in humans. Furthermore, research on the dose level and bioavailability of these compounds is required, and the safety and toxicity have to be tested.

In view of the decreased risk for stomach carcinoma, possibly related to bacterial infection, it might be worthwhile to investigate the antibacterial effect of Allium vegetables more extensively.

\section{References}

1. Fenwick GR, Hanley AB. The genus Allium - Part 1. CRC Crit Rev Food Sci Nutr 1985;22:199271.

2. Block G, Patterson B, Subar A. Fruit, vegetables, and cancer prevention: a review of the epidemiological evidence. Nutr Cancer 1992;18:1-29.

3. Steinmetz K, Potter JD. Vegetables, fruit, and cancer. I. Epidemiology. Cancer Causes Control $1991: 2: 325-357$.

4. Steinmetz KA, Potter JD, Folsom AR. Vegetables, fruit, and lung cancer in the lowa Women's Health Study. Cancer Res 1993;53:536-543.

5. Swanson CA, Mao BL, Li YI, Lubin JH, Yao SX, Wang JZ, Cai SK, Hou Y, Blot WJ. Dietary determinants of lung cancer risk: results from a case-control study in Yunnan Province, China. Int J Cancer 1992;50:876-880.

6. Macquart-Moulin G, Riboli E, Cornee J, Charnay B, Berthezene P, Day N. Case-control study on colorectal cancer and diet in Marseilles. Int J Cancer 1986;38:183-191.

7. Haenszel W, Kurihara M, Segi M, Lee RKC. Stomach cancer among Japanese in Hawaii. J Natl Cancer Inst 1972;49:969-988.

8. Tajima K, Tominaga S. Dietary habits and gastro-intestinal cancers: a comparative case-control study of stomach and large intestinal cancers in Nagoya, Japan. Jpn J Cancer Res (Gann) 1985;76:705-716.

9. Trichopoulos D, Ouranos G, Day NE, Tzonou A, Manousos O, Papadimitriou C, Trichopoulos A. Diet and cancer of the stomach: a case-control study in Greece. Int J Cancer 1985;36:291-297.

10. Hu J, Zhang S, Jia E, Wang E, Liu S, Liu Y, Wu Y, Cheng Y. Diet and cancer of the stomach: a case-control study in China. Int J Cancer 1988;41:331-335.

11. You W, Blot WJ, Chang Y, Ershow AG, Yang Z, An Q, Henderson B, Xu G, Fraumeni JF, Wang $T$. Diet and high risk of stomach cancer in Shandong, China. Cancer Res 1988;48:3518-3523.

12. You W, Blot WJ, Chang Y, Ershow AG, Yang Z, An Q, Henderson B, Xu G, Fraumeni JF, Wang T. Allium vegetables and reduced risk of stoomach cancer. J Natl Cancer Inst 1989;81:162-164.

13. You WC, Chang YS, Yang ZT, Zhang L, Xu GW, Blot WJ, Kneller R, Keefer LK, Fraumeni JF. Etiological research on gastric cancer and its precursor lesions in Shandong, China. In: Relevance to human cancer of $\mathrm{N}$-nitroso compounds, tobacco smoke and mycotoxins. Ed. IK O'Neill, J Chen, H Bartsch, Lyon International agency for research on cancer, 1991: pp 33-38.

14. Buiatti E, Palli D, Decarli A, Amadori D, Avellini C, Bianchi S, Biserni R, Cipriani F, Cocco P, Giacosa A, Marubini E, Puntoni R, Vindigni C, Fraumeni J, Blot W. A case-control study of gastric cancer and diet in Italy. Int J Cancer 1989;44:611-616.

15. Cipriani F, Buiatti E, Palli D. Gastric cancer in Italy. Ital J Gastroenterol 1991;23:429-435.

16. Palli D, Bianchi S, Decarli A, Cipriani F, Aveliini C, Cocco P, Falcini F, Puntoni $R$, Russo A, Vindigni C, Fraumeni JF, Blot WJ, Buiatti E. A case-control study of cancer of the gastric cardia in Italy. Br J Cancer 1992;65:263-266.

17. Graham S, Haughey B, Marshall J, Brasure J, Zielezny M, Freudenheim J, West D, Nolan J, Wilkinson G. Diet in the epidemiology of gastric cancer. Nutr Cancer 1990;13:19-34.

18. Boeing H, Jedrychowski, Wahrendorf J, Popiela T, Tobiasz-Adamczyk B, Kulig A. Dietary risk factors in intestinal and diffuse types of stomach cancer: a multicenter case-control study in Poland. Cancer Causes and Control 1991;2:227-233.

19. Gonzalez CA, Sanz JM, Marcos G, Pita S, Brullet E, Saigi E, Badia, A, Riboli E. Dietary factors and stomach cancer in Spain: a multi-centre case-control study. Int $J$ Cancer 1991;49:513-519.

20. Tuyns AJ, Kaaks R, Haelterman M, Riboli E. Diet and gastric cancer. A case-control study in Belgium. Int J Cancer 1992;51:1-6.

21. Haenszel H, Berg JW, Segi M, Kurihara M, Locke FB, Large-bowel cancer in Hawaiian Japanese. $\mathrm{JNCl} 1973 ; 51: 1765-1779$.

22. Haenszel W, Locke FB, Segi M. A case-control study of large bowel cancer in Japan. J Nati Cancer Inst 1980;64:17-22. 
23. Manousos O, Day NE, Trichopoulos D, Gerovassilis F, Tzonou A, Polychronopoulou A. Diet and colorectal cancer: a case-control study in Greece. Int J Cancer 1983;32:1-5.

24. Graham S, Marshall J, Haughey B, Mittelman A, Swanson M, Zielezny M, Byers. T, Wilkinson G, West D. Dietary epidemiology of cancer of the colon in western New York. Amı J Epidemiol $1988 ; 128: 490-503$.

25. Tuyns AJ, Kaaks R, Haelterman M. Colorectal cancer and the consumption of foods: a casecontrol study in Belgium. Nutr Cancer 1988;11:189-204.

26. Hu J, Liu $Y, Y u Y$, Zhao $T$, Liu S, Wang $O$. Diet and cancer of the colon and rectum: a casecontrol study in China. Int J Epidemiol 1991:20:362-367.

27. Steinmetz K, Potter JD. Food group consumption and colon cancer in the Adelaide case-control study. I. Vegetable and fruit. Int J Cancer 1993;53:711-719.

28. Zheng W, Blot WJ, Shu XO, Gao YT, Ji BT, Ziegler RG, Fraumeni JF. Diet and other risk factors for laryngeal cancer in Shanghai, China. Am J Epiderniol 1992;136:178-191.

29. Cook-Mozaffari PJ, Azordegan F, Day NE, Flessicaud A, Sabai C, Aramesh B. Oesophageal cancer studies in the Caspian littoral of Iran: results of a case-control stucly. $\mathrm{Br} J$ Cancer 1979;39:293.

30. Li JY, Ershow AG, Chen ZJ, Wacholder S, Li GY, Guo W, Li B, Blot WJ. A case-control study of cancer of the esophagus and gastric cardia in Linxian. Int J Cancer 1989;:43:755i-761.

31. Prasad MPR, Krishna TP, Pasricha S, Krishnaswamy K, Quereshi MA. Esophageal cancer and diet - a case-control study. Nutr Cancer 1992,18:85-93.

32. McLaughlin JK, Gao YT, Gao RN, Zheng W, Ji BT, Blot WJ, Fraumeni JF. Risk factors for renalcell cancer in Shanghai, China. Int J Cancer 1992;52:562-565.

33. Katsouyanni K, Trichopoulos D, Boyle P, Xirouchaki E, Trichopoulou A, Lisseos B, Vasilaros S, Macmahon B. Diet and breast cancer: a case-control study in Greece. Int J Cancer 1986:38:815820.

34. Levi F, La Vecchia C, Gulie C, Negri E. Dietary factors and breast cancer risk in Vaud, Switzerland. Nutr Cancer 1993;19:327-335.

35. Shu XO, Zheng W, Potischman N, Brinton LA, Hatch MC, Gao YT, Fraumeni JF. A populationbased case-control study of dietary factors and endometrial cancer in Shanghai, People's Republic of China. Am J Epidemiol 1993;137:155-165.

36. Levi F, Franceschi S, Negri E, La Vecchia C. Dietary factors and the risk of endometrial cancer. Cancer 1993;71:3575-3581.

37. Yu Y, Taylor PR, Li J, Dawsey SM, Wang G, Guo W, Wang W, Liu B, Blot WJ, Shen Q, Li B. Retrospective cohort study of risk factors for esophageal cancer in Linxian,People's. Republic of China. Cancer Causes Control 1993;4:195-202.

38. Lawson LD, Wang ZYJ, Hughes BG. Identification and HPLC Quantification of the sulfides and dialk(en)yi thiosulfinates in commercial garlic products. Planta Med 1991;57:363-370.

39. Rothman KJ. Modern epidemiology. Boston: Little, Brown and Company, 1986.

40. Van den Brandt PA, Van 't Veer P, Goldbohm RA, Dorant E, Volovics A, Hermus RJJ, Sturmans F. A prospective cohort study on dietary fat and the risk of postmenopausal breast cancer. Cancer Res 1993;53:75-82.

41. Willett W. Epidemiologic studies of diet and cancer. Med Oncol Tumor Pharmacol 1990;7:93-97.

42. Moller Jensen O. Wahrendorf J, Rosenquist A, Geser A. The reliability of qeustionnaire-derived historical dietary information and temporal stability of food habits in individuats. Am $J$ Epidemiol 1984;120:281-290.

43. Wu ML, Whitternore AS, Juñy DL. Errors iñ reported dietary intakes. Il. Long-term recall.. Am. $J$ Epidemiol 1988;128:1137-1145.

44. Koch JP, Donaldson RM. A suryey of food intolerances in hospitalized patients. New Eng! J Med $1964: 271: 657-660$.

45. Allen ML, Mellow MH, Robinsor, MG, Orr WC. The effect of raw onions on acid reflux and reflux symptoms. Am J Gastroenterol 1990;85:377-380.

46. Goldbohm RA, Van den Brandt PA. Brants HAM, Van 't Veer P. AI M, Sturmans F, Hermus FJJ. Validation of a dietary questionnaire used in al large-scale prospective cohort study on diet and cancer. Eur J Clin Nutr 1994:48:253-265.

47. Salvini S, Hunter DJ, Sampson L, Stampfer MJ, Colditz GA, Rosner B, Willett WC. Food-based validation of a dietary questionnaire: the effects of week-to-week variation in food consumption. Int J Epidemiol 1989;18:858-867.

48. Potosky AL, Block G, Hartman AM. The apparent validity of diet questionnaires is influenced by number of diet-records used for comparison. J Am Diet Assoc 1990:90:810-813. 
49. Block E, Naganathan S, Putman D, Zhao SH. Allium chemistry: HPLC analysis of thiosulfinated from onion, garlic, wild garlic (ramsoms), leek, scallion, shallot, elephant (great-headed) garlic, chive, and Chinese chive. Uniquely high allyl to methyl ratios in some garlic samples. J Agric Food Chem 1992;40:2418-2430.

50. Bilyk A, Sapers GM. Distribution of quercetin and kaempferol in lettuce, kale, chive, garlic chive, leek, horseradish, red radish, and red cabbage tissues. J Agric Food Chem 1985:33:226-228.

51. Hertog MGL, Hollman CH, Katan MB. Content of potentially anticarcinogenic flavonoids of 28 vegetables and 9 fruits commonly consumed in The Netherlands. J Agric Food Chem 1992;40:2379-2383.

52. Bylik A, Cooper PL, Sapers GM. Varietal differences in distribution of quercetin and kaempferol in onion (Allium cepa L.) tissue. J Agric Food Chem 1984;32:274-276.

53. Starke H, Herrmann K. Flavonols and flavones of vegetables. VI. On the changes of flavonols of onions. Z Lebensm Unters Forsch 1976;161:137-142.

54. Weisberger A.S., Pensky J. Tumour inhibiting effects derived from an active principle of garlic (allium sativum). Science 1957;126:1112-1114.

55. Cavallito CJ, Bailey JH. Allicin, the antibacterial principle of allium sativum. I. Isolation, physical properties and antibacterial action. J Am Chem Soc 1944;66:1950-1951.

56. Hansson LE, Engstrand L, Nyren O, Evans DJ, Lindgren A, Bergströrn R, Andersson B, Athlin L, Bendtsen O, Tracz P. Helicobacter pylori infection: Independent risk indicator of gastric: adenocarcinoma. Gastroenterol 1993;105:1098-1103.

57. Parsonnet J, Samloff IM, Nelson LM, Orentreich N, Vogelman JH, Friedman GD. Helicobacter pylori, pepsinogen, and risk for gastric adenocarcinoma. Cancer Epidemiol Biomarker Prevention $1993 ; 2: 461-466$. 


\section{Summary}

This thesis concentrates on the relation between the consumption of onions and leeks, the use of garlic supplements and the incidence of cancer.

Results from epidemiologic studies indicate that consumption of onions, leeks, garlic. or other Allium vegetables, such as chives and shallots, might reduce the risk for various cancer types considerably. It has been suggested that specific chemical compounds typically present in Allium plants are accountable for the lower risk. Chapter 2 presents an overview of the literature on the relation between garlic consumption and cancer risk. in human populations, as well as on the effect of garlic and garlic constituents on mutagenesis, carcinogenesis and tumour development investigated in in vitro and in vivo experiments. Epidemiologic studies from China and Italy suggested a decreasing risk for stomach cancer with increasing consumption of garlic or related Allium vegetables. The evidence from laboratory experiments was not conclusive yet as to the preventive potential of garlic and garlic compounds, although many in vitro and in vivo tests indicated that certain 'organosulfur' compounds, which contain large amounts of organically bound sulfur, act antimutagenically and might also inhibit carcinogenesis by inhibition of metabolic activation of procarcinogens, induction of enzymes important for detoxification of carcinogens or by inhibition of tumour promotion. It was concluded that the available evidence from epidemiologic and experimental studies warrants further research into the possible role of garlic in the prevention of cancer in humans.

Some of the potentially chemopreventive compounds from garlic have also been detected in garlic supplements. To gain more insight in the use of dietary supplements in general and of garlic supplements in particular in The Netherlands, data of the first Dutch national Food Consumption Survey, conducted in 1987/88, were analyzed. The results are presented in chapter 3 . In this large survey in a representative sample of the Dutch population of 5898 persons aged 1-75 years, information on the use of dietary supplements has been collected by means of a two-day dietary record. More than $17 \%$ of the population had been using at least one dietary supplement on at least one day of the survey. Age, sex, season, social class, alternative food habits, smoking and diet were related to the use of supplements. In young persons mainly fluoride and vitamin $A D$ preparations were used, while a shift toward other supplements, like garlic and brewer's yeast preparations, was observed with progressing age. The use of single vitamin C supplements was not related to the level of mean daily vitamin $\mathrm{C}$ intake by food consumption.

A substantial part of this thesis is formed by results of The Netherlands Cohort Study on diet and cancer, a large-scale prospective cohort study that was started in 1986 among 120,852 persons aged $55-69$ years. An important methodological issue in epidemiologic studies is correct ranking of subjects in distinct exposure categories. 
Chapter 4 deals with the relative validity of the open-ended question on the use of dietary supplements included in the self-administered questionnaire used in the Netherlands Cohort Study. Subjects in the validation study were participants of a larger validation study carried out in a randomly selected subgroup (59 men and 50 women) of the cohort, living in 12 municipalities in the eastern and western region of The Netherlands. Questionnaire data on dietary supplement use were compared with reference information from three personal interviews collected by trained dieticians within a period of 10 months. The overall sensitivity of the questionnaire concerning the use of any dietary supplement was $65.9 \%$, the specificity was $98.5 \%$; kappa as measure of agreement was estimated at 0.69. A high percentage of recall was observed among women, users of at least three types of dietary supplements, long-term supplement users and those in the oldest age group. Recall of intake of specific supplements ranged from $77.8 \%$ for garlic preparations to $11.8 \%$ for 'other' supplements. It was concluded that estimates of consumption of specific supplements (garlic and vitamin preparations) may provide enough precision to correctly classify individuals as user or nonuser of those supplements.

In chapters 5-8, results of the Netherlands Cohort study on diet and cancer are presented, focusing on the consumption of onions and leeks, the use of garlic supplements and the incidence of lung, breast, colon, rectum and stomach carcinoma. The Netheriands Cohort Study on diet and cancer was started among 58,279 men and 62,573 women, sampled from 204 municipal population registries in The Netherlands, by collecting baseline information on usual diet, the use of dietary supplements and other risk factors for cancer (e.g. smoking habits, education, medical history) with a questionnaire. Toenail clippings were collected for use as exposure biomarker. Cancer incidence in the cohort has been measured by record linkage with all nine cancer registries in The Netherlands and with PALGA, the Dutch network and National Database for Pathology. A case-cohort approach was used, in which accumulation of person-time in the cohort was estimated by follow-up of a randomly selected subcohort of 1688 men and 1812 women. For this thesis, analyses are based on histologically confirmed carcinoma diagnosed in the first 3.3 years of follow-up (September 1986 - December 1989). The follow-up for vital status in the subcohort was complete in this period.

After excluding cases with prevalent cancer other than skin cancer and with incomplete or inconsistent dietary information, the following numbers of incident cases with malignant primary carcinoma remained for analysis: 484 lung, 435 breast, 150 and 143 male and female colon, 93 and 57 male and female rectum and 139 stomach carcinoma cases. Dietary data were available for 3123 members of the subcohort 11525 men and 1598 women) without a previous history of cancer other than skin cancer.

We found no evidence of relation between the consumption of onions or leeks and the incidence of lung carcinoma or any of the four histologic subtypes after controlling for important dietary and nondietary risk factors. The observed rate ratio estimates for lung carcinoma associated with garlic supplement use were inconsistent. The higher risk observed among non-smokers for those using exclusively garlic supplements, compared with those not using dietary supplements, will be investigated further when a larger number of cases is available (chapter 5). For female breast carcinoma, no association was found between onion or leek consumption, the use of garlic supplements and cancer risk (chapter 6). The results of the Netherlands Cohort Study do also not support an inverse association between the consumption of onions and leeks and the incidence of male colon or rectum carcinoma. In women, a lower risk was found for rectum carcinoma among those consuming less than 0.25 onions per day (rate ratio $(R R)=0.36,95 \%$ confidence interval ( $\mathrm{CI}) \quad 0.13-0.99$ ) compared to those not consuming onions, but the 
trend in the RRs was not statistically significant. All other RRs for female colon and rectum carcinoma associated with onion consumption were slightly higher than one, but not significantly. Leek consumption was not associated with colon and rectum carcinoma incidence in women and the use of garlic supplements was not associated with colon and rectum carcinoma in men and women combined (chapter 7). A significant inverse association was observed between onion consumption and stomach carcinoma risk. The rate ratio for stomach carcinoma for those in the highest onion consumption category $(\geq$ 0.5 onions per day), compared to those not consuming onions, was $0.50(95 \% \mathrm{Cl} 0.26$ $0.96)$ after controlling for confounding. The protective effect of onions was restricted to carcinoma risk in the non-cardia part of the stomach (RR $=0.31,95 \% \mathrm{C}$ ! 0.14-0.70, in the highest consumption categoryl, and remained after exclusion of those with a stomach disorder in their history $(R R=0.35,95 \% \mathrm{Cl} 0.15-0.86$, in the highest consumption category). Neither the consumption of leeks, nor the use of garlic supplements were significantly associated with stomach carcinoma risk (chapter 8).

To account for the possible influence of preclinical disease on dietary intake, all analyses presented in chapters 5-8 were also carried out after exclusion of cases diagnosed during the first follow-up year. The results differed little from those observed for the entire group.

In chapter 9, the results of the Netherlands. Cohort Study on diet and cancer presented in chapters 5-8 were discussed within the context of the evidence from earlier epidemiologic studies on Allium vegetable consumption and the risk for cancer. Overall, our results are not in line with those from most case-control studies, except for the lower risk for stomach carcinoma associated with onion consumption. Possible explanations for this discrepancy were considered in chapter 9 and suggestions for future research were made. 


\section{Samenvatting}

Dit proefschrift gaat over het verband tussen de consumptie van uien en prei, het gebruik van knoflooksupplementen en het risico op kanker.

Uien, prei en knoflook, maar ook andere groenten die behoren tot de Alliums, worden sinds mensenheugenis gebruikt voor het voorkómen en behandelen van allerlei aandoeningen. Een van de mogelijke werkingen zou het voorkómen van kanker kunnen zijn. In een aantal epidemiologische onderzoeken die recent zijn gepubliceerd zijn aanwijzingen gevonden dat consumptie van uien, bieslook, sjalotten, prei, knoflook en ander groenten behorende tot de Alliums, het risico op verscheidene soorten kanker aanzienlijk kan verlagen. In hoofdstuk 2 van het proefschrift wordt een overzicht gegeven van de literatuur op het gebied van knoflook en het risico op kanker. Resultaten uit epidemiologisch onderzoek in China en Italië suggereren dat het risico op maagkanker daalt bij toenemende consumptie van knoflook of andere Alliumgroenten. Aanwijzingen voor een beschermende werking van knoflook verkregen via experimenteel onderzoek zijn nog verre van afdoende. Niettemin blijkt uit veel in vitro en in vivo laboratoriumonderzoek dat bepaalde organische zwavelverbindingen die alleen in Alliumplanten voorkomen, antimutagene activiteit vertonen en mogelijk ook de carcinogene activiteit van verschillende stoffen kunnen tegengaan door remming van metabole activering van procarcinogenen, door inductie van enzymen die een belangrijke rol spelen bij het onschadelijk maken van carcinogene stoffen of door remming van tumorontwikkeling in de promotiefase. De resultaten van epidemiologisch en experimenteel onderzoek samen vormen voitdoende reden om de rol van knoflook en knoflookbestanddelen in het voorkomen van kanker bij mensen verder te onderzoeken.

Enkele van de mogelijk beschermende stoffen uit knoflook zijn wellicht ook aanwezig in knoflooksupplementen. Om meer inzicht te krijgen in het gebruik van voedingssupplementen in het algemeen en knoflooksupplementen in het bijzonder in Nederland, zijn de data van de eerste landelijke Voedselconsumptiepeiling geanalyseerd (hoofdstuk 3). In dit onderzoek, dat in 1987 en 1988 werd uitgevoerd bij een representatieve steekproef van 5898 Nederlanders van 1.75 jaar, is informatie verzameld over het gebruik van voedingssupplementen met behulp van een tweedaagse dagboekmethode. Ruim $17 \%$ van de Nederlandse bevolking gebruikte een of meer voedingssupplementen op een of beide onderzoeksdagen. Leeftijd, geslacht, rookgedrag, seizoen, sociale klasse, alternatieve voedingsgewoonten en het volgen van een dieet hielden verband met het gebruik van voedingssupplementen. In de jongste leeftijdscategorieën bevonden zich voornamelijk fluoride- en vitamine $A D$-gebruikers, terwijl bij vorderende leeftijd er een verschuiving optrad naar het gebruik van meer bijzondere preparaten zoals knoflookpillen en biergist. Het gebruik van enkelvoudige vitamine $\mathrm{C}$-preparaten was niet gerelateerd 
aan de hoogte van de gemiddelde vitamine C-inneming via de voeding per persoon per dag.

Een substantieel deel van dit proefschrift is gewijd aan de resultaten van de Nederlands Cohort Studie naar voeding en kanker, die sinds 1986 onder 120.852 personen in de leeftijd van 55-69 jaar wordt uitgevoerd. Een belangrijk methodologisch aspect in epidemiologisch onderzoek is het vaststellen of de deelnemers op basis van de meting correct zijn ingedeeld in de verschillende expositie-categorieẽn. In hoofdstuk 4 zijn gegevens over het gebruik van voedingssupplementen, die zijn gemeten met behulp van een open vraag, vergeleken met referentiegegevens verzameld via interviews. Deze studie maakte deel uit van een grotere valideringsstudie naar de validiteit van de schriftelijke voedselfrequentielijst die in de Nederlandse Cohort Studie naar voeding en kanker wordt gebruikt om de gebruikelijke voedingsgewoonten te meten. De deelnemers aan de valideringsstudie vormden een sub-groep uit het cohort (59 mannen en 50 vrouwen), die twee jaar na de start van het cohortonderzoek elk driemaal zijn geïnterviewd. De interviewgegevens dienden als referentie voor de informatie uit de open vraag naar het gebruik van voedingssupplementen uit de vragenlijst die twee maanden na het laatste interview nogmaals werd ingevuld. Het percentage personen dat op basis van de open vraag terecht als gebruiker van een voedingssupplement werd bestempeld was $65,9 \%$. Het percentage personen dat terecht bij de niet-gebruikers werd ingedeeld was hoger: $98,5 \%$. Kappa, als maat van overeenstemming, vas 0,69 . Het percentage deelnemers dat zich terecht het supplementgebruik herinnerde was hoger onder vrouwen, onder gebruikers van tenminste drie verschillende supplementen, onder personen die minstens twee jaar supplementen gebruikten en onder de oudere deelnemers. Knoflooksupplementen scoorden het best: $77,8 \%$ van de knoflooksupplementgebruikers noemde het gebruik ook in de vragenlijst. Van de mensen die. 'overige supplementen' gebruikten, herinnerde zich slechts $11,8 \%$ het gebruik ervan. De conclusie op basis van deze studie luidde dat de voor specifieke supplementen (knoflook. en vitamines) de informatie gemeten met de open vraag in de vragenlijst goed genoeg is om personen als gebruiker van zo'n supplement in te delen.

In de hoofdstukken 5-8 zijn resultaten uit de Nederlandse Cohort Studie naar voeding en kanker gepresenteerd met betrekking tot het verband tussen de consumptie van uien en prei, het gebruik van knoflooksupplementen en het risico op kanker van de long, borst, colon, rectum en maag. De Nederlandse Cohort Studie is in 1986 gestart onder 58.279 mannen en 62.573 vrouwen afkomstig uit 204 gemeenten verspreid over geheel Nederland, met het verzamelen van gegevens over de gewoonlijke voedselconsumptie, het gebruik van voedingssupplementen en potentiële confounders, zoals rookgewoonten, opleiding en medische voorgeschiedenis. Daarnaast zijn teennagelknipsels verzameld als "biomerker" van de lichaamstatus van een aanta! sporenelementen. De incidentie van kanker in het cohort wordt gemeten door middel van geautomatiseerde koppeling met alle negen regionale kankerregistraties in Nederland, en met PALGA, het Pathologisch Anatomisch Landelijk Geautomatiseerd Archief. $\mathrm{Er}$ is voor een $\mathrm{zg}$. case-cohortbenadering gekozen waarbij de persoonsjaren 'at risk' die door het cohort worden opgebouwd, worden geschat aan de hand van gegevens van een aselect getrokken subcohort van 3500 personen (1688 mannen en 1812 vrouwen). De analyses die in de hoofdstukken 5-8 worden gepresenteerd zijn gebaseerd op de incidentie van kanker in 
de eerste 3,3 jaar vanaf de start van het onderzoek (van september 1986 tot en met december 1989). In deze periode was de follow-up van het subcohort volledig.

$\mathrm{Na}$ uitsluiting van personen die al voor de start van het onderzoek kanker hadden gekregen of waarvan de vragenlijstinformatie inconsistent of incompleet was, bleven er 484 longkanker, 435 borstkanker, 150 mannen en 143 vrouwen met colonkanker, 93 mannen en 57 vrouwen met rectumkanker en 139 maagkanker cases over. Van het subcohort waren na uitsluiting nog 3123 personen beschikbaar (1525 mannen en 1598 vrouwen). Er werd geen significant verband voor longkanker gevonden met de consumptie van uien en prei na controle voor belangrijke andere risicofactoren, ook niet voor een van de vier histologische subtypen die zijn onderscheiden. De resultaten van de analyses met betrekking tot het gebruik van knoflooksupplementen waren inconsistent. Het risico voor longkanker leek voor mensen die uitsluitend knoflooksupplementen gebruikten verhoogd, vergeleken met personen die geen voedingssupplementen gebruikten, met name onder de niet-rokers. Dit verband za! nader onderzocht worden als er meer cases beschikbaar zijn (hoofdstuk 5). Voor borstkanker bij vrouwen werden geen aanwijzingen gevonden dat er een verband was met de consumptie van uien en prei en het gebruik van knoflooksupplementen (hoofdstuk 6). De analyses voor colon- en rectumkanker zijn afzonderlijk voor mannen en vrouwen verricht. Voor mannen werd geen verband gevonden met het eten van uien en prei en het risico op colon- en rectumkanker. Voor vrouwen werd weliswaar een verlaagd risico voor rectumkanker gezien voor diegenen die hooguit een kwart ui per dag aten vergeleken met degenen die geen uien aten (relatief risico $(R R)=0,36,95 \%$ betrouwbaarheidsinterval $(B \mid)=0,13$ $0,99)$, de trend in de relatieve risica's was niet significant. Consumptie van prei hield ook bij vrouwen geen verband met het risico op colon- of rectumkanker. Voor mannen en vrouwen samen werd geen verband gevonden tussen het gebruik van knoflooksupplementen en het rísico op colon- en rectumkanker (hoofdstuk 7). Met betrekking tot het risico op maagkanker lieten de analyses een significant negatief verband zien met het eten van ui. Het risico voor maagkanker voor personen die tenminste een halve ui per dag aten was 0,50 (95\% Bl 0,26-0,96) ten opzichte van mensen die geen uien aten. Het beschermend effect beperkte zich tot het non-cardia deel van de maag ( $P R=0.31,95 \% \mathrm{BI} 0,14-0,70)$, en bleef aanwezig na uitsluiting van personen die een maagaandoe-ning in de voorgeschiedenis hadden. Consumptie van prei en het gebruik van knoflook-supplementen hielden geen verband met het risica op maagkanker (hoofdstuk 8).

Om te onderzoeken of preklinische ziekte heeft geleid tot een verandering in de gewoonlijke voedșelconsumptie, zijn alle analyses die in de hoofdstukken 5-8 zijn gepresenteerd ook vitgevoerd na uitsluiting van patiënten waarbil kanker in het eerste follow-up jaar werd gediagnosticeerd. De resultaten van deze analyses waren niet wezenlijk verschillend van die voor de totale groep.

In hoofdstuk 9 zijn deze resultaten van de Nederlandse Cohort Studie besproken, samen met uitkomsten van eerder gepubliceerd epidemiologisch onderzoek naar het verband tussen de consumptie van Alliumgroente en het risico op kanker. Er werd geconcludeerd dat de resultaten uit onze studie niet overeenstemmen met wat uit eerder onderzoek bekend was, behalve het negatieve verband voor maagkanker dat we vanden met de consumptie van ui. Er zijn een aantal mogelijkheden opgesoma ter verklaring hiervan en er werder, aanbevelingen gedaan voor verder onderzoek. 


\section{Dankwoord}

1986. Co-schap Heelkunde in het Lucas in Amsterdam-West, een oude grauwe buurt met veel eenzame oudere mensen. Het zou weer een dag worden met open wonden, gekneusde enkels, gebroken tenen, mensen zó van de straat - gestruikeld over een losliggende tegel... Wachtend op m'n eerste patiënt lees ik de krant, totdat een kop mijn aandacht trekt:

Teennagels leveren cijfers voor kans op kanker. Groot onderzoek in Nederlandse bevolking. Deze week is het "prospectief cohort-onderzoek naar voeding en kanker" gestart. De Rijksuniversiteit Limburg en TNO-Zeist vragen de medewerking van honderdduizenden Nederlanders tussen de 55 en 69 jaar voor een onderzoek naar de relatie tussen voedingsgewoonten en het ontstaan van kanker. Met gegevens uit de vragenlijst die door elke deelnemer wordt ingevuld en analyse van de bijgeleverde teennagelknipsels, hopen we meer inzicht te krijgen in het verband tussen voedingsgewoonten en verschillende vormen van kanker, aldus de onderzoekers: Piet van den Brandt en Sandra Bausch-Goldbohm.

Piet, Sandra, bovenstaand bericht staat me nog helder voor de geest, door de herinnering aan mijn reactie: ongeloof, verbazing, hilariteit, bewondering ... Hoe verzint iemand het, wat halen ze zich op de hals, honderdduizenden mensen, en dan, al die teennagels! Wat zou dat trouwens zijn, een prospectief cohortonderzoek? ...

Ik kon toen nog niet vermoeden dat ik er enkele jaren later mijn beroep van zou maken en me dagelijks met alle haken en ogen die aan een dergelijk grootschalig onderzoek zitten, zou mogen bezighouden. Veel van wat ik sindsdien heb geleerd over het doen van kwalitatief hoogstaand onderzoek, maar ook wat erbij komt kijken en hoe uitgekiend je moet zijn als je een onderzoek op zo'n grote schaal onderneemt, heb ik van jullie geleerd. Van jou, Piet, door onze dagelijkse contacten en het veelvuldige overleg over mijn werkzaamheden in mijn AlO-tijd en daarna. Van jou, Sandra, door goed naar je te luisteren en de kunst van je af te kijken. Veel van wat er in dit proefschrift staat, over de methodologische aspecten van het onderzoek, de ins en outs van de analyses, maar ook hoe ingewikkeld onderzoek op het gebied van voeding kan zijn, heb ik van jullie geleerd. Ik beschouw het als een eer dat jullie beiden (op alfabetische volgorde of niet) mijn copromotor zijn. Ik hoop dat onze plannen voor de toekomst van de grond komen!

Natuurlijk wil ik ook mijn beide promotoren, Ferd Sturmans en Ruud Hermus, bedanken voor alle tijd en moeite die ze aan mij hebben besteed. Ferd, bedankt voor je inzet toen het mis dreigde te gaan met mijn aanstelling. De stoel waarop ik sinds het aflopen van mijn AlO-aanstelling heb mogen zitten, zat mede dankzij jou zeer comfortabel. Ik hoop dat ook jij een rol blijft spelen bij mijn toekomstige werkzaamheden.

Geen onderzoek zonder deelnemers. Ik heb bewondering voor de 120.852 mensen die meewerkten aan het onderzoek door destijds met veel zorg de vragenlijst in te vullen, waardoor een onderzoek als het onze mogelijk werd. Dat follow-up van zoveel deelnemers een klus is die je niet in je eentje kunt klaren is duidelijk. Ik ben daarom veel dank 
verschuldigd aan de medewerkers van de regionale kankerregistraties, die het mogelijk hebben gemaakt dat ik informatie over de incidentie van kanker kreegi waarmee ik uit de voeten kon. De pathologen van Nederland met hun landelijk archief PALGA leverden mij behalve de nodige incidente cases bovendien menig vrolijk uurtje.

En dan, een onderzoek als dit doe je (gelukkig!) niet alleen. Een team van mensen heeft een steentje, groot of klein, gedurende korte of langere tijd, bijgedragen. Enkelen daarvan wil ik met name noemen:

Jolanda Nelissen, jij weet. als geen ander mijn dag op te vrolijken, met het kopje koffie dat ik vaak 's ochtends op mijn bureau vind, je verhalen en 'stomme' mopjes, je roze beeldscherm en soms het rode potlood. Patricia Florax, jouw plat 'Mestreechs' is onbetaalbaar, evenals je zorgen voor de inwendige mens. Jullie hulp en bijdragen aan mijn kennis over WP zijn zo waardevol gebleken dat ik mijn proefschrift bijnal geheel in eigen beheer heb kunnen afwerken. Dat jullie mij niet van onze kamer wilden hebben toen het er even naar uitzag dat mijn plekje aan iemand anders werd toebedeeld, zegt mij meer dan genoeg. Jeanne van Loon, bedankt voor je hulp bij de follow-up en veel succes met jouw analyses; Willy van Dijk, bedankt voor het versturen en verwerken van die duizenden gemeenteformulieren; Harry van Montfort en Ruud Schmeitz bedankt, niet alleen voor de computerprogrammatuur maar ook voor de discussies over het opzetten van de database en het verwerken van gegevens waardoor ook ik een stukje wijzer werd.

(Oud-)Collega's en stagiaires die nu of ooit op het cohort hebben gewerkt, van de vakgroep en van TNO in Zeist bedank ik voor de gezelligheid en de goede werksfeer.

Een zeer speciaal woord van dank betreft mijn beide paranimfen: Sacha van de Crommert en Diana Rietdijk. Sacha, dat ik bij jou niet. alleen mijn enthousiaste verhalen kwijt kon, maar ook stoom kon afblazen als me iets of iemand tegen zat, heb ik altijd zeer gewaardeerd. Jouw organisatorische talenten hoop ik ook op de dag van mijn promotie te kunnen aanspreken. Diana, dat jij in mijn voetsporen getreden bent, vind ik heel erg leuk. Wie weet sta jij ooit waar ik nu sta. Dat je mijn paranimf wilde zijn vind ik 'te gek.'

Tenslotte ben ik mijn ouders zeer veel dank verschuldigd voor hun nimmer aflatende steun en belangstelling, voor de gezelligheid op vrijdagmiddag waardoor mijn weekenci altijd goed begint, maar ook voor de soms verhitte discussies mede waardoor ik de stap naaí de gemeentepolitiek heb durven wagen. Pa en ma, dankzij jullie heb en hou ik oog voor andere dingen dan $\mathrm{m}^{\prime} \mathrm{n}$ werk, woon ik bovenclien op het mooiste plekje van Zuicl-Limburg, heb ik een tuin waarin ik me kan uitleven, en ben ik er altijd gerust op dat ik op echt belangrijke momenten gekleed ga in iets heel bijzonders.

Last but not least, Rob, de laatste regel is aan jou gewijd, want een ding is zeker: zonder jou was ik nooit aan dit karwei begonnen en was ik ook nooit zover gekomen. Ik beschouw mijn promotie dan ook als een mijlpaal die we samen bereikt hebben. Het zal mij benieuwen welke avonturen ons nog te wachten staan! 


\section{Curriculum vitae}

Elisabeth Dorant werd geboren op 31 maart 1958 te Laren $\mathrm{NH}$. Na het behalen van het diploma gymnasium- $\beta$ in 1976 aan Het Nieuwre Lyceum te Hilversum is ze gaan studeren aan de Vrije Universiteit te Amsterdam, waar ze op 20 november 1987 het artsexamen behaalde. Sinds haar indiensttreding op 1 juni 1988 bij de Rijksuniversiteit Limburg is ze werkzaam geweest bij de vakgroep Epidemiologie, aanvankelijk vier jaar als assistent-inopleiding en vanaf 1 juni 1992 ais universitair docent in tijdelijke dienst. Haar postacademische scholing bestond onder meer uit deelname aan binnen- en buitenlandse cursussen op het gebied van de epidemiologie. Naast haar werkzaamheden voor de in dit proefschrift beschreven Nederlandse Cohort Studie naar voeding en kanker, vervult ze diverse onderwijstaken. Sinds juni 1993 is ze lid van de Editorial Board van de Journal of Optimal Nutrition. 
Al 1 ivin scorigdepr L.t. bieslowk. Al. headed garlic. (6) Allium Earinatoum trifonrsuras Nomed Allivin-tursintim. Napol i tagnse Knot latalogiend ras Al lium hi erochunt Alliumi cernuum : angul gsum: Siberi prei. A1L1 Luri bley Thexicana, Allicim gewone Ui: AI lituin Allitin astalgniet. bergphei. Allium wilde prei. A11 it knoflanti a Allium fistril esum: japan bergarei. Alli ilum Al1.ium cepas var A1 11 um firbrillun maly var. bulbill tricoccune wilde Allinim Sanbornti sphaterocephal ght? 